Portland State University

PDXScholar

Spring 6-5-2013

\title{
Designing Innovative Alternatives to Traditional High Schools: What Leaders Need to Know
}

Chester Roy Edwards

Portland State University

Follow this and additional works at: https://pdxscholar.library.pdx.edu/open_access_etds

Part of the Educational Assessment, Evaluation, and Research Commons, Educational Leadership Commons, and the Elementary and Middle and Secondary Education Administration Commons Let us know how access to this document benefits you.

\section{Recommended Citation}

Edwards, Chester Roy, "Designing Innovative Alternatives to Traditional High Schools: What Leaders Need to Know" (2013). Dissertations and Theses. Paper 1036.

https://doi.org/10.15760/etd.1036

This Dissertation is brought to you for free and open access. It has been accepted for inclusion in Dissertations and Theses by an authorized administrator of PDXScholar. Please contact us if we can make this document more accessible: pdxscholar@pdx.edu. 
Designing Innovative Alternatives to Traditional High Schools:

What Leaders Need to Know

by

Chester Roy Edwards

A dissertation submitted in partial fulfillment of the requirements for the degree of

\section{Doctor of Education}

in

Educational Leadership: Administration

Dissertation Committee:

Thomas Chenoweth, Chair

Patrick Burk

Samuel Henry

Yves Labissiere

Portland State University

2013 
(C) 2013 Chester Roy Edwards 


\begin{abstract}
The need for new and innovative alternatives to traditional high schools has never been greater. Never designed to graduate all students on time, traditional high schools and their high dropout rates have remained unchanged for the last 30 years. Improving secondary schooling for all young people is a worthwhile social and educational objective. Many school leaders want to create alternative high schools but may lack the knowledge of what to do, nor may they have a comprehensive design process to follow. The research question explored in this dissertation is: What do leaders in education need to know to design innovative alternatives to traditional high schools?

This dissertation studied four aspects or assumptions that school leaders should understand when designing alternatives to traditional high schools: (a) consider all of the elements of successful alternative high schools, (b) start over conceptually when designing a new alternative high school, (c) use regional accreditation standards as a framework for design, and (d) begin design with the end in mind for program evaluation. Research literature topics of alternative education, organizational leadership, school accreditation standards, and program evaluation were reviewed.

The research conducted was theoretically and practically grounded in Bridges and Hallinger's (1995) Problem-Based Learning (PBL) and Borg and Gall's (1989) Research and Development (R\&D) Cycle. The product of the research conducted in the R\&D cycle was a process for designing alternative high schools. Qualitative and quantitative data collected from school leaders and designers during field tests was analyzed to improve a
\end{abstract}


prototype of an alternative high school design process. An effective process that is ready for dissemination was the result of this research. A larger implication of the application of this process will be the improvement of high school experiences for all students through the creation of new designs for innovative forms of secondary schooling. 


\section{Acknowledgments}

Dr. Tom Chenoweth, without whom this dissertation would not have been possible.

I would also like to thank my committee members: Dr. Pat Burk, Dr. Sam Henry, and Dr. Yves Labissiere for their suggestions, support, and questions.

Drew Hinds, for his steadfast collaboration.

Paul Coakley, Jr., for sharing his writing ability.

Dr. Melanie Plaut, for her editorial contributions.

Dr. Changhua Wang, for his encouragement.

And especially to my wife, Lynn, without whom this lifelong family dream would not have come true. 
Table of Contents

Page

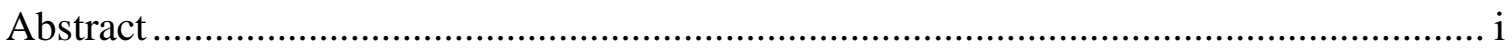

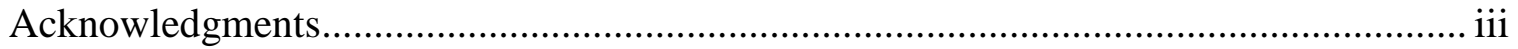

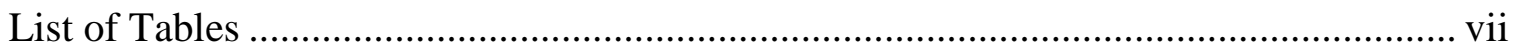

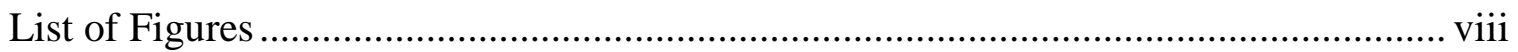

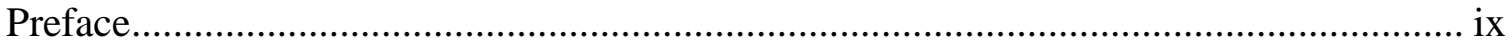

\section{CHAPTER}

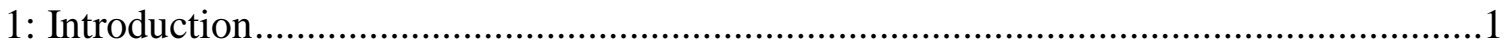

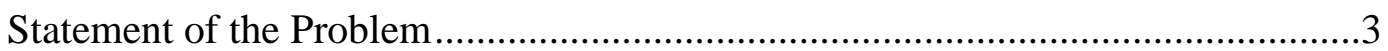

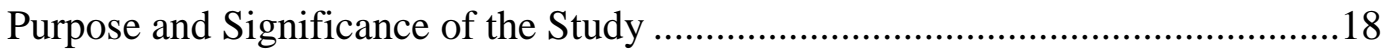

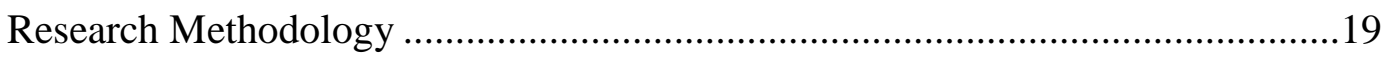

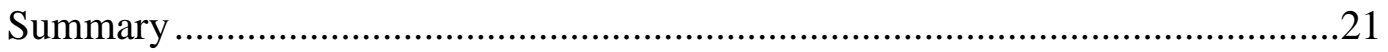

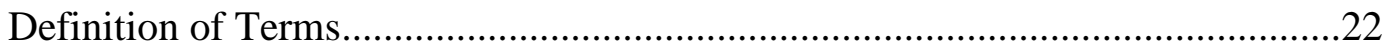

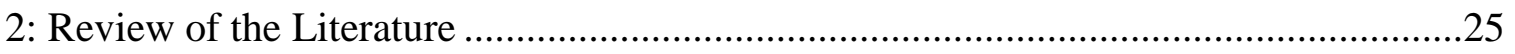

Alternative Education: Consider All Elements.............................................28

Organizational Leadership: Starting Over ...................................................48

Accreditation Standards: A Framework for Design..........................................60

Program Evaluation: Begin With the End in Mind.........................................78

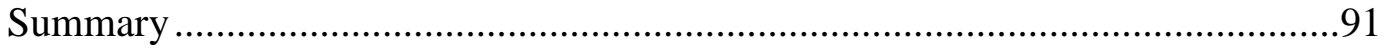




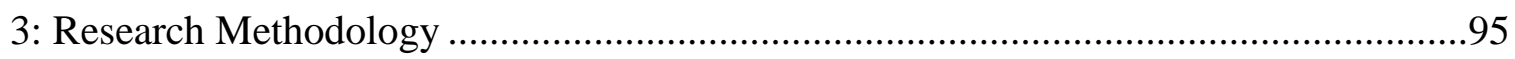

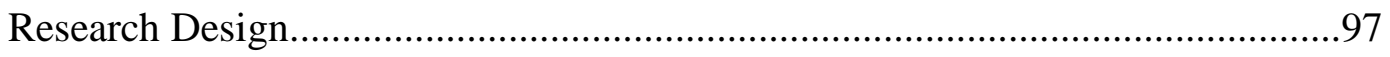

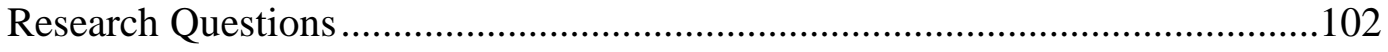

Data Collection Procedures.................................................................................. 103

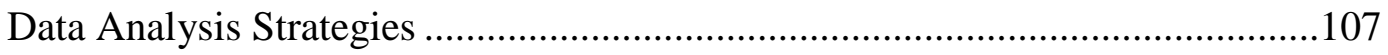

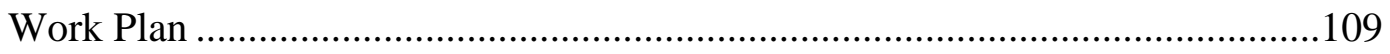

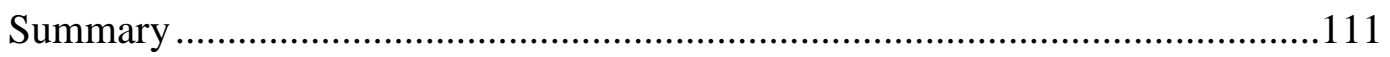

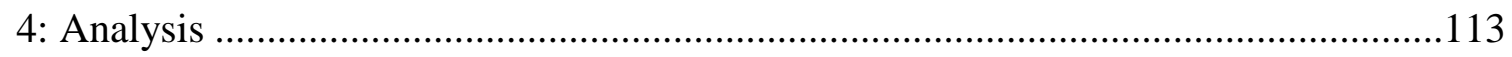

Research Questions and General Design .........................................................114

Development and Implementation ................................................................117

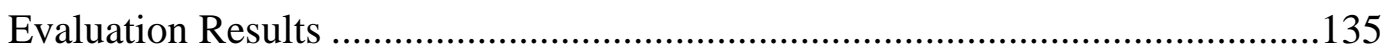

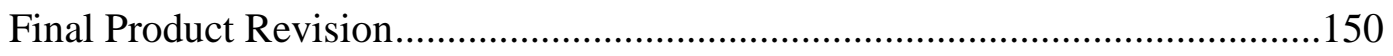

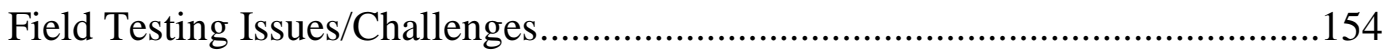

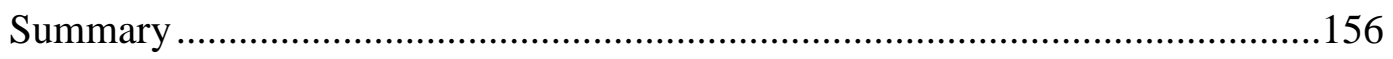

5: Conclusions, Speculations, and Recommendations for Leadership ...........................157

Overall Conclusions and Assessment of the Experience ………..........................158

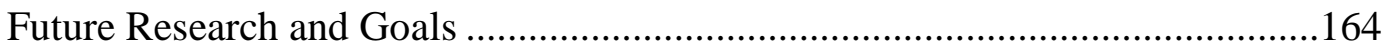

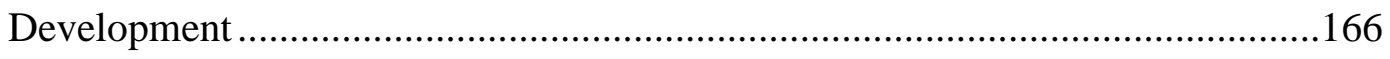

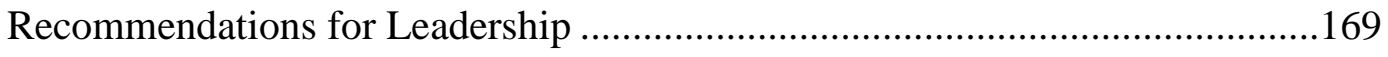

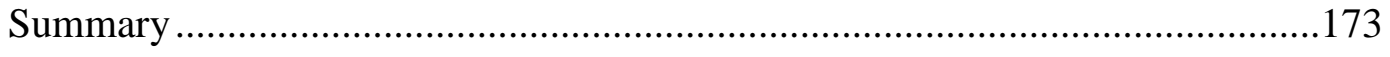

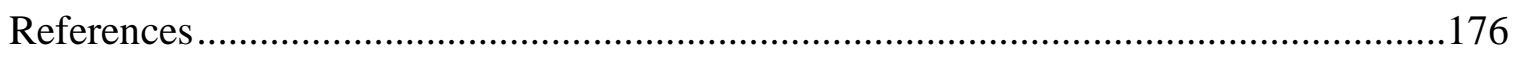




\section{Appendices}

A Alternative High School Leadership Design Survey.....................................193

B Research Letter to Alternative High School Designers ..................................202

C Program Description for Whyland School .................................................205

D First Session of the School Design Process: Annotated Agenda .....................215

E Second Session of the School Design Process: Annotated Agenda ..................217 
List of Tables

Table

1 Steps in Borg and Gall's R\&D Cycle........................................................... 19

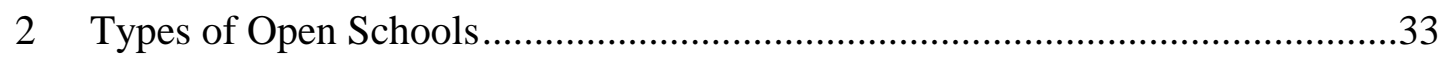

3 Comparative Advantages and Disadvantages of Types of Alternative Schools .39

4 Presentations of the School Design Process Prototype ....................................99

5 Preliminary List of Innovative School Designers and Schools ........................101

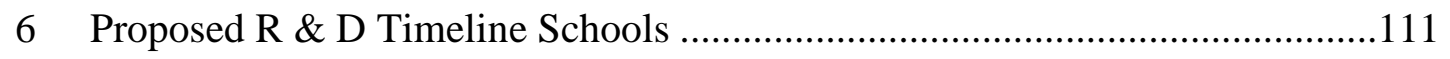

7 Innovative Alternative High School Designers Surveyed...............................123

8 Whyland High School Design Team Membership......................................132

9 Essentialness of Elements of Effective Alternative Schools ...........................142

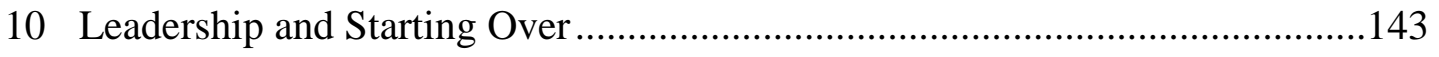

11 Using Accreditation Standards as a Framework for Design ..........................145

12 Program Evaluation and Beginning With the End in Mind ...........................146 


\section{List of Figures}

Figure

1 New School Development .........................................................................

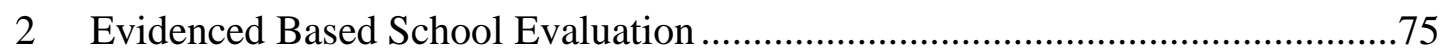

3 Designing and Evaluating Innovative Alternative High Schools .......................164 
Preface

A group of three superintendents recently told me about their small school districts' general problem: each of their high schools had a significant number of high school dropouts. As we discussed this problem, four areas of concern stood out. First, it became apparent the superintendents were aware of various alternative school models, but did not have a complete understanding of the essential elements of alternative education. Second, they were uncertain whether it was best to add alternative programs to the existing high schools, to try to turn around the existing but failing alternative school, or to start over to design a new alternative high school. Third, each superintendent had some ideas about what a new alternative school or program would entail, but they had no framework from which to organize their ideas. Fourth, they all agreed they wanted the new school or program to be successful, and that the state and local communities would eventually require a comprehensive evaluation of the educational program. With my assistance, they decided to pool existing and potential resources to design and implement a brand new and innovative regional high school to attract and engage students at-risk of failing to graduate from their high schools. This leads me to the question I wish to explore in this dissertation: What do educational leaders need to know to design innovative alternatives to traditional high schools, and more specifically, what process should be followed and what underlying assumptions or theoretical frameworks should be understood?

I was referred to the superintendents by an alternative education specialist in the department of education in the state in which we live. I have been involved in developing 
alternatives to traditional schools since the 1970s. Most notably, during my career I served for nearly 20 years as an administrator in charge of the educational options of a large urban school district. I helped to develop and evaluate alternative, charter, and magnet schools serving students from kindergarten through grade 12 that were different from traditional models of schooling. Most of my work was with alternative schools and programs that prevented students from dropping out, or retrieved students who had already dropped out, of traditional high schools. A pivotal element of my work was the referral of students to alternative schools operated by local community-based organizations. This effort grew steadily during my tenure, from five schools serving about 150 students, to more than 30 schools enrolling nearly 3,000 students annually. These schools were founded and maintained through contractual agreements with my school district. Public and private entities such as community colleges, city and county governmental agencies, and experienced private school operators were involved. The school design and development process generally began with identifying and targeting groups of out-of-school youth in local areas, as well as district-wide, and engaging community partners in the creation of new alternative schools.

Based on this experience I began to develop a process that will guide local teams through the design and development of alternatives to traditional high schools. Over the years, I have studied existing processes used to develop new alternative schools, but they seemed to lack key pieces or were haphazard at best. One well-known product marketed on the East Coast, I recall, neglected to mention curriculum and instruction. A charter school development strategy I looked at seemed to be based on free-market political 
ideology aimed at breaking the monopoly of public school systems, rather than as a comprehensive and de-politicized process. Some school leaders described their process for developing a new school as simply getting school board approval and assigning a high school principal to carry out the new school's development and implementation. In the existing processes there seemed to be little reference to program evaluation, other than stating a vague mission statement about educating all students. None of these approaches, in my estimation, adequately address the nitty-gritty know-how school leaders need and the key assumptions they should know to design an innovative alternative to traditional high schools.

In my lengthy experience designing alternatives to traditional high schools, I have learned there are four key areas of school development: Assessment of student needs, school design, implementation, and continuous school improvement. As discussed later in this dissertation, program evaluation is a theme that impacts all parts of new school development. Figure 1 illustrates phases in the development of new schools.

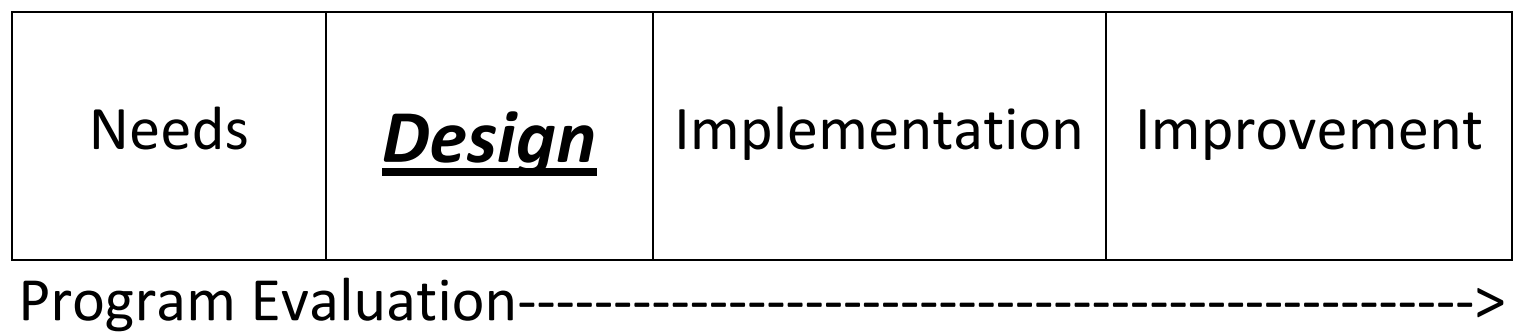

Figure 1. New school development.

This dissertation focuses on the area of school design which is the area between student needs and school implementation, where a "blueprint" for the new school is 
created. If done well, a comprehensive school design process will ameliorate a host of problems that may otherwise arise. The beliefs and assumptions needed to ward off problems are explored in this dissertation.

This dissertation examines four aspects of school design, or assumptions related to designing alternatives to traditional high schools that can be used as integrated frameworks to help teams of designers re-imagine what high schools can be. Gay, Mills, and Airasian (2009) thought "An assumption is an assertion presumed to be true but not actually verified" (p. 109). The four assumptions used in this dissertation are: (a) consider all of the "essential elements" of alternative schools, (b) deploy organizational leadership strategies that cause designers to "start over" when designing a new alternative school, (c) use school accreditation standards as a framework for design, and (d) weave program evaluation throughout the design process.

The superintendents described in this preface eventually used a prototype of a design process I developed "on the job" to successfully create and implement a regional alternative high school. A goal of the new school was to be fully enrolled by spring break, but the school was fully by its third week of operation. I believe that indicates, at least partially, the value of having a school designed by leaders who understood the elements, assumptions, and standards for school design. 


\section{CHAPTER 1}

INTRODUCTION

“Look at the history of innovation! If people don't call you nuts, then you are doing something wrong." -Peter Eisenberger

In recent years I worked to facilitate the development of alternative high schools for several school districts. During that experience I often saw the situation addressed in this dissertation: school leaders did not know how to design new and innovative alternatives to traditional high schools. To assist them I undertook the development of a comprehensive process that guides a local design team through the creation of a plan or "blueprint" for an alternative high school. This dissertation sought to explore this topic with new research into the development of a high school design process.

This dissertation reviewed the gaps in traditional public high school design, as evidenced by their high dropout rate, and the need for innovation. Four topics emerged from the literature related to four assumptions presented in the preface: (a) Alternative education and its essential elements, (b) organizational leadership strategies that can be used to start over when designing a new alternative high school, (c) accreditation standards and its use as a framework for school design, and (d) program evaluation and the need to begin designing with the end in mind. These topics are briefly introduced in this chapter and further explored in chapter 2. Knowledge of these topics, as they relate to designing alternative high schools, helps leaders overcome barriers when designing innovative alternative high schools. 
The need for innovative alternatives to traditional high schools has never been more critical. Users of public education are dissatisfied with traditional high schools that exhibit persistent achievement gaps, declining attendance patterns, and high dropout rates. High school dropout rates, specifically, have remained essentially the same for the last 30 years, despite significant increases in expenditures on education (Heckman \& LaFontaine, 2007; Warren \& Halpern-Manners, 2007). Youth who drop out have a significantly greater chance of ending up in prison and have worse health outcomes and lower life expectancies (Moretti, 2007; Muennig, 2007). Racial and economic disparities between "have" and "have not" high schools are rampant (Fine, 1986; Rumberger, 2004). Each year dropouts represent $\$ 320$ billion in lost lifetime earning potential; the difference in lifetime salary for a dropout and a high school graduate is about $\$ 300,000$ (Fields, 2008). Something drastic needs to be done to reduce high cost of high school dropout rates.

Attempting to prevent economic and societal consequences of high dropout rates has contributed to growth in the number of non-traditional alternative schools. In the U.S. in 2007-2008 there were 10,300 alternative schools (Tice, Carver, \& Lewis, 2010) and from 1999-2000 to 2008-2009, the number of students enrolled in public charter schools more than tripled from 340,000 to 1.4 million students (National Center for Education Statistics [NCES], 2011a). The number of magnet schools, primarily to engage students around curricular themes, has increased over the past 20 years to more than 3,000 in 2008-2009 (NCES, 2011a). Other innovative educational options operate within public school systems. These are usually hybrids of alternative, charter, and magnet schools that 
have proliferated in recent years. Online schools are also relatively new phenomena in providing new forms of educational experiences.

Ongoing need, public demand, and increasing growth in the number of alternatives to traditional high schools argues for an improved process for designing new forms of high schools. A number of researchers, including Barr and Parrett (1995, 1997, 2001, 2008), Raywid (1982, 1989, 1994, 2001), Fizzell and Raywid (1997), Smink (1997), and Cash and Edwards (2007) studied innovations developed in alternative schools and concluded such options in education are vital for retrieving and succeeding with students who have left traditional high schools prior to graduation. While I agree with the results of these studies, it is also apparent that this research can be built upon through further research used to develop a better process for designing alternatives to traditional high schools. Not only do new forms of high school need to be designed and developed to meet the needs of youth who drop out of traditional high schools prior to graduation, but new high schools need to be designed and developed for students who will directly enroll in them, and who will never have to experience failure in traditional high schools in the first place.

\section{Statement of the Problem}

Perhaps nothing is wrong with traditional public high schools for the more than three million students in the U.S. who graduated from them each year. But something is wrong for the one million students who failed to graduate from traditional high schools last year. As previously asserted, in my view traditional high schools were never meant to graduate every student, as evidenced by a 4-year graduation rate of 73.2\% (NCES, 
2011b). This low 4-year cohort graduation rate means more than one in four students who entered ninth grade did not graduate 4 years later. Other experts report the dropout rate has been historically under-reported and may be even higher, especially in urban areas and among minority students (Fine, 1986; Rumberger, 2004). Today, traditional high schools enroll approximately $80 \%$ of high school students (NCES, 2011a). In the past students who dropped out of traditional public high schools could find manual labor jobs, but today employment options for under-educated and unskilled workers are severely limited (Rumberger \& Lamb, 2003).

Traditional American education, especially in the design of comprehensive urban public high schools, emphasized mass production, batch processing, and scientific management, concepts imported from business and industry (Callahan, 1962; Eisner, 1985; Tyack, 1974). MacDonald, Mohr, Dichter, and McDonald (2007) argued the traditional system is currently more popular than at any time in recent decades, given the current trend of heightened academic accountability. As already stated, traditional public high schools were never designed to meet the educational needs of all students who enroll in them, nor have they kept up with changing demands of student demographics (Barr \& Parrett, 2008; Wilson \& Davis, 1994). Contemporary commentary calls traditional high schools

Relics of the past based on an antiquated economic formula designed for the Industrial Revolution, high schools... are ill-suited for the emotional and intellectual well-being of our young people and profoundly out of step with the needs of our contemporary economy. We have been tinkering with the high school formula for decades, but the recipe for innovation has yet to be written. (Diakiw, 2012, Whitepaper, para. 1) 
B. Levin (2010) wrote that traditional high schools "Embody an industrial model of organization in a postindustrial world, and an authoritarian and hierarchical character in a world where networks and negotiations are increasingly prevalent” (p. 95). Indiana University (Yazzie-Mintz, 2010) conducted a survey of high school engagement. It report $73 \%$ of respondents did not like high school, and $75 \%$ thought the educational material uninteresting.

Yazzie-Mintz's (2010) findings also corroborated my personal “Theory of Thirds." While traditional public high schools do a good to excellent job of educating perhaps a third of their best students (using their best teachers), another third receive a less than adequate high school education and the bottom third drop out and receive little or no education during their high school years. A major problem with this system is that the resources traditional public high schools receive for the education of the bottom two thirds are spent "upward" for the benefit of the elite third. This dissertation does not advocate for abolishing traditional high schools, as some leaders in education may insist (Botstein, 1997); but this dissertation does suggest traditional high schools are only one model of schooling, successful with some students, and that this model should not exist at the expense of children who need other models. Sizer (1997) argued that we should "...devoutly believe that there is no one best model" (p. 7). More innovative models of schooling, designed to meet the needs and interests of all students, need to be imagined and developed. To begin to meet these needs and solve the dropout problem, I believe many school leaders want to know what to do to design new and innovative alternatives to traditional high schools - the topic of this dissertation. 


\section{Innovation in Education}

The problem of how successful innovation takes place and the urgency for change in education in recent decades has continuously increased since Sputnik in the 1950s, as has knowledge about effective leadership and school change processes, though a great deal remains to be learned about effective change processes (Chenoweth \& Everhart, 2002; Fullan, 2001; Purkey \& Smith, 1983). Since the mid-twentieth century many efforts have been made to address the question of how to provide the best education for all school children. Top-down reforms to change schools through restructuring school governance and administration have proliferated and have led to higher levels of standardization and accountability within the American system of education (Cuban, 1984; B. Levin \& Riffel, 1997; Meyer, 1992; Tyack \& Cuban, 1995). These reforms seem to have been adopted politically and administratively, but have encountered remarkable resistance to create change in traditional classroom practices (Lubienski, 2003). As Vicki Phillips (2011), who leads U.S. education reform efforts for the Bill and Melinda Gates Foundation, famously said,

First, the only things that are viral in education are the viruses that come to school during cold and flu season. To actually transmit best practices from classroom to classroom, much less from school to school, district to district, and state to state, is incredibly hard. (p. 29)

Top-down political and administrative reforms have not been as successful in fostering innovative school change as has the alternative education movement that began in the 1960s, particularly as alternative schools and programs adapted to the educational needs and interests of students at-risk of failing high school. The alternative education movement had its philosophical roots in the progressive and democratic ethos of Dewey 
(1916). The 1960s were a time of great innovation and experimentation in education, with lasting repercussions.

Some educators during the last few decades contend that if an educational option is provided to students at-risk of school failure, they will succeed (Barr \& Parrett, 2001). Alternative schools evolved since the early 1960s to become a popular option for students at-risk of school failure, and alternatives to traditional high schools are crucial if the needs and interests of all students are going to be met (Barr \& Parrett, 2001; Raywid, 1989; Wehlage \& Rutter, 1987; Wehlage, Rutter, Smith, Lesko, \& Fernandez, 1989). Raywid (1994) thought alternative schools led school reform and innovation in education, as "small size, curricular foci, student and teacher choice, school as community of learners, active learner engagement, and authentic assessment and other practices were pioneered in alternative schools" (p. 26).

Critics such as Sagor (1999) and Fitzsimons-Lovett (2001) contended ineffective alternative education programs neither enable or empower students, but entrap them in "a dumping ground and/or holding tank for students who cannot be molded to fit in general education" (Fitzsimons-Lovett, 2001, p. 39). Proponents of alternative schools, such as Barr and Parrett (1997), also found a dark political side of alternative education wherein "Even those who support alternative schools may do it for selfish motives" (p. 89). Some advocating for alternative schools may want to remove disruptive students so the socalled "good kids" can learn. Some may want to keep the state dollars that would be lost when a student drops out. Some may even want poor and minority children kept away 
from their own children. Any or all of these negative motives may be implemented with little regard for the quality of the school and its educational program.

My response is that the innovations harnessed by an alternative school greatly depends on how well it is designed by knowledgeable, local school and community leaders who come together to follow a comprehensive design process founded on the development of a shared vision and purpose. Prospective parents and students should be involved in the design of the new school. The vision for the alternative school should be built on the search for the ideal school that will meet its students' educational needs and interests, and it should also be built on values such as the belief that the designers would send their own children to the new alternative school.

Charter schools, a recent form of alternatives to traditional schools, began operating in the late 1990s. Charter schools, conceived and created by leaders including Albert Shanker (Finn, Manno, \& Vanourek, 2001) and Nathan (1999) were seen as a way to bring innovation and flexibility to schools through liberation from restrictive bureaucracy in the traditional education system. In my opinion, charter schools soon became co-opted as a conservative political movement employing market-style mechanisms meant to inspire innovation by elevating competition through school choice (Lubienski, 2003). At the same time, charter schools exchanged greater autonomy for increased accountability (Finnigan, 2007). Ravitch (2010) noted that with good intentions one of the original goals of charter schools was meeting the needs of high school dropouts and other underserved students. Lubienski (2003) further asserted that although some organizational innovations have been created by charter schools, such as unique 
timeframes during which schooling takes place during the day or year, classroom teaching strategies tend to regress to the familiar. Some charter school operators and authorizers, it appears, tend to "cut and paste" the newest trend in schooling into local communities. I also believe it is better to create local designs that meet local problems by mixing the best components and using essential elements learned from alternative school research—especially when it comes to innovative instruction. On the other hand, in my experience other charter school authorizers have used Federal charter school start-up funds as a means to create alternatives to traditional schools.

Originally founded in the 1960s as a strategy to desegregate schools by offering attractive enrichment activities and curricular foci, magnet schools have continued to increase in number of during the past 20 years to more than 3,000 in 2008-2009 (NCES, 2011a). Magnet schools offer effective models for developing innovative curriculum and student engagement protocols to innovative alternative high school designers.

Whatever the motives and whatever "type" of school is involved, what is needed is design process for new and more innovative schools. This design process means not just tinkering at the edges, for instance, by lengthening the school day with study halls, but by considering the educational needs and interests of students and parents involved in the design of their new schools. Not only are there legal and ideological challenges, but the need is also to challenge our own assumptions about education and to design more ideal schools for each and every student. This was the original dream of founders of the alternative education movement. 
Four assumptions about Alternative high school design. This chapter next introduces key assumptions about alternative school design that address the central question of this dissertation: What do leaders need know to design innovative alternatives to traditional high schools? Topics in the literature related to the four assumptions about alternative school design are further explored in chapter 2. These topics are: alternative education, organizational leadership, school accreditation standards, and program evaluation.

At my suggestion the superintendents portrayed in the preface created a "design team" that included themselves and other internal and external school community stakeholders as members. In addition to the superintendents the committee included the principals of three traditional high schools, three high school teachers, and three community members, one from each of the local communities - a total of 12 members. The Design Team held an initial meeting during which one of the superintendents presented facts and figures describing the students that the school was going to be designed to serve. All members were familiar with the kind of at-risk youth described since they live with them in their communities.

\section{Consider All of the Essential Elements of Alternative Education}

To begin to resolve the problem of what these leaders needed to know to create an alternative to traditional high schools, I suggested the design team consider the work of Barr and Parrett (1997) who have identified 10 "essential elements" of innovative alternative schools from research conducted during the past half century. These 10 elements of innovative schools are: Shared vision, educational diversity, relevant 
curriculum, creative instruction, student assessments, caring teachers, school choice, comprehensive programs, small size, and local autonomy. Barr and Parrett posited that innovative alternative school designs will not be successful if various elements are experimented with incrementally, but only "If each and every one of the essential elements is carefully considered...these essential elements represent a formula for success" (pp. 32-33). These authors remind us it is also important to remember that traditional education has adopted most of the innovations developed in alternative schools, but too often partially and with incomplete change from the status quo of past practice.

Some college and university training programs for aspiring high school administrators, while giving lip service to the latest fashions in education, do not appear to foster innovative thinking about what a "school" can be. In fact, higher education encourages conformity so the aspirants can be placed in traditional vice principal jobs and work their way up to principal by learning the tricks of the trade, the first of which is maintaining the status quo.

A comprehensive understanding of successful alternative schools is gained by paying attention to all the elements at the same time when designing an innovative school. Perhaps the original dream of alternative education as a way to find the ideal school has never been realized because leaders of educational organizations were unable to sustain the leap of faith needed to boldly combine all elements in a complete formula for school success. 
How to consider all of the essential elements of innovative alternative schools is discussed in more depth in chapter 2.

\section{Starting Over Requires Organizational Leadership}

The design team members brought to the committee their own mental model (Senge et al., 2000) of what a high school should be and what it takes for a high school to succeed. One of the teachers on the team talked at the beginning about how she had worked in an alternative school, but over time its students had exhausted school staff, and students were allowed to do whatever they pleased, coming and going at will, some sleeping on couches for days on end until the school ceased to exist. A high school principal could not understand why a new school was needed, his traditional program should be good enough for any student and they should take it or leave it. He even revealed he was thinking about leaving the team because he did not believe creating a new high school was necessary. One superintendent said if a traditional high school was failing, it should be given the resources: fiscal, human, and temporal to turn it around, but that the alternative school could be a stopgap until then. Finally, however, a community member eloquently suggested every design team member should set aside their baggage and start over by committing to creating the best alternative school they could. To do less, she added, would be a disservice to its eventual students and to local communities.

It was once thought changing an existing school for the better would take five to seven years, if successful at all (H. M. Levin, 1989). Stuit (2012) concluded it was easier to close a low-performing charter or traditional school, and have students start over elsewhere, than to try to turn a school around. Many administrators believe effective 
leadership can turn around an existing school, but that politics and bureaucracy are the biggest hindrances (Farkas, Johnson, Duffett, \& Foleno, 2001). I believe starting over with a new innovative school design is more efficient and should lead to a school design within six months to one year depending on the commitment and cohesion of the design team. Starting over requires strong leadership and may require local board policy to implement. Well executed and comprehensive design also reduces the likelihood of subsequent costly school failure.

An effectively led design team, especially with a leader capable of getting a team to set aside its differences and start over from a new beginning, is critical to designing a new and innovative high school. The organizational leadership needed may take various forms, and may be a combination of cultural and symbolic, historic, and visionary leadership.

Morgan (2006) and Bohman and Deal (2003) presented frameworks for understanding how organizations work and how they are led. Leaders who know how organizations develop a culture and its symbols can influence its development, especially during the exciting time when an organization, such as a new high school, is being conceived.

As cited by the British National Churchill Museum, Winston Churchill once said, "The further backward you look, the further forward you can see" (Unsourced). A leader guiding a design team may help it start from "square one" by presenting the perspective as to how schools began historically, and that American education has renewed itself again and again over time. This foundation may help a team come to the conclusion or 
realization that it is acceptable to start over, and to create something new. Early discussion with a design team about the historical purposes of public school, and questions as to who should be educated, who should teach, and what the educated should learn, that have permeated public school designs since their beginning may help team members originate new ideas (Tyack, 1974; Tyack \& Cuban, 1995).

"Vision" has become a buzzword that has been around since the 1990s. D. T. Conley (1996) has the belief that leaders in education have become cynical about the value of vision, yet creating a vision for a new school is a critical task. D. T. Conley observed that vision exists when the people in an organization share an agreement on values, beliefs, purposes, and goals that form an internal compass. Whitaker and Moses (1994) suggested vision is a compelling dream with a clear scenario as to how it will be accomplished. Leaders who can facilitate a team getting quickly to this dream state, in the search for the ideal school, will also convince the team to start anew in its quest for an innovative school.

Organizational leadership perspectives needed to guide a committee as it starts over from the beginning are discussed in more depth in chapter 2.

\section{Use Accreditation Standards as a Framework for Design}

During an early meeting the superintendents told the rest of the design team they knew of a centrally located building where the high school could be housed and that they would resolve among the districts ways to transfer other resources so the school would be adequately supported. In the minds of the superintendents, resolving the issues of facilities and finance was their primary concern. As the design team's facilitator, 
however, I suggested that while resolving facilities and finance issues are highly important parts of the process, there were other critical pieces to be considered. I proposed we use accreditation standards, with which most school administrators are familiar, as a framework. Not only would this assure we covered all the bases of school design, but the new high school would meet all the standards and become accredited soon after it opened.

Accreditation standards are readily available from six regional, nationally recognized organizations in the U.S. and many countries. Though conventional and originally developed to evaluate traditional high schools, these standards are comprehensive and can be employed as a design framework for a new high school. However traditional in concept, these standards can be adapted to serve as the building blocks any school design team needs. The standards have been developed over a long period of the history of education, vary from accrediting organization to accrediting organization, and continue to be updated and refined. A set of accreditation standards includes standards for school vision and mission, educational program, supports for learning, and continuous improvement (Northwest Accreditation Commission, 2011). Standards are based on fundamental beliefs and expectations for learning. School policies and operations grow up around these standards and the standards align with state laws.

Without a framework to build upon, the development of a new high school within a school district may be a hit and miss proposition at best. Simply getting the support of a bare majority of school board members, hiring a principal with perhaps some experience in alternative education, and assigning teachers to the new school may, or may not, be 
successful. A better way, to ensure "buy-in" from community members from the school board to students, is to use a process composed of sequential standards. Sequential means starting with the development of a shared foundational vision. Such a process will lead to a well-researched and well- developed new school tied to program evaluation and should lead to positive outcomes for student achievement.

Using school accreditation standards as a framework for design is discussed in more depth in chapter 2 .

\section{Begin With the End in Mind for Program Evaluation}

The design team realized from the beginning that the local communities and media would be very interested in what the new school would be like and the kinds of students it would house. This was secondary, however, to the school board and the state wanting to measure the school's success and know if students were learning, even before the end of the new school's first year of operation. The team, at my prompting, saw the importance of imbedding program evaluation into the design from the beginning of the process. Thinking about educational outcomes from the outset had the important benefit of forcing the team to think positively about what the school could achieve, thus creating a self-fulfilling prophecy.

Program evaluation is more than determining questions and methodologies that determine a school's effectiveness. When designing a school, fidelity as to how well a design process is being followed is essential to assess the new school's impact on student learning. Chenoweth and Everhart (2002) highlighted the need, in the case of changing an existing school, to "Evaluate the progress of the design model and assess its impact on 
student learning” (p. 158). Starting with the end in mind, especially as it relates to effective teaching and learning, is the goal.

A plan for school program evaluation needs to be embedded from inception in an innovative school design process that will work. Ways to evaluate non-traditional schools that go beyond standardized, high-stakes tests of literacy and numeracy need to be examined. Non-traditional school program evaluation should delve into the affective domain (Bloom, 1994) related to how students and other members of the school community feel and react emotionally in regard to schooling. It should also examine selfconcepts related to schooling. These concepts need to be incorporated into school design from the beginning.

One example of a program evaluation methodology is developmental evaluation, which Patton (2011) asserted adapts to emergent and dynamic realities in a complex environment. Developmental evaluation thereby seeks to involve characteristics of complex adaptive systems in the process of evaluation. Patton drew distinctions between traditional evaluation methods and complexity-sensitive developmental evaluation. Traditional methods often involve fairly simple validation methods that prove or disprove program models, while complexity-sensitive evaluations include differing evaluation methods due to differences in evaluation purpose and focus. Such methods include accounting for dynamic and difficult-to-measure variables and require collaboration with those engaged in the change effort to co-create an evaluation that is useful and matches the school design process philosophically and organizationally. 
Program evaluation and beginning with end in mind is discussed in more depth in chapter 2.

\section{Purpose and Significance of the Study}

This dissertation aimed to further explore the development of a new educational product: a process to design alternative high schools.

The study had practical significance for researchers, policy makers, and school administrators for various reasons. First, while educational literature contains definitions of innovative elements of alternative schools, such as those found in the work of Barr and Parrett (1997), there was a lack of a well-researched, developed, and comprehensive process for combining these elements. Second, this type of study clarified the process for designing alternative high schools. As discussed in chapter 3, school leaders with a range of school design experience were surveyed and the process will be field tested during the design and development of an alternative high school. Third, there may be benefits yet to be determined from the development of a new process for the design of alternative high schools. These benefits may include, as examples: (a) more fully realizing alternative education as a model for school reform, (b) improving community relations as local teams work to build new conceptions of alternative schools, (c) finding new tools for evaluating alternative schools, and (d) improving analysis of the positive impact on dropouts in local communities.

Increasing the clarity of a new school design process gives school leaders, policy makers, and researchers a more accurate basis on which to make decisions and pursue further study. 


\section{Research Methodology}

This study used Problem-Based Learning (PBL; Bridges \& Hallinger, 1995) and a research and development (R\&D) cycle developed by Borg and Gall (1989) to improve educational products. PBL leads to the development of a product that can be used to address leadership challenges in the educational workplace. Product development is grounded R\&D that Borg and Gall (1989) described as "a process used to validate educational products" (p. 782). PBL and the R\&D cycle are explained more fully in chapter 3.

Borg and Gall (1989, pp. 784-85) identified 10 steps in an R\&D cycle, presented in Table 1.

Table 1

Steps in Borg and Gall's R\&D Cycle

1. Research and information collecting

2. Planning objectives, learning activities, and small-scale testing

3. Develop preliminary form of the product

4. Preliminary field testing

5. Main product revision

6. Main field testing

7. Operational product revision

8. Operational field testing

9. Final product revision

10. Dissemination and implementation Source: Borg and Gall (1989)

The R\&D cycle is a strategy compiled by Borg and Gall (1989) for developing professional development programs for public school teachers. "The purpose of the R and 
D cycle is to translate basic and applied educational research findings into programs and products that can be used in the field" (Lorenz \& Pichert, 1989, p. 253). Although the $\mathrm{R} \& \mathrm{D}$ process was developed for teacher training, it can be applied to a school design process as well. For the purposes of doctoral research using PBL, step seven completes the R\&D cycle.

The first seven steps in the R\&D cycle are as follows: Step one identifies and defines a problem and educational need in a field of research. Step two includes planning objectives, learning activities, and small scale testing. Step three is the development of a preliminary form of the product. Step four, preliminary field testing, is used to evaluate the process in a systematic way. Step five, product revision, analyzes data from step four to determine what works well and what does not work well, especially as that efficacy correlates to the research topics and suggest preliminary changes in preparation for the main field test. Step six, main field testing, is used to further evaluate the product's efficacy and may rely on an experimental evaluation design that assesses implementation of the product and creates a summative evaluation. Step seven, operational field testing, uses the collected evaluation data to revise and improve the product and to determine the product's ability to produce the desired effect. Step seven also requires a researcher to determine "whether an educational product is fully ready for use in schools" (Borg \& Gall, 1989, p. 793). The results of this study therefore were used to determine if the school design process was ready to help leaders better design alternatives to traditional high schools. 


\section{Summary}

This study clarified four assumptions I believe school leaders need to know to design new alternatives to traditional high schools. Those seeking to create alternative high schools that are different from traditional high schools may lack knowledge needed to design new schools in an effective way. School leaders may have extensive knowledge and experience in traditional high schools and may understand how traditional models work, but leaders may also be confused by other models that lack conformity to the norm. A new and comprehensive design process, as part of the development of new and innovative high schools, enables leaders to literally "think outside the box" and stretch their definitions of what schools are. Such a design process also gives school leaders the psychological permission to pursue school organizational patterns and theoretical frameworks that would otherwise be constrained by conventional thinking that encourages maintenance of the status quo.

The significance of the problem, that school leaders do not know what to do and need a process that will enable them to change high schools for the better, is evidenced by achievement gaps that lead students to low attendance, low achievement, and eventually dropping out of high schools in crisis proportions. Eighty percent of high school students in the U.S. today attend traditional high schools: if the indicators of poor performance are to improve, that percentage will decrease as more innovative high schools are created. A well-developed design process, situated between assessment of student needs and the day the new school opens, will provide a template for design team decision making that will minimize the tendency to tinker each time a new idea is 
proposed as part of the design for an alternative high school. A well-developed design process aligns with models of school reform and for reforming our national education infrastructure (Chenoweth \& Everhart, 2002; Wilson \& Daviss, 1994).

Developing an educational product, a process for innovative alternative high school design, started with collecting information, planning objectives, developing a preliminary form of the product, field testing and revision (Bridges \& Hallinger, 1995). The research methodology and analysis used in this study emphasized how the prototypical product was revised through data collected from potential users, comparison with processes used by others who have recently led the development of existing innovative schools, and through main field testing during the design of an actual new alternative high school by an Oregon school district.

\section{Definition of Terms}

This chapter concludes by defining some key terms, while pointing out limitations contained within these definitions. These definitions also refer to the four assumptions school leaders need to know to design alternative high schools.

School Design: A research-based process using conceptual frameworks, assumptions, and procedural steps to complete planning that follows an educational needs assessment, and before the implementation and full development of the newly designed school.

Innovative Schools: For the purposes of this dissertation, "innovative schools" are public schools other than traditional public schools. Innovative schools may be designated alternative, charter, magnet or other forms of non-traditional schools. Another 
form, for example, would be a charter school hybrid that serves as an alternative for students at-risk of school failure, as designated by the NCES (2011a). Traditional public schools are also called "regular," "conventional," or "mainstream" and are the dominant model of public education in American, both historically and contemporaneously. As previously cited, about four of every five students attend traditional high school in America. Some traditional schools may offer some innovation, such as small size or flexible schedules, but those types of schools are less useful as examples of what leaders need to know to start to plan truly comprehensive, new, and innovative schools. Many private and parochial schools may also be considered to be innovative, but they are outside the scope of this paper.

School v. Program: There also exists some confusion about the definitions of school and a school program. For the purposes of this proposal, a program may have some features of an innovative school, but a school program, especially an "alternative program," is part of and in service to a larger traditional school. A school, including an innovative school, stands alone and meets regional accreditation standards, including (a) an autonomous mission, (b) educational program (a school's curriculum, instruction, and assessment system), (c) leadership and organization, (d) supports for learning, (e) finance and facilities, and (g) plans for improvement. School programs, in service to a larger traditional school, may have one or more of the features of innovative schools, but the focus of this paper is comprehensive and meant to help school leaders create holistic schools, rather than school programs. "School program," as defined here, is distinguished 
from "educational program" (commonly the curriculum, instruction, and assessment methods of a school).

Model Schools: Model schools are those schools that have innovative features and elements which developers of new schools may replicate. School leaders often compulsively want to begin by trying to borrow currently successful models, or fads, and to try to apply those practices to local needs. This assertion is supported by Ravitch (2010). In my experience leaders may waste time by becoming lost in the plethora of models, or find later that a chosen model is not replicable locally. Instead, local leaders can bring experience and ideas that can be synthesized into a shared vision leading to student success. Leaders will have mental models (Senge et al., 2000) and should arrive at a shared vision they believe will meet local needs, then spend time doing research, visiting innovative schools, and experiencing best practices to affirm and augment their vision. 


\section{CHAPTER 2}

\section{REVIEW OF THE LITERATURE}

"Great things are not accomplished by those who yield to trends and popular opinion." - Jack Kerouac

High school leaders may want to design alternatives that address the problem of students dropping out of traditional high schools, but perhaps because their careers were spent in traditional high school hierarchies, many high school leaders may lack an understanding of what is needed and where to begin. The question therefore is: What do leaders need to know to design alternatives to traditional high schools, and where should they begin? A solution lies in leaders receiving a well-researched and fully developed process to follow, and one that gives them permission to think creatively about what a high school can be. The purpose of this dissertation is to further research the development of a process that will give school leaders the structures needed to design alternatives to traditional high schools, using research-based standards and innovations. Leaders will need to know the literature on key topics that contribute to the process for designing alternative high schools. These topics, as previously presented, are: alternative education, organizational leadership, accreditation standards, and program evaluation.

Other topics of the literature that may be useful in a school design process and that could receive further study may include: organizational change and school reform for the purpose of turning around troubled schools (Chenoweth \& Everhart, 2002; Fullan, 2006; Herman et al., 2008); why charter schools have come into being (Barr \& Parrett, 1997; Nathan, 1999), and descriptions as to how small schools were developed (Clinchy, 
2000; Raywid, 1999; Wasley et al., 2000). Also, relatively few studies have suggested the need for new processes that foster more innovation in education (Wilson \& Daviss, 1994) or the redesign of "factory model" high schools (Darling-Hammond, Ancess, \& Ort, 2002). For the purposes of researching and developing a new process, this dissertation is limited to the topics previously cited.

This literature review begins with the important work of Barr and Parrett (1997), who present 10 "essential elements" (p. 32) of alternative schools gleaned from decades of study by themselves and others (Finn et al., 1991; Raywid, 1982, 1983, 1989). Barr and Parrett (1997) made the important assertion that all of the elements of effective and innovative alternative schools must be understood and utilized at the same time, not incrementally, when planning new alternative schools. Lists of elements presented in various studies, however, seem to have no coherent pattern or sequence that is useful in designing alternative high schools. This dissertation, by developing a new process for designing alternative high schools, seeks to rectify this situation.

The second topic I explored in this literature review was organizational leadership, especially examples of leadership strategies that can be used to encourage a team of local people to agree to start over when conceptualizing what a high school can be. Different forms of organizational leadership are needed if a team facilitator is to enable a design team to start over in a way that will speed the design of a new school. Educational organization leadership that puts starting over in a historical, cultural/symbolic, and visionary leadership context was included in this review. These forms of leadership may not have been applied in this way before, but their usefulness in 
facilitating the new process bridges the gap between group consensus and design conceptualization. Other forms of organizational leadership may also serve as strategies for getting a design team to start over and should receive further study, but they are not included this review.

The third topic of this review was regional school accreditation standards. The assumption was that these standards can be used as a framework for school design. Literature that sets accreditation standards in a contemporary context was presented. This review examined regional accreditation standards and the research that has influenced the development of these standards.

The fourth was program evaluation. The assumption was that program evaluation must be kept in mind throughout the design process to ensure the desired outcomes are realized, and so that the design of an innovative alternative high school begins with its eventual outcomes in mind. A colleague, Drew Hinds, is doing research into program evaluation of alternative schools. The problem he is researching is how best to evaluate alternative high schools, and how to describe methods for a process that will result in a product intended for use by evaluation teams in evaluating the impact of alternative high schools. We collaborate in our research while studying potential and actual design and evaluation users during the development of an alternative high school in an Oregon school district. This collaboration is fully described in chapters 3 and 4 .

This dissertation sought to further develop an effective and comprehensive process for designing alternative high schools. Many leaders in education today are uncertain as to what to do to design and develop schools that will meet the needs of every 
student. To design innovative high schools, it is important school leaders become more knowledgeable about the four topics as they relate to creating new schools. A review of these topics sheds light on what leaders need to know. The first topic was alternative education, and its underlying assumption is the importance of understanding and using all of the essential elements of alternative schools simultaneously.

\section{Alternative Schools: Consider All Elements}

This review provides a history of the alternative education movement and the context for what alternative education is today. Alternative education literature that discusses dropout prevention and at-risk youth was also reviewed in this chapter, while bearing in mind that I believe dropping out is a symptom of traditional high schools that were never designed to graduate all potential graduates, and this gap points to the need for innovative alternatives to traditional high schools. A review of literature related to essential elements of effective alternative schools was needed. Most of the references were books and refereed journals associated within the alternative school movement. The terms "alternative school" and alternative program appear to be used interchangeably throughout the literature (Lange \& Sletten, 2002), with "alternative education" as the umbrella term including both school and program. The definition of terms section in the introduction of this dissertation included "school v. school program." It concluded that an alternative program is defined as part of a larger traditional high school. Because the purpose of this dissertation was to help school leaders design a high school, I intended to use "alternative high school" throughout, with the understanding that other researchers may use both school and program to represent similar options in alternative education. 
The development of alternative schools began in the 1960s during time of great innovation and change. The emergence of alternative schools originated in a search for the ideal school (Barr \& Parrett, 1995, 1997; Nolan \& Deal, 1978). Ideal schooling situations would cause students and teachers to work in a learning community to which parents would want to send their children. Such a school would be a different model than traditional public high schools. Though one ideal school for all will never exist, a search by local design teams for their ideal school will lead to greater diversity in secondary education, one built first and foremost on the needs of students. Alternative schools, and the creation of ideal schools that meet the needs of all students in a diverse system, symbolize a successful approach to school reform (Barr \& Parrett, 1995, 1997; Fizzell \& Raywid, 1997; Morley, 1991, 2002, 2003; Raywid, 1982, 1994; Reimer \& Cash, 2003; Schargel, 2003; Smink, 1997; Smink \& Schargel, 2004).

Because well-conceived and developed alternative schools were often successful in educating all of their students, alternative schools gradually became known in many places as schools for students at-risk of school failure. High school age youth drop out for a multiplicity of variables. Research by Rumberger (1987, 2002, 2004) confirmed the causes of dropping out, which align into two broad categories, school-related factors and student-related factors. Bradley and Renzulli (2011) broadened the "either/or" proposition of either being in school or being a dropout to offer a model of three outcomes: in school, pushed out, or pulled out. This study is important because it uses empirical data from the Educational Longitudinal Survey to find a link between differences in socio-economic status and being either pushed or pulled out of high school, 
especially among black and Latino minority students. To an extent, alternative schools have also become recognized as places where students with learning disabilities experience success (Lange \& Sletten, 2002). School reform and restructuring research into alternative schools has shown that if alternatives to traditional schools are available to students at-risk of school failure, they will succeed (Barr \& Parrett, 2001; Natriello, McDill, \& Pallas, 1990; Raywid, 1989; Wehlage \& Rutter, 1987; Wehlage et al., 1989; Young, 1990). Some charter schools have been implemented as alternatives to address the issue of at-risk youth, (Lange \& Sletten, 2002). Though alternative schools have been around for decades, out of the necessity of meeting at-risk students' needs they have departed from traditional practice and become innovative models of school reform (Raywid, 1983). Alternative education, meaning alternative schools and programs, has also been recognized as a basic core strategy for dropout prevention (Reimer \& Cash, 2003).

Those who want to design and start an alternative school should know something about their history. To understand the correlation between alternative education as a school reform movement, its emergence as a dropout prevention strategy, and innovative elements developed in alternative schools over time, it is necessary to begin with a brief history of alternative schools.

\section{History of Alternative Schools}

Those who have studied or been involved in the history of American education trace the development of alternative schools to the early 20th Century progressive and experiential education theories of Dewey (B. E. Conley, 2002; Cremin, 1961; Deal, 
1978). The origin of alternative schools today seems rooted in the civil rights movement of the late 1950s and early 1960s, when many stakeholders saw the traditional public school system as either racist or designed for the success of the few at the expense of the many. Early pioneers in alternative education sought to change traditional public school systems, from either the outside or the inside. Traditional high schools were viewed as "cold, dehumanizing, irrelevant institutions, largely indifferent to humanity and the 'personhood' of those within them" (Raywid, 1981, p. 551). The traditional system defined education "solely in narrow cognitive terms at the expense of equity" (Young, 1990, p. 9). In other words, youth were sorted into vocational tracks according to their perceived intellectual capabilities, which limited their opportunities, especially among minority youth. Alternative schools are often referred to in the as "schools of choice," because there were no other significant choices in schooling, other than traditional schooling, when the movement began (Barr \& Parrett, 1997). By the late 1960s, the alternative school movement split into the two basic approaches, those working inside the public school system and those working outside the system (Koetke, 1999; Reimer \& Cash, 2003). These early experiments were predicated on the beliefs that there has to be more than one best way to become educated and that all children can learn (Morley, 1991, 2003).

Alternative schools referred to as Freedom Schools were developed outside the public school system as a reaction to the inequality and inferior education minorities received in traditional schools. Examples included community schools run in store front and church settings. Local community control of education came first as the Freedom 
School movement sought to take control away from oppressive educational processes to which the local community saw their children being subjected (Graubard, 1972). Similarly, during the same time period, another non-public set of alternative schools emerged, known as the Free School Movement. This movement was based on individual achievement and fulfillment instead of community development. Its proponents saw public education as stifling creativity and natural educational curiosity. The British school Summerhill is the movement's most familiar example, which was created to give children the freedom to learn without restrictions (Vaughan, 2006).

Similarly, in the latter part of the sixties and seventies proponents of change within the public school system used elements of alternatives from outside the system to design new alternatives within the system. These became known as Open Schools. Examples of open schools were the Murray Road Annex in Massachusetts, John Adams High School in Oregon, and the St. Paul Open School in Minnesota. These schools had characteristics such as student, parent, and teacher choice; autonomy in learning and pace; non-competitive assessments of student performance; and a holistic, child centered approach (Lange \& Sletten, 2002). Open Schools greatly influenced the design of public school alternatives at all grade levels and contributed many elements of innovation still seen in public alternative schools. Open schools evolved into several forms; Table 2 lists these variations and presents their defining characteristics as defined by Young (1990); 
Table 2

Types of Open Schools

\begin{tabular}{ll}
\hline Type & Characteristics \\
\hline Schools Without Walls & $\begin{array}{l}\text { Emphasized community-based learning where individuals were } \\
\text { brought in to teach students, or students sent out to learn. }\end{array}$ \\
Schools Within a School & $\begin{array}{l}\text { Intended to make large schools into smaller communities of belonging } \\
\text { where individual groups were designed to meet the educational needs } \\
\text { and interests of students. }\end{array}$ \\
Multicultural Schools & $\begin{array}{l}\text { Designed to integrate culture and ethnicity into the curriculum where } \\
\text { some schools had a diverse student body and some served a specific } \\
\text { ethnic group. }\end{array}$ \\
Continuation Schools & $\begin{array}{l}\text { Used as an option for those who were failing in the regular school } \\
\text { system because of issues including dropout, pregnancy, and poor } \\
\text { grades where school was less competitive and more individualized. }\end{array}$ \\
Learning Centers & $\begin{array}{l}\text { Intended to meet particular student needs by including special } \\
\text { resources, such as vocational education, in a school setting. }\end{array}$ \\
Fundamental Schools & $\begin{array}{l}\text { Emphasized a back to basics approach in reaction to a perceived lack } \\
\text { of rigor in other alternative schools. }\end{array}$ \\
\hline
\end{tabular}

Magnet schools were another important form of open school developed during this era. This type of school was seen as a way to both integrate public schools and to keep middle class families in the urban public school systems. Magnet schools did so by offering themed curricula such as performing arts, science, or mathematics.

During the 1970s alternative schools were written about as promoting democracy and as a tool for school reform (Barr, Colston, \& Parrett, 1977; Fantini, 1973a, 1973b; Raywid, 1989). The number of public school alternatives grew exponentially during the seventies, from approximately 100 to more than 10,000 (Raywid, 1981). Throughout the 1980s and 1990s a new kind of alternative school emerged as the number of innovative open schools declined. These alternative schools focused on behavioral objectives and academic remediation of disruptive youth at-risk of failing school. Young (1990) 
attributed this to the more conservative political climate of the Reagan era. Raywid claimed alternative schools increasingly focused on basic skills and less on innovations such as democratic decision-making by staff and students. As an example, the John Adams High School in Portland, Oregon, which was organized as schools-within-aschool and designed around students' interests, opened in 1969 but was closed in 1981, because of difficulties associated with its unconventional approach to education (Guernsey, 1970; Tyack \& Cuban, 1995).

The early alternative school movement has had a lasting influence on public education by putting forward the idea that a single inflexible system that excluded certain students could not be tolerated, and that schools designed to meet the needs of students who were not served by the traditional system had to be developed. To better meet student needs flexibility was granted in school organization and the creation of studentcentered learning environments. Although many early experiments were short-lived, in a seminal study Raywid (1981) identified elements of innovation that contribute to academic success among students who attend alternative schools. The methodology used by Raywid was a scholarly analysis and brought greater credence to the alternative education movement. As with any movement, change was difficult, as many early alternative schools struggled to align their characteristic need for individualization of student learning with the economic efficiency and accountability demands of the traditional educational system (Deal, 1975). Barr and Parrett (1997) later elaborated on the elements of effective alternative schools that Raywid and others such as Wehlage et al. (1989) identified, and made the important assumption that for alternative schools to 
be truly innovative and lasting, it is critical that school creators pay simultaneous attention to all of the elements of effective alternative schools during the design process. I believe the recent and unsuccessful small schools movement, in which traditional high schools in particular were recast into smaller isolated units wherein nothing else changed, is an example of trendy tinkering rather than comprehensive design with all elements of effective alternative schools. Historically, it is well known that incrementalism has hindered education reform (Tyack \& Cuban, 1995).

The elements of alternative schools as identified by educational research are presented in the next section of this review.

\section{Characteristics of Alternative Schools}

Alternative schools have evolved in recent times to mean different things to different people, and there are about as many definitions of alternative school as there are alternative schools. The question, "What is alternative education?" has eluded an answer, especially in the last decade. However, some specific elements and types have been emphasized in the literature.

Lange and Sletten (2002) observed alternative schools are characterized by:

- Small size (Arnove \& Strout, 1980; Barr, 1981; Bryk \& Thum, 1989; Morley, 1991; Natriello et al., 1990; Tobin \& Sprague, 1999; Young, 1990). Small school size is a tremendously important factor, especially at the high school level. In the 1960s alternative high schools sought to maintain an enrollment of less than 200 students with a low student-teacher ratio of 15 or fewer students for each teacher, and more recently "Most believe an alternative should be no more than 400 students in order to be effective" (Barr \& Parrett, 1997, p. 182). The purpose of small school size is to break down the anonymity and isolation often experienced by students in large high schools, and to make learning more personal as well as communal. 
- Individualized instruction and one-on-one interaction between students and teachers (Arnove \& Strout, 1980; Tobin \& Sprague, 1999). How instruction is delivered is often the deciding factor in a student's willingness to participate in learning. Students in alternative high schools need a variety of instructional opportunities, including individualized instruction so that learning is personalized and flexible enough to meet each student's individual needs. Recent scholarship emphasizes the importance of one-on-one interaction to promote positive student-teacher relationships, though more empirical evidence is needed to support the efficacy of the power of student-teacher relationships to alter the influence of parents or peers (Hamre \& Pianta, 2006).

- Supportive learning environment (Arnove \& Strout, 1980; Bryk \& Thum, 1989; Case, 1981; Tobin \& Sprague, 1999; Young, 1990). Barr and Parrett (1997) insisted "Almost everyone wants to find the ideal school" (p. 29). The goal of every alternative school is to create a community of support which will be a positive experience for every student. When students are in a community of support they will have a chance at success, and they will have found their own ideal school. A key to establishing and maintaining a supportive learning environment is bringing together a group of teacher who are idealistically committed to educating every student by responding to a wide range of student needs (Wehlage et al., 1989).

- Relevance to student lives in learning (Arnove \& Strout, 1980; Barr, 1981; Natriello et al., 1990). Meier and Scherer (1994) discussed the concept that finding relevance starts as a conversation among educators, parents, and students about what it means to be an educated person. Barr and Parrett (1997) found school choice, the ability to choose among educational programs, should be unlimited, and programs should be designed cooperatively among parents, educators, and students to meet each student's educational needs and interests. Student needs must define the school design process. "At the high school level, student interest is critical to the design of educational alternatives" (p. 36). Relevant curricula are highly motivating to students and teachers, and create learning opportunities which students will attend (Narvaez, 1994).

- Flexibility in organizational structure (Barr, 1981; Barr \& Parrett, 1997; Gold \& Mann, 1984; Natriello et al., 1990). Creative alternative schools invent new ways of organizing, for example, their daily, weekly, and school-year schedules. Some operate year-round, extended day, and 3-week or 5-week blocks where students study one subject at a time. Some give Friday's off if the students meet learning expectations Monday through Thursday. Some alternative schools currently operate 24 hours a day through on-line learning opportunities. 


\section{Types of Alternative Schools}

The ambiguity as to what an alternative school is or represents has existed since the beginning of the alternative education movement. School leaders wanting to design alternative high schools that will reduce dropout may be confused by the growing number and types of alternative schools in existence today. The number of alternative schools operating separately from traditional schools grew by $47 \%$ between school years $1993-$ 1994 and 1997-1998 (Kleiner, Porch, \& Farris, 2002). Kleiner et al. (2002) also found that if an expanded definition of alternative schools is used to include public alternatives, charters, juvenile justice, and other programs targeting youth at-risk of school failure, the number of alternative schools reported in 2000-2001 was 10,900 schools serving 612,000 youth in the United States. That number has surely risen over the last decade with the rise of the small school movement and other efforts to re-create schools using non-traditional models, though some innovative schools are alternatives to traditional high schools but do not designate themselves as such.

To sift through this confusion when considering what type of alternatives may be suited to their students' needs, leaders should become familiar with the historical debate as to the typology or taxonomy of alternative schools. Raywid (1994) conducted a wellknown synthesis of research of alternative schools which defined three types of alternative schools: innovative, last-chance, and remedial. All three types have been in existence for at least the past two decades and are still commonly found in school systems (Foley \& Pang, 2006). Raywid (1994) decried the lack of institutional legitimacy and the pejorative connotations associated with alternative schools, despite their history 
of pioneering innovations later pursued as reforms by traditional schools. These innovations include small scale, curricular focus, school as community, informal studentteacher relationships, school choice, staff empowerment, active learning, authentic assessment, and non-bureaucratic procedures. Despite developing such practices, alternative schools have not been widely recognized in the literature as models of innovative school change.

Raywid (1994) fixed the causation as to why the innovations founded in alternative schools have not been adopted by in their entirety by all schools on the considerable ambiguity as to the purpose of alternative schools. Fizzell and Raywid (1997) questioned whether the purpose of alternative schools was to serve as then ideal of what schools should be, or to serve as places for students who were unsuccessful in the traditional system. Because their students were non-traditional, alternative schools had to depart from traditional school organization, programs, practices, and environments. The two consistent traits in alternative schools are those emphasizing service to "at risk" students who cannot succeed in traditional schools, and those linked to innovation and creativity in educational practice and organization. These traits are not mutually exclusive, however. Changing demographics and needs of students make new types of schools essential. More challenging students are also more dependent on good education. The central question regarding types of alternative schools is: Is the school for all students, or just for some? Famously, schools like Central Park East in New York (Schwarz, 1993) and the Metropolitan Learning Center in Portland, Oregon are explicit in 
stating that their schools are alternative, but not their students. Good education for at-risk youth is good education for all youth.

As previously stated, a wide variety of alternative schools exist, but Raywid (1994) identified three pure types of alternative schools that Foley and Pang (2006) recognized as still in existence. Raywid further synthesized the research to determine their comparative advantages and disadvantages of each type of alternative school, presented in Table 3.

Table 3

Comparative Advantages and Disadvantages of Types of Alternative Schools

\begin{tabular}{lll}
\hline Type & Definition & Advantages and Disadvantages \\
\hline I & $\begin{array}{l}\text { Popular Innovations. Schools of } \\
\text { choice that seek to make school } \\
\text { fulfilling for all involved. }\end{array}$ & $\begin{array}{l}\text { Compared to Type II and III schools, Type I schools } \\
\text { are less expensive and the benefits longer lasting } \\
\text { (Raywid, 1982). }\end{array}$ \\
II & $\begin{array}{l}\text { Last-Chance Programs. Where } \\
\text { students are "sentenced" as a last step } \\
\text { before expulsion. }\end{array}$ & $\begin{array}{l}\text { Compared to Type I, Type II programs contribute little } \\
\text { to the problems they were designed to solve. }\end{array}$ \\
III & $\begin{array}{l}\text { Remedial Focus. For students who } \\
\text { need academic and social } \\
\text { rehabilitation. }\end{array}$ & $\begin{array}{l}\text { Compared to Type II, Type III programs have better } \\
\text { achievement, but Types II and III are costlier and have } \\
\text { poorer outcomes than Type I (Gold \& Mann, 1984). }\end{array}$ \\
\hline
\end{tabular}

Most alternative schools can be identified as one of these types, though some are hybrids. For example, a student may be given the "choice" to attend or not attend a Type II program. This defacto school assignment is different from giving the student a choice between diverse schools designed to meet students' needs and interests. Such a false choice seems to come from a "take-it-or-leave-it" mentality that permeates alternative education programs closely aligned and in service to traditional high school systems, such as those described by Foley and Pang (2006). 
Leaders of Type I alternative schools, those that students truly choose to attend, assume learning and behavioral difficulties result from an inadequate school-student match, and altering a student's educational environment will result in improved performance. Importantly, the power of truly giving students the ability to choose their school results in "ownership" of the school by the student, and assumes that pride of ownership will result in improved academic achievement (Narvaez, 1994; Wehlage et al., 1989). Type I alternative schools have other success factors, and the underpinning elements of Type I alternative school success are discussed in the next section of this dissertation.

"Despite the history of alternative education programs, few data are available describing the governance, physical facilities, student population, educational programming, and supports being provided to students at risk of educational failure" (Foley \& Pang, 2006, p. 11). Foley and Pang (2006) surveyed 50 leaders of alternative high schools in Illinois for the purposes of describing the organization and student population of Type II alternative schools. Though the study is limited in size, the data are corroborated by previous research (Kleiner et al., 2002). In my opinion, leaders of traditional schools typically conceive of alternative schools as Type II models.

The data collected by Foley and Pang (2006) are significant and instructive. Their quantitative research showed that Type II schools predominantly required site-based management, were housed in off-campus (apart from the local high school) facilities, and had a closed campus. Though the principals surveyed rated the physical facilities "above average," accessibility to libraries and science laboratories was limited, with $40 \%$ having 
no library access. Program supports such as parent involvement were also limited, with only one-third of the alternative programs providing any opportunity for parent involvement. Other supports, such as counselors, nurses, psychologists, and vocational educators, were available in less than half the programs. The predominant support service providers were social workers (74\% of programs) and juvenile justice staff (82\% of programs). Students in Type II alternative programs ranged in age from 12 to 21 years. Student populations varied widely in size (11 to 458$)$ with an average size of 90 . Foley and Pang did not report finding disproportional representation among ethnic groups in the alternative programs studied. Students with disabilities also appear to comprise a large percentage of students enrolled, though the number of staff certified as special educators is considerably fewer than those certified as general educators. The programs studied also used non-certified and paraprofessionals to support activities.

Type III alternatives programs are designed to remediate reluctant learners and return them to traditional schools. Type III programs are limited in scope, content, and duration, and because the purpose of this dissertation is to research and develop a process for designing an innovative alternative high school, Type III programs are outside the scope of this study.

Raywid (1994) demonstrated bias toward Type I alternatives by likening Type II alternatives to "soft jail” (p. 2). As the study by Foley and Pang (2006) illustrated, most Type II alternatives are designed to serve traditional high schools by diverting students who have behavioral and academic issues into inadequate facilities and programs. The purpose of this dissertation is to develop a process to design innovative alternatives to 
traditional high schools. Though the process could be used to design a school exclusively for dropouts retrieved from the streets, it will be better used to design effective alternatives to traditional high schools so that dropping out is rendered unnecessary.

Type I alternative schools contain factors that, when employed together, account for success in education. These factors include membership and ownership of the school by students and families, positive student-teacher relationships, compelling curriculum, and creative instruction such as experiential learning, and a collaborative organizational structure. All of the elements leading to the establishment of effective alternative schools are discussed in the next section.

\section{Elements of Effective Alternative Schools}

Much of the literature on alternative schools expounds on descriptors of alternative schools that define their "essential elements" (Barr \& Parrett, 1997, p. 32). Such elements can be used as part of a design framework for alternative high schools. It is an assumption of this dissertation that leaders in education who want to design alternative schools need to be concerned with all of them at the same time, or risk inadequately designing and thereby defaulting to developing Type II or III alternative schools. Many lists of these elements exist in the literature (Dupper, 2008), but the most cogent and complete list seems to have been gathered by Barr and Parrett who identified a set of set of elements of effective and innovative alternative schools from research conducted during the past half century. A summary of points about 10 elements of successful alternative schools, with associated research and definition, follows:

- Shared vision among all school participants with clearly identified goals and re-evaluation over time (Gregg, 1999; Narvaez, 1994; Senge et al., 2000). In 
the political climate of a school district that is part of a larger community, an individual may have a vision for an original plan for a new school, but until like-minded partners are enlisted and a shared vision is developed, a vision may have little chance of fruition (Heifetz \& Linsky (2002). A process for designing an alternative high school should spend considerable time developing a shared vision that will lead to a mission statement. Barr and Parrett (1997) asserted that the search for an ideal school through the creation of a shared vision becomes self-fulfilling prophecy, especially when faculty, students, and parents are all involved.

- Educational program diversity based on student needs and interests with links to local communities (Dynarski \& Gleason, 1998; Leone \& Drakeford, 1999). School choice, discussed below, requires diverse programs of curriculum and instruction and demands that an innovative alternative high school be innovative in its range of course offerings. For example, some alternative high schools go so far as to provide individualized instruction for every student, so that each student in the English classroom is in a different place in the English curriculum at any point in time, but under the supervision of and receiving oneon-one instruction from a teacher who is always present. Furthermore, advancements in computer-assisted instruction and on-line learning widen the opportunities for diverse educational programming, though in my opinion, under the synchronous supervision and instruction of a physically-present teacher during school hours, and asynchronously during non-school hours. Curriculum and instruction should align with common core state standards, but more importantly a students' educational program should be cooperatively designed and developed by parents, teachers, and the student (Barr \& Parrett, 1997). One way to make students' educational program more diverse and is to involve the local community through community service projects or careerrelated opportunities for learning.

- Relevant and focused curriculum that meaningfully connects with students with their school (H. M. Levin, 1987, 1989, 1998, 2004). Implementing and improving a curriculum is what makes learning relevant and meaningful to students, essential to the success of any school. It is especially important and critical in designing any new and innovative alternative high school to include students at risk of school failure in its student population. Many at risk students may get to high school age having received mostly remedial and uninspiring curriculum delivered at a glacial pace. A reliance on repetitive curriculum is viewed as contributing to a gap in achievement for at-risk students leading to failure and dropping out of high school. While every high school curriculum is slightly different, a key component of making curricula relevant and focused is having the ability to serve a wide range of student academic skill levels and to accelerate each student's acquisition of new skills. The goal is to assess where each student is academically, and take them forward and upward from there as 
rapidly as possible by providing high-interest materials and learning opportunities.

- Creative instructional approaches wherein teachers provide a variety of flexible learning opportunities in a community of learners (Legters, Balfanz, Jordan, \& McPartland, 2002; Wehlage et al., 1989). Forming a community of learners is central to the effectiveness of an alternative high school. Community and flexibility in learning is tied to the element of small size, which may have more to do with each student's sense of closeness than the number of students in an alternative high school (Raywid, 2001). Smallness combined with flexible, individualized, and personalized learning, wherein each student is a partner in learning with teachers and other students, is a potent instructional environment. The delivery of instruction is usually the key factor in a student's decision to participate in learning (Barr \& Parrett, 1997). Barr and Parrett emphasized several approaches that characterized instructional delivery in successful alternative high schools: (a) Focus on individual needs based on careful assessment of each student's needs and abilities; (b) opportunities to accelerate learning and learn as fast as possible through, as examples, independent study, career exploration, and interdisciplinary courses (H. M. Levin, 1989); (c) flexible use of time wherein time and scheduling is the variable instead of the constant; (d) diverse instructional practices in a range of formats including independent, tutorial, small group, and large group instruction; and, (e) using students as resources wherein students tutor one another or even teach a special-interest course of their own.

- Student assessment for learning authentically derived from precisely what students have learned, and based on individualized graduation plans (DarlingHammond, Ancess, \& Falk, 1995; Darling-Hammond et al., 2002; Reeves \& Okey, 1996). Traditional high schools, as they continue to exist today, count student success based on units of credit earned, which in turn is based on "seattime" or the number of hours of instruction students had the opportunity to be exposed to whether they were in attendance or not. Except for mid-term letter grades, traditional high school seem to receive little formal feedback as to how they are doing in a course until they receive letter grades and credits at the end of a semester, by which time it is impossible to correct under-achievement. This industrial era relic of "pay" (credits) for "work" (seat time) has been replaced in innovative alternative high schools by frequent assessments of achievement that inform each student as to where they are in relationship to graduation at virtually any point in time. Some alternative school schools give students and parents weekly reports of progress (T. Jones, personal communication, January 25, 2012). It is a given that individual graduation plans must align with common core state standards, and this makes it simpler to build a curriculum. But when state standardized tests of literacy and numeracy are used as the sole assessments of a school's success in achieving 
state standards, standardized test serve as a distraction from authentic assessments of what students are learning and able to do-and of what students may actually need to know to become both literate and employable. Multiple assessments, in addition to state tests, are essential (Stiggins, 2002).

- Caring and demanding teachers who choose to work in an intimate learning environment while requiring high quality student work in a community of learners (Noddings, 1992; Sergiovanni, 1994; Wehlage et al., 1989). Teachers who were invited to help design and work an innovative alternative high school are presumably there because they want to have close personal and professional relationships with their students. Some teachers in traditional high schools may be said to view their jobs as content delivery only, with little time for caring about students on a personal level. Teachers in successful innovative alternative high schools more likely view part of their job as getting to know each of their students, and for their students to know them, so that communication and learning is based on mutual trust, a key factor when working with students who may at first be oppositional and suffer from low self-esteem and efficacy. The term "the new 3 R's, Rigor, Relevance, and Relationships" has been in vogue in recent years. I believe the order is backwards, and that learning becomes more relevant after relationships are formed, and that rigor grows from relevance. By knowing their students, teachers in innovative alternative schools also know how each of their students learn and how each is motivated to learn.

- School choice or voluntary participation in which all involved are in schools of choice in which participation is not mandated (Duke \& Perry, 1978; Finn et al., 2001; Raywid, 1982, 1983, 1984, 1989). The concept of school of choice should permeate an innovative alternative high school. School choice within and between school districts and among state school systems is often a loaded political concept connoting school vouchers and No Child Left Behind transfers of students out of low performing schools. Within the context of this dissertation choice is limited to choices available within a single alternative high school. The concept is for students, parents, teachers, and administrators choose to work in the alternative high school in contrast to being mandated to participate. In operation, students are given a wide range of courses to choose from and a wide range of opportunities to demonstrate what they are learning. Choice enables an alternative high school to meet the needs and interests of each student (Barr \& Parrett, 1997). Choice within an innovative alternative high school may have a positive effect on students' core self-evaluation traits: self-esteem, self-efficacy, locus of control, and emotional stability in relation to performance and satisfaction (Judge \& Bono, 2001). Volunteering and seeking to enroll in an innovative alternative high school increases a student's sense of ownership in the school, and armed with that power students may take control of their own learning, and their own lives. 
- Comprehensive programs are available to all students (Barr \& Parrett, 1997; Raywid, 1982). As with choice, the term "comprehensive" means different things in traditional and alternative high school settings. A traditional comprehensive high school tries to be all things to all students but often succeeds only in tracking students by ability and socio-economic status, which contributes to a high dropout rate (Fine, 1991). Barr and Parrett discussed comprehensive alternative programs to mean having an array of alternative schools within a school district that are diverse enough to meet the needs and interests of all learners in all grades. In addition to educational program diversity, discussed earlier in this section, comprehensive programs imply having educational programs that are holistic and equitable for all students. This has to do with the working conditions of the innovative alternative high school, and the need to consider its student population, fiscal condition, and the experience of its staff so that quality educational program (curriculum, instruction, and assessment) equally available to every student.

- Small school size leading to highly personalized learning environments (Darling-Hammond et al., 2002; Meier, 2002). In addition to the student population numbers cited previously, small school size, when coupled with the other elements of innovative alternative high schools cited here, leads to a highly personalized learning environment. That environment looks different from a traditional high school in operation. While every high school is different, a large traditional high school may have highly structured and busy classrooms with intermittent periods of chaos outside classrooms before and after school, during breaks, at lunch, and after school. Due to their large size, many traditional high school students may feel anonymous, isolated, and lost. Though efforts have been made in recent years to downsize large high schools into smaller units, the overall size, organization, and general campus climate remained the same due to internal traditions as well as inhibiting external public school district political pressures (Raywid, Schmerler, Phillips, \& Smith, 2003). Raywid et al. also found efforts to develop small schools in New York City, Chicago, Philadelphia, Boston, and Portland (Oregon) were transforming schools into educational environments where everybody knows one another, which encourages a more personal and humanistic educational program. Leaders wanting to start an alternative high school must ensure it is organized as a small school, while also paying attention to all of the other elements discussed in this section.

- Shared governance and local autonomy that increases "ownership" of the school by all involved (Narvaez, 1994). As school choice increases ownership in an alternative high school, so does shared governance and local school autonomy. By shared governance researchers mean community participation, parent involvement, and student commitment that is increased beyond the level of participation commonly found in traditional schools (Barr \& Parrett, 1997). 
Increased control of budget, curriculum, and instruction by groups from the local community and parents, teachers, and students can lead to more creative instructional approaches and student engagement in school. Barr and Parrett also found local autonomy to be essential in developing an effective alternative school and in fostering bold innovations. Shared governance and local autonomy may be valuable in theory, but power sharing by building administrators at the local school level, and by superintendents and other central office administrators at the district level, may be difficult to put into practice. These concerns must therefore be addressed as part of the school design process so that leaders have pre-agreed upon degrees of shared governance and local autonomy in advance of the implementation of alternative high schools.

Other researchers have cited additional elements of innovative alternative schools, and some overlap or refine those identified by Barr and Parrett (1997). Lange and Sletten (2002) also found clear goals, student-centered atmosphere, integration of research and practice in the educational program, and professional development for teachers are important elements. Similarly, Darling-Hammond et al. (2002) detailed design features as attributes of small school size that contribute to positive outcomes in redesigned secondary schools in New York City. These features are personalized education and collaborative learning structures leading to

The schools' practices including small units within schools, keeping students together over multiple years, forming teaching teams, assuring common planning time for teachers, involving staff in problem solving, involving parents, and fostering cooperation. (Darling-Hammond et al., 2002, p. 641)

The lists of elements of innovative schools seem endless. Nevertheless, I have found the elements delineated by Barr and Parrett, though somewhat overlapping, are discrete enough to serve as parts in the process of designing new and innovative alternative high schools. Other elements not subsumed under Barr and Parrett's list may be discovered and used during the implementation and development phases of new schools. 
In summary regarding alternative schools and their essential elements, Barr and Parrett (1997) declared innovative alternative school designs will not be successful if elements are experimented with incrementally, but only "If each and every one of the essential elements is carefully considered...these essential elements represent a formula for success" (pp. 32-33). Raywid (1993) also asserted there must be wholehearted implementation of an alternative school without a piecemeal approach to structuring an educational program. Barr and Parrett insisted it is also important to remember that traditional education has adopted most of the innovations developed in alternative schools, but too often partially and with incomplete change from the status quo of past practice.

\section{Organizational Leadership: Starting Over}

The second topic of this chapter is organizational leadership that will induce a design team to start over when designing an innovative alternative to traditional high schools. Leadership strategies can be employed to cause a team of local people with mixed backgrounds to reach consensus about creating a new school rather than trying to change an existing school. As described in the preface, school district leaders may already have an existing alternative high school that is not working as well as it should. The assumption here is that it is more efficient to have a design team agree to conceptualize and mentally build a new alternative high school than to try to remodel an unsuccessful school that already exists. The design process could be used to redesign an existing alternative school, but only if the designers agree to restart their thinking as to what an alternative high school can become, and to set aside their histories and biases. 
This effort needs effective organizational leadership strategies that will convince a design team to agree to start over, rather than trying to "turn around" an existing but troubled alternative high school. Team membership should represent various stakeholders and views. Team membership may also include the leader of the existing alternative high school who brings the sentiments of the old school and its staff. Another team member may be a traditional school administrator who may not see the need to have an alternative high school at all. Other team members may range between these extremes. An organizational leadership strategy or strategies that can achieve consensus among these disparate players are needed to reach agreement about the design of the new alternative high school. This section focuses on three strategies that may be employed to achieve that end. These strategies are cultural and symbolic, visionary, and historical leadership.

Starting over is more efficient in time and effort than trying to turn around a trouble school. I call it the "etch-a-sketch" approach. An education luminary, Barth (1990) found "Probably the most important—and most difficult—job of the school-based reformer is to change the prevailing culture of a school" (p. 7). The effort put forth to change an existing school is therefore better channeled into creating a new school. Also, it may also be faster to start over, from scratch, to design and implement a new alternative high school than to try to change an existing school. H. M. Levin (1989) found changing an existing school takes five to seven years, if the change process is successful at all. Rourke and Mero (2008) suggested troubled high schools can be turned around in two or three years. Barr and Parrett (2001) suggested troubled schools can be saved by incorporating elements of effective alternative schools, though they do not appear to 
present a timeframe for doing so. Stuit (2012) concluded it is easier to close a lowperforming charter or traditional school, and have students start over elsewhere, than to turn around a troubled school. Other research reports that effective leadership can turn around an existing school, but local politics and centralized bureaucracy are the biggest hindrances (Farkas, Johnson, Duffett, \& Foleno, 2001). I believe, based on experience and the research just cited, that starting over when designing a new high school will be more effective than school turnaround, and will lead to the implementation of a newly designed in six months to one year. Because there is little evidence in the literature to support this claim, the concept of starting over, and its contribution to the development of a successful design, is one of the research questions posed in this dissertation. Getting a design team, where its various members may bring their own personal and professional histories to the table, to agree to start over may be the most difficult part of the design effort. An effectively led design team, with a leader able to get a team to not just set aside differences, or to use differences coherently to start over is critical to designing an alternative high school. As seen in the business sector with corporations that try to renew themselves, it is notoriously hard to drive people out of their comfort zones (Kotter, 1995). This literature review studies three relatively simple leadership approaches that may be employed individually or in combination to drive change by starting over when designing an alternative high school.

\section{Cultural and Symbolic Leadership}

A well led team that has been welded by considering how to develop the school culture of an innovative high school will be better able to accomplish the most difficult 
task of planting the seed of a new school's culture. If successful, the people living and working in the new school culture will be unafraid to take a risk and will give themselves permission to literally think outside the box as to what is the ideal school for meeting the needs of students, and especially students at-risk of dropping out. Developing symbolic forms that communicate the unique organizational culture of the new school will also go a long way toward instilling a deep sense of purpose and resolve in a design leadership team, which can then be communicated to the broader school community. A key symbolic ritual that needs to be planned as part of support for student learning is commonly called the school enrollment or "intake process." This occurs when a new student enters the new school and is oriented or initiated into the school's culture. This process plays a powerful role in preparing students to work together to carry out the school's mission.

Morgan (2006) and Bohman and Deal (2003) pointed out frameworks for understanding organizations and how they are led by leaders who know how organizations develop a culture and its symbols. Morgan's metaphor of organizations as cultures and Bohman and Deal's "symbolic lens" helps people make sense of the confusing world in which we live. Starting a new kind of school requires a leap of faith and a concrete understanding of one's beliefs and the beliefs of a design group. People have to be led to agree and reach consensus as to meaning of symbols used to communicate. "Meaning is not given to us, we have to create it" (Morgan, 2006, p. 240). Bohman and Deal observed that over time organizations, consciously and unconsciously, build their own beliefs and gather values. The culture of an organization is seen in the 
myths, stories, and other symbolic forms of communication within an organization. Leaders who understand how organizations develop symbols can influence its development, especially during the exciting time when an organization, such as an innovative alternative high school, is beginning to be conceived as part of the process of starting over.

A search of the literature regarding leadership for developing the school culture and symbolism of a new school, when starting from scratch, revealed most of the literature was about leadership for changing or reforming the culture of an already existing school (Deal \& Peterson, 1999; Sarason, 1972, 1996). This research confirms, however, the impact of meaningful purpose and shared values in school culture and must be applied as an initial step when designing an alternative high school. "Pre-cultural" symbolism in the forms of rituals, ceremonies, stories and lore, artifacts, mottos, and other symbols can be considered by the design team during the process of creating a shared vision and mission for the new alternative high school, as it is for any school or any organization.

Perhaps the most useful literature for the development of culture and symbolism by a design team for a new school comes from school reform literature, especially Barth (1990, 2001), who suggested ways to build school culture among adult learners in ways that will increase their engagement in learning together-in this case adults who are learning to design an alternative high school. Barth (1990) suggested ways for adults in a school to decrease adversarial relationships and become collaborative as a "community of learners" (p. 37) and later as a community of leaders. This thinking can be applied by 
adroit leaders of a design team, as described in the preface and introduction of this dissertation, with team members who more than likely will come together with diverse notions as to what is needed in a new alternative high school.

A school leader can begin the design process of a new school by employing school culture and symbolism. The leader of a new school design team must be aware of the dominant culture in the local community where the new school is to be situated. Cultural norms of the existing traditional high school, highly competitive sports teams, for example, may be contrasted with the youth culture needs of the students for whom the new school is to be designed. Symbolism that creates meaning for design team members may take the form of a school mascot, logo, or "picture" of an ideal school that team members create during the design process. A later public ceremony that will communicate the essence of the new school's vision and mission may be proposed by the leader as a symbol of the new school's independence. When the design team for new alternative high school has begun to commonly see the artifacts and symbols of the new alternative school, and can express them as part of their shared vision, they can be said to have started over.

\section{Visionary Leadership}

Closely related to cultural and symbolic leadership, visionary leadership is required to inspire a design team to start over to design a new and innovative alternative high school. Vision has become a buzzword that has been around organizational leadership since the 1990s, and everyone has seen examples of new visions among recent trends in education (Sergiovanni, 1998; Southworth, 2002). D. T. Conley (1996) has the 
belief that leaders in education have become cynical about the value of vision, yet creating a vision for a new school is a critical task. D. T. Conley also found vision exists when the people in an organization share an agreement on values, beliefs, purposes, and goals that form an internal compass. Whitaker and Moses (1994) suggested vision is a compelling dream with a clear scenario as to how it will be accomplished. A clear vision for an alternative high school must be a collaborative school community vision, and ideally facilitated by someone from outside that community. It must emerge from communications of all community members: students, teachers, staff, parents, community members and administrators. Otherwise, a force that may hinder the clarity and accomplishment of the vision may be school leadership itself. Elmore (2000) contended:

Contrary to the myth of visionary leadership that pervades American culture, most leaders in all sectors of society are creatures of the organizations they lead. Nowhere is this more true than in public education, where principals and district superintendents are recruited almost exclusively from the ranks of practice. As in the military and the church, one does not get to lead in education without being well socialized to the norms, values, predispositions, and routines of the organization one is leading. (p. 2)

A shared vision when starting over to design a new school is critical because it distinguishes between what is real and what is ideal (Senge et al., 2000). A "charge" by an authority figure, such as a superintendent, should give the team permission think creatively about their vision of the ideal school for the students who are going to be educated there (and a school to which they would be proud to send their own children). A design team is then inspired to work together diligently to bridge the gap between perceived restrictions and the dream of an ideal school. Effective visionary leadership thus enables the development of clear pictures of a strategic plan, "where we are" and 
“where we want to go." Saphier and King (1985) contended there are norms that positively impact group leadership and school effectiveness. Part of the norms that should be developed at the outset would be for the team to think without restrictions, but not unrealistically, as to budget, facilities, educational programs, and other building blocks. Since the team is composed of internal and external stakeholders, it would reflect the internal and external school communities, and consider some constraints, but not restraints. Barth (1990) noted components of a healthy school culture. A healthy school culture wherein the daily interactions between people at the school reflect and support the vision for the new school is what the design team is trying to achieve.

Does the vision for the new school need to be top-down or bottom-up? Neither. As long as the vision is one all team members can accept, authorship is irrelevant (Fritz, 1996). The new principal, or an outside independent facilitator working with the superintendent and principal, will guide the team through an evolutionary process that continuously reflects, acts, and evaluates. Teachers, especially, have to be players on the team with the understanding it may take them considerably longer to adjust to the new vision, and that they will need professional development to incorporate into their thinking what the new vision means in terms of their classrooms. If, for example, the vision for the new alternative high school calls for extensive community partnerships, the new classrooms could embrace the use of community members as guest lecturers. The principal must often highlight and discuss the agreed upon vision, no matter what circumstances get in its way. Decision-making must be consistent with the new vision. Creating a shared vision is not a panacea, a quick fix, or an easy answer (Senge et al., 
2000), but it is a critical first step in designing an innovative alternative high school. Without a vision achieving a dream is impossible.

\section{Historical Leadership}

A historical perspective of leadership in general and the historical underpinnings of shared leadership in particular (Gardner, 1995; Pearce \& Conger, 2003) may be employed to drive a school design team to agree to start over when designing an innovative alternative to traditional high schools. Though it may seem odd to use historical leadership to lead a team to start over to design a new school, it may be useful to stimulate team members' imaginations by suggesting that American education has renewed itself time and time again. Team members may need to be given a sense that change and innovation are not only acceptable as traditions, but that they are essential. In other words, this foundation may help a team agree that it is acceptable to start over, and to use American ingenuity to create something new and innovative. This realization may help team members to come up with new ideas based on the historical purposes of public school, and to answer questions as to who should be educated, who should teach, and what the educated should learn. These questions have permeated public school designs since the beginning of American history (Tyack, 1974; Tyack \& Cuban, 1995). A leader

facilitating design team may do well to review the various kinds of schooling throughout the history of American education to take into consideration team members' willingness to establish a new form of schooling and to make a new beginning.

Early American educational philosophy leaders include the evangelist Horace Mann, who in 1837 declared, "A nation cannot remain ignorant and free" (Tyack \& 
Hansot, 1982, p. 16). He used this tactic to argue for universal public education, a school common to all people, open to all, and supported by taxes. The common school quickly replaced the pre-1830s laissez faire model of education, wherein predominately upperclass males were educated. By the middle of the nineteenth century the common school became the dominant and uniform model of education in America. The model midnineteenth century school existed in the small, rural one-room schoolhouse with a small number of pupils. This movement came to be considered by proponents as the best system for educating all Americans, and the only system of schooling with a monopoly on public financing. The one-room schoolhouse may be thought of or remembered nostalgically by some Americans to this day, perhaps because it featured some elements of effective schooling such as small size and peer tutoring. The one-room schoolhouse also featured a teaching corps composed of primarily young females who were often barely older or better educated than the students themselves.

As America became more urban and industrialized at the beginning of the Twentieth Century, educational leaders sought to redesign schools by using a business model on top of the foundation of common schools. These new leaders, called “administrative progressives” (Tyack \& Hansot, 1982, p. 106), had a passion for the efficiency of factories and saw schooling as full of problems that could be solved by shifting decision-making up to trained superintendents and school boards of "successful men" (p. 107). These men were worried about immigrants invading America, but believed they could engineer any human being into becoming an efficient worker (Taylor, 1911). This scientific management model of schooling is evident in traditional 
school systems today that are composed of school districts with large central offices and isolated high schools. Scientific educational research exploded in an effort to inform school development by defining the work of teachers and to determine the one best curriculum. Conformity, especially among teachers, was considered to be an innovation during this time, keeping order in the school and in classrooms while trying to teaching students how to meet new academic test standards was a goal which shaped the design of progressive schools (Cremin, 1961; Cubberley, 1916; Ravitch, 1974; Tyack \& Cuban, 1995).

None of the leading critics of progressive administration during this era was more influential than John Dewey. Dewey believed democracy could not be divorced from education in a truly democratic society (Dewey, 1916). Nothing was more antithetical to a democratic education than top-down management. Dewey sought schooling congruent with a cooperative society and thought administrative progressive were covertly embedding conservative values into their version of educational science. Regarding school design, Dewey (as cited in Tyack \& Hansot, 1982) warned in 1902 "it is easy to fall into the habit of regarding the mechanics of school organization and administration as something comparatively external and indifferent to educational ideals" (p. 202). Great disparity in the education of white and black Americans exposed the weaknesses in who made progress under the regime of administrative progressives (Tyack \& Cuban, 1995). Administrative progressivism dominated American education until the social unrest of the Civil Rights Movement and counterculture movement of the 1960s caused educational philosophers, such as Goodman (1960), to repeat Dewey's call for idealism 
in education. Alternatives education, with idealistic and innovative leadership, arose and reinvested in Dewey's principles.

The leader/facilitator of an alternative high school design team may assist the team members to consider historical perspectives and reasons to start over by asking members to describe the pros and cons, the good and the bad, of their own school experiences. This could take the form of a "go-round" protocol where members are asked to describe one thing they liked about the way they were educated in high school and one thing they disliked. From these historical perspectives, a consensus of what worked and what did not work can be defined around the concept of what is the ideal school. Since, presumably, a team would include older community members who remember ways of the past, to contemporary school leaders, to student voices relating the experience of high school as it is today. A diverse view of school histories should convince a team to start over by being open to new, diverse, and visionary, views as to what an alternative high school, and an ideal school, can be.

Winston Churchill once said, "The further backward you look, the further forward you can see" (Unsourced). Although any prognosis about the needs of students during the remainder of the $21^{\text {st }}$ century may be speculative, predictions may be generalized regarding the influence of teachers and school administrators based on perceived generational characteristics. As the Millennial generation, born approximately between 1982 and 2002, continue to become teachers and to lead schools, the digital technology they grew up with and their preference for working in groups will also become a greater part of schooling (Coomes \& DeBard, 2004). Lancaster and Stillman 
(2002) found that Millennials seem to value authority, especially when compared to Generation $\mathrm{X}$, the generation that preceded them. Using digital technology, maintaining group effort, and valuing authority seem to fit with some of the principles discussed in this dissertation, in that technology may provide the element of comprehensive curriculum, group effort can lead to better designed and innovative high schools that are different from the traditional high schools of the past, and authority may include regional accreditation standards that can be used as a framework for school design.

\section{Accreditation Standards: A Framework for Design}

The third topic of this literature review is accreditation standards, and how they may be used as part of a framework for designing innovative alternatives to traditional high schools. Most school leaders are familiar with regional accreditation organizations and the standards by which most schools become accredited. This familiarity is useful when alternative school designers seek a framework from which to hang their designs. In my experience, all sorts of questions will arise during the design process, especially at its outset. Who is going to lead the school? What financial and resources are available? Where will the new school be located? Why are we doing this? How are we going to get it all done? Without a framework within a step-by-step process, even if a design team is willing to start over, little forward progress will be made because the team will not know where to start or where they are going. An obvious framework with a place to start is readily available to through regional accreditation standards which are used nationally and internationally. Accreditation standards that are used as process steps also effective place the steps in an effective and progressive sequence. 


\section{Regional Accreditation Standards}

Before presenting and discussing accreditation standards, I would like to review

the history and the current status of regional accreditation standards; how schools become regionally accredited; and the value of regional accreditation.

School accreditation is recognition from a regional association that a school is of high-quality and meets certain standards of improvement based on effective schools research (Lezotte, 1989). Regional accreditation comes through membership in one of six regional, nationally recognized associations that accredit schools in all 50 states and in many countries. Regional accreditation is not new. The Northwest Accreditation Commission (NWAC, 2010) was founded in 1917. Currently, three of the six regional accreditation associations, the North Central Association Commission on Accreditation and School Improvement, NWAC, and the Southern Association of Colleges and Schools Council on Accreditation and School Improvement have joined with and become divisions of an international educational organization known as AdvancED (n.d.b). The three regional accrediting agencies of AdvancED (n.d.a) accredit 30,000 schools in over 70 countries serving 16 million students. The remaining three of six accrediting associations, not affiliated with AdvancED, are: Middle States Association of Colleges and Schools (MSACS), New England Association of Schools and Colleges (NEASC), and Western Association of Schools and Colleges (WASC). According to the director of AdvancED Oregon, all regional associations are governed by officers selected from regional member schools and school districts (R. Darst, personal communication, May 10, 2012). 
Schools become accredited through a step process requiring schools to renew themselves on a 5- or 6-year cycle by conducting a self-study, hosting a peer evaluation team to review and validate the self-study, completing a school improvement plan, and engaging in continual school improvement. The process usually includes the completion of an annual report confirming compliance with a set of standards. Regional accreditation involves a quality assurance review (QAR) of comprehensive school improvement and plans to increase student achievement. Accreditation leads to self-improvement and positive change through periodic review requiring the commitment of the whole school. Parents and other community stakeholders can be assured of the professionalism and quality of an accredited school. Regional accreditation processes also focus on meeting the needs of the individual learner. School leaders can draw on a network of professionals to help improve the education provided students in an accredited school (NWAC, 2010; R. Darst, personal communication, May 10, 2012). Member schools of regional accreditation associations nationally are approximately equal numbers of elementary and high schools. High schools become accredited because they issue credits for completion of courses and diplomas for completion of programs of study, and they are more assured of the efficacy of credits taken in transfer from other accredited schools. In fact, an accredited high school may jeopardize its own accreditation if it refuses to accept credit from another accredited high school (R. Darst, personal communication, May 10, 2012). Though historically developed for evaluation of traditional high schools, it is my belief that regional accreditation standards can be useful as a framework for the design of alternative high schools. It is also assumed that regional accreditation standards can be 
used as a framework to create any type of school, including alternative high schools. Accreditation standards are readily available from all six regional accrediting bodies in the U.S. Accreditation standards are comprehensive and have been adapted to accredit all types of education providers around the world (AdvancED, n.d.c, p. 3).

Schools designated "Special Purpose" by regional accreditation associations include alternative schools designed for students at-risk of school failure (NWAC, 2011). Traditional high schools, though perhaps successful with a majority of students who manage to graduate from them, have been called comprehensive but were never designed to meet the academic or certainly the social/emotional needs of all students (Ravitch, 2010; Wilson \& Daviss, 1994). However traditional in concept, these standards can be adapted to serve as the building blocks any school design team needs. The standards have been developed over a long period of the history of education and continue to be updated and refined. A set of accreditation standards includes standards for school vision and mission, educational program, supports for learning, and continuous improvement (NWAC, 2011). Standards are based on fundamental beliefs and expectations for learning. School policies and operations grow up around these standards and the standards align with state laws.

Without a framework to build upon, the development of an alternative high school within a school district may be a trial-and-error proposition at best. Simply getting the support of a bare majority of school board members, hiring a principal with perhaps some experience, and assigning teachers to the new school may, and more likely may not, be successful. A better way, to ensure buy-in from community members is to use a process 
composed of standards. Using familiar standards may also increase the chances for board approval of a new high school. Standards give the team something familiar to work with also and promote good community relations by standardizing the school in advance of its implementation. Such a process will lead to the development of a new school committed to program evaluation and positive outcomes for higher student achievement for years to come.

As an example of regional accreditation standards, the eight standards of the NWAC (2011) with associated documentation and each standard's written “Guiding Principles," are presented below and followed by a brief discussion as to why each standard is useful as part of a conceptual framework for designing an alternative high school.

Standard 1: Mission, Beliefs, and Expectations for student learning. Guiding Principle: The school's mission statement describes the essence of what the school as a community of learners is seeking to achieve. The expectations for student learning are based on and drawn from the school's mission statement. These expectations are the fundamental goals by which the school continually assesses the effectiveness of the teaching and learning process. Every component of the school community must focus on enabling all students to achieve the school's expectations for student learning.

The idea of vision is a central tenet of transformation leadership (Bass, 1985; Leithwood \& Jantzi, 2000), an approach to leadership in which an organizational leader, in this instance a leader of schools, influences constituencies (Hallinger \& Heck, 1996; 
2002). The mission for an alternative high school may be derived from a design team's shared vision (Senge et al., 2002) of expectations for the new school based on the team's beliefs about its community, teaching and learning, and student success. Some team members may mistrust the charismatic nature of achieving a shared vision, such as when a team leader asks the team to trust in a consensus driven protocol to create the vision, but having a well-defined vision and mission is the essential first step in new school design.

Standard 2: Curriculum for mission fulfillment.

Guiding Principle: The curriculum including coursework, co-curricular activities, and other school-approved educational experiences, is the school's formal plan to fulfill its mission and expectations for student learning. The curriculum links the school's beliefs, its expectations for student learning, and its instructional practices. The strength of that link is dependent upon the commitment and involvement of the professional staff to a comprehensive, ongoing review of the curriculum.

The educational program of curriculum, instruction and assessment is the heart and soul of any innovative alternative high school design. One of the elements of effective alternative schools is a relevant and focused curriculum (Barr \& Parrett, 1997; Raywid, 1994). To successfully design new curriculum on an on-going basis, teachers and alternative school leaders must be independent initiators and risk takers and willing to examine their beliefs about what a high school curriculum can be (Barth, 1991). At the same time, and as with any school, an alternative high school must always strive for a 
coherent curriculum using language literacy as its basis, meet common core standards, and measure results for growth in student learning over time (Boyer, 1995). Marzano (2003) ranked a "guaranteed and viable curriculum" (p. 22), including opportunities to learn and time to learn, as having the most impact on student achievement at the school level. The flexibility of learning opportunities and the use of time inherent in successful alternative schools lends itself to successful alternative high school design. Similarly, professional learning communities focus on learning rather than teaching, working collaboratively, and being accountable for results (DuFour, 2004). Intentional opportunities for teachers to learn from fellow teachers, especially about curriculum and instruction that works, must also be a large part of the design of alternative high schools.

Standard 3: Instruction for student learning.

Guiding Principle: The quality of instruction in a school is the single most important factor affecting the quality of student learning, the achievement of expectations for student learning, the delivery of the curriculum, and the assessment of student progress. Instructional practices must be grounded in the school's mission, beliefs, and expectations for student learning, supported by research in best practice, and refined and improved based on identified student needs. Teachers are expected to be reflective about their instructional strategies and to collaborate with their colleagues about instruction and student learning. At the most basic level, instruction in an alternative high school is designed using the same process for instructional design as does any other school: Analyze the goals of instruction, strategize how to achieve the goals, and evaluate when the goals have been 
achieved (Mager, 1984; Smith \& Ragan, 1999). What is different in an alternative high school, compared to traditional high school, is the recognition that individuals learn at different rates, and a highly individualized educational program requires a greater commitment to creativity and flexibility on the part of alternative high school teachers (Barr \& Parrett, 1997; Raywid, 1994). This commitment requires consistent and frequent review of curriculum and student assessment data. Such an effort is beneficial to alternative school students, as Morrison, Ross, Kemp, and Kalman (2009) pointed out "much evidence supports the belief that optimum learning takes place when a student works at his or her own pace, is actively involved in performing specific learning tasks, and experiences success in learning" (p. 185). Morrison et al. also cited evidence that learners in individualized, self-paced, and active learning educational programs work harder and learn and retain more than do students in conventional classes. The strengths and limitations of any effective instructional design must be considered when designing alternative high schools.

Standard 4: Assessment for student learning.

Guiding Principle: Assessment is an integral part of the teaching and learning process. Its purpose is to inform students regarding their learning progress and teachers regarding ways to adjust the curriculum and instruction to respond effectively to the learning needs of students. Further, it communicates to the school community the progress of students in achieving the school's expectations for student learning as well as course-specific learning goals. Assessment results must be continually analyzed to improve curriculum and instruction. 
Traditional high schools have focused on testing for retention of knowledge and its application in highly limited contexts, especially with the rise of state-mandated standardized tests of literacy and numeracy (Reeves \& Okey, 1996; Wiggins, 1998). Formative classroom assessments for learning, that occur continuously during the teaching and learning process rather than after it, wherein students are involved in the assessment process, can improve learning and raise test scores (Black, Harrison, Lee, Marshall, \& William, 2003; Stiggins, 2004; Wiggins, 1995). Alternative high schools have sought to evaluate the effectiveness of diverse instructional approaches and curricula through authentic assessments of student achievement through methods such as portfolios, competencies, community service, and narrative appraisals that go beyond spelling quizzes and certainly go beyond standardized tests (Barr \& Parrett, 1995, 1997; Wasley et al., 2000). Design teams of alternative high schools should include teachers who are practicing, or have a willingness to change to practice formative classroom and authentic assessments. The design process should encourage and enable the formation of the educational program, curriculum, instruction, and assessment, to never solely be about students "passing" standardized tests.

Standard 5: Leadership and Organization for teaching and learning (Blase \& Blase, 2000; Sergiovanni, 1992, 2001).

Guiding Principle: The way that a school organizes learning for students, fosters leadership, and engages its members has a profound effect on teaching and learning. The professional culture of the school must be characterized by 
thoughtful, reflective, and constructive discourse about decision-making and practices that support student learning and well-being.

One of the elements of effective alternative schools is shared governance and local autonomy (Barr \& Parrett, 1997). While this element implies democratic participation and local control, due to the complexity in contemporary educational contexts, an individual leader or small core group of leaders must emerge to set directions, develop people, and develop the organization (Leithwood, 2003). At the same time, leadership practice must have a moral dimension based on purpose or mission, with the understanding that, true to the values of alternative education, the organization is a community and needs to be understood by leaders as community (Sergiovanni, 1992, 1994).

Narvaez (1994) pointed out that communities of learners want the autonomy to use resources locally to define an agenda for staff and students that leads students to become educated persons. Blase and Blase (2000) studied the perspectives of more than 800 teachers from which emerged two themes of effective instructional leadership: teachers wanted a leader who talked with them to promote reflection and to promote professional growth. Leithwood (2003) also concluded that major findings from research showed leadership has significant effects on student learning, second only to the effects of quality curriculum and instruction. Designers of alternative high schools need to keep the importance of leadership in mind, and ideally include the intended leader or leaders of the new school in the design team. 
Standard 6: School Services for support of learning.

Guiding Principle: Student learning and well-being are dependent upon adequate and appropriate support programs and services. The school is responsible for providing an effective range of integrated resources to enhance and improve student learning and well-being and to support the school's mission and expectations.

Promoting a climate for learning by providing basic school support services also applies to an innovative alternative high school. Support services include activities such as: personal, career, and college counseling, health services, library services, Special Education support services, and access to family and community services (Boyer, 1995). Research has found the importance of library services, for example, and the impact of school library media specialists' leadership on student achievement (Lance, Rodney, \& Hamilton-Pennell, 2000), especially in the age of the internet. As another example, a 3-year study of nearly 4,000 high school students, who had access to school-based health care, found a substantial increase in visits for mental health and substance abuse concerns compare to those with only access to traditional sources of health care (Anglin, Naylor, \& Kaplan, 1996).

While support services may seem an afterthought in the design of an alternative high school, they present opportunities for innovation. For example, longitudinal studies by Epstein (1995) and Epstein et al. (2009) suggested student attendance can be improved through family and community involvement and shared supports. Student absenteeism is a concern of many schools across America and may be especially acute in alternative 
high schools, as chronic absenteeism is a precursor of dropping out of school (Rumberger, 1987). Community partnerships that work to reduce absenteeism may be worked into the design of an alternative, beginning with a shared vision and mission/purpose that may include the importance of regular school attendance to the local community.

Standard 7: Facilities and Finance for support of student learning.

Guiding Principle: The school plant (consisting of site, buildings, equipment, and services) is an important factor in the functioning of the educational program. The school plant serves as a vehicle for the implementation of the schools mission. The school plant should provide for a variety of instructional activities and programs and for the health and safety of all persons. The school plant should incorporate aesthetic features that contribute to a positive educational atmosphere while providing for needed flexibility. In addition to an appropriate facility, sufficient fiscal resources must be available, accounted for and effectively used in order for any school to accomplish its mission and expectations for student learning.

Studies have supported the view that student performance and outcomes are not systematically related to variations in school expenditures alone (Hanushek, 1989; Hanushek, Rivken, \& Taylor, 1996). Designers of alternative high schools will do well to heed the advice of Barr and Parrett (1997) and use existing school district funds (p. 83) and operate at no additional cost to the district once the school has started. Barr and Parrett wrote about the need for extra start-up funding, but offer no suggestions as to how 
to get start-up funding. In my experience agreements between a school district with other school districts and with city, county, and state agencies may be useful in getting start-up resources, including facilities.

Finding adequate, not to mention ideal, facilities to serve as a school plant may be problematic. That said, alternative schools have been established in office buildings, churches, community centers, and just about any place else (Henderson \& Raywid, 1994; Raywid, 1982). Innovative alternative high school designers may wish to start planning with an already existing facility in mind because it may represent the biggest obstacle to implementation and it helps design team members conceptualize what the new school will be like. Ideally, it is better to start with the learning needs of the students who will attend the school, and to look for a facility after that vision has been achieved, though in practicality facilities may be limited to whatever is available. In the case of limited availability of space, facilities must be adapted to the learning needs of the students who will attend the new alternative school. Also, it is important that the facility be one to which design team members would send their own children. Earthman (2002) cited numerous studies that showed the overall condition of school facilities has an important impact on student performance and teacher effectiveness. Earthman analyzed such factors as school and classroom temperatures, noise levels, overcrowding, and class size. This study reported that students attending buildings in better condition outperform students in substandard buildings, and that building conditions influence teacher effectiveness.

Standard 8: Continual School Improvement (Edmonds, 1982; Fernandez, 2011; O’Day, 2002). 
Guiding Principle: A quality school develops and maintains an externally validated process and plan for school improvement. Goals resulting from the evaluation process should include targeted levels of achievement and should be measureable.

Regional accreditation is a continual school improvement process. School improvement processes began to be developed in the late 1970s to study the characteristics of schools as important determinants of academic achievement (Edmonds, 1982). Researchers concluded effective schools share these characteristics (Brookover \& Lezotte, 1977; Rutter, Maughan, Mortimore, \& Ouston, 1979). Edmonds (1982) has the belief that the characteristics of effective schools revolve around leadership, instructional focus, climate, teacher expectations, and "measures of pupil achievement as the basis for program evaluation" (p. 4). The effective schools movement greatly influenced the development of accreditation standards and alternative schools and is reflected in the accreditation standards and the elements of effective alternative schools. School improvement plans (SIP) became integral to regional accreditation standards, though almost no studies examined the effectiveness of SIPs until Fernandez (2011) explored the relationship between the quality of SIPs and school performance. Fernandez found a consistent association between school planning and overall student performance.

Though it seems counterintuitive to create a school improvement plan for an alternative high school that has not been implemented, a final step in the school design process should be to begin to develop academic goals and accountability measures aligned with state and local expectations. These goals must be based on the vision and 
mission established for the new alternative school. All roads must lead back to the purpose of the school as envisioned by its designers. After the school is implemented the foundation for its school improvement plan will have been laid during the design process. This dissertation recommends using the standards of the NWAC as a conceptual framework for design alternative high schools. An overview of those standards, as they are used for evaluation of school improvement, is shown in Figure 2. The first set of standards (1-4) focus on teaching and learning, the core of the educational program based on school mission and expectations and incorporating instruction, curriculum, and assessment. Learning expectations are based on measurements of school wide and course specific goals tied to students' academic, civic, and social needs. Evidence in the form of a self-study using stakeholder surveys provides evidence of goal attainment. A second set of standards (5-7) are centered around supports for learning and focus on school leadership and organization, services, and facilities and finance. A second set of surveys of stakeholders supports the efficacy of the school meeting these standards. Lastly, a school improvement standard (8) is critical to the school providing a culture of continual improvement. Evidence of stakeholder involvement and support for the school's improvement plan is collected using self-study stakeholder surveys.

Research regarding the relationship of educational quality, student achievement, and regional accreditation standards in general appears to be limited to that conducted by accreditation associations themselves. Comparing regional accreditation standards to research on student achievement suggested any indirect approach to assessing institutional performance rests on a frail empirical basis (Troutt, 1981). Lopez (1999) 
Evidence Based School Evaluation: Teaching and Learning Standards (1-4)

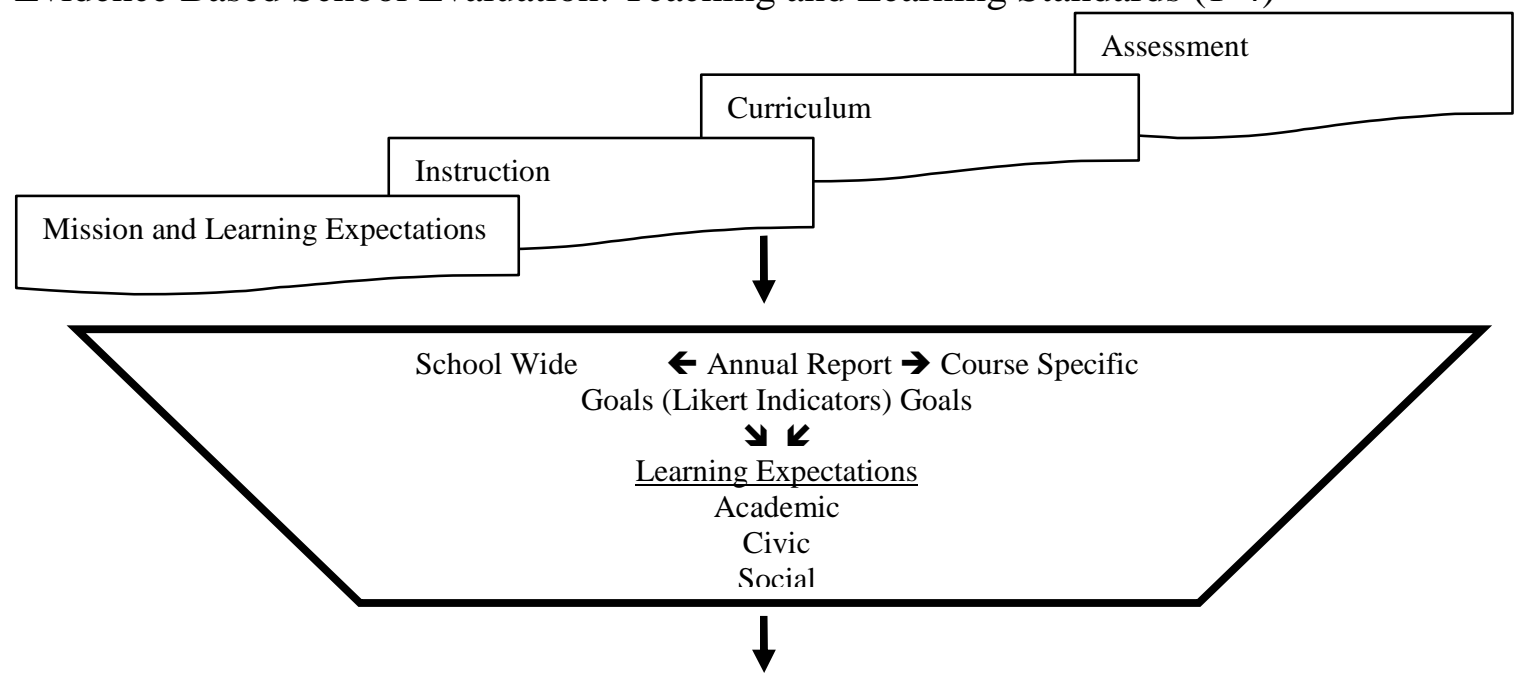

Survey Students, $\leftarrow$ Self Study $\rightarrow$ Survey Students,

Parents, Staff, (Likert Indicators) Parents, Staff,

and Administration and Administration

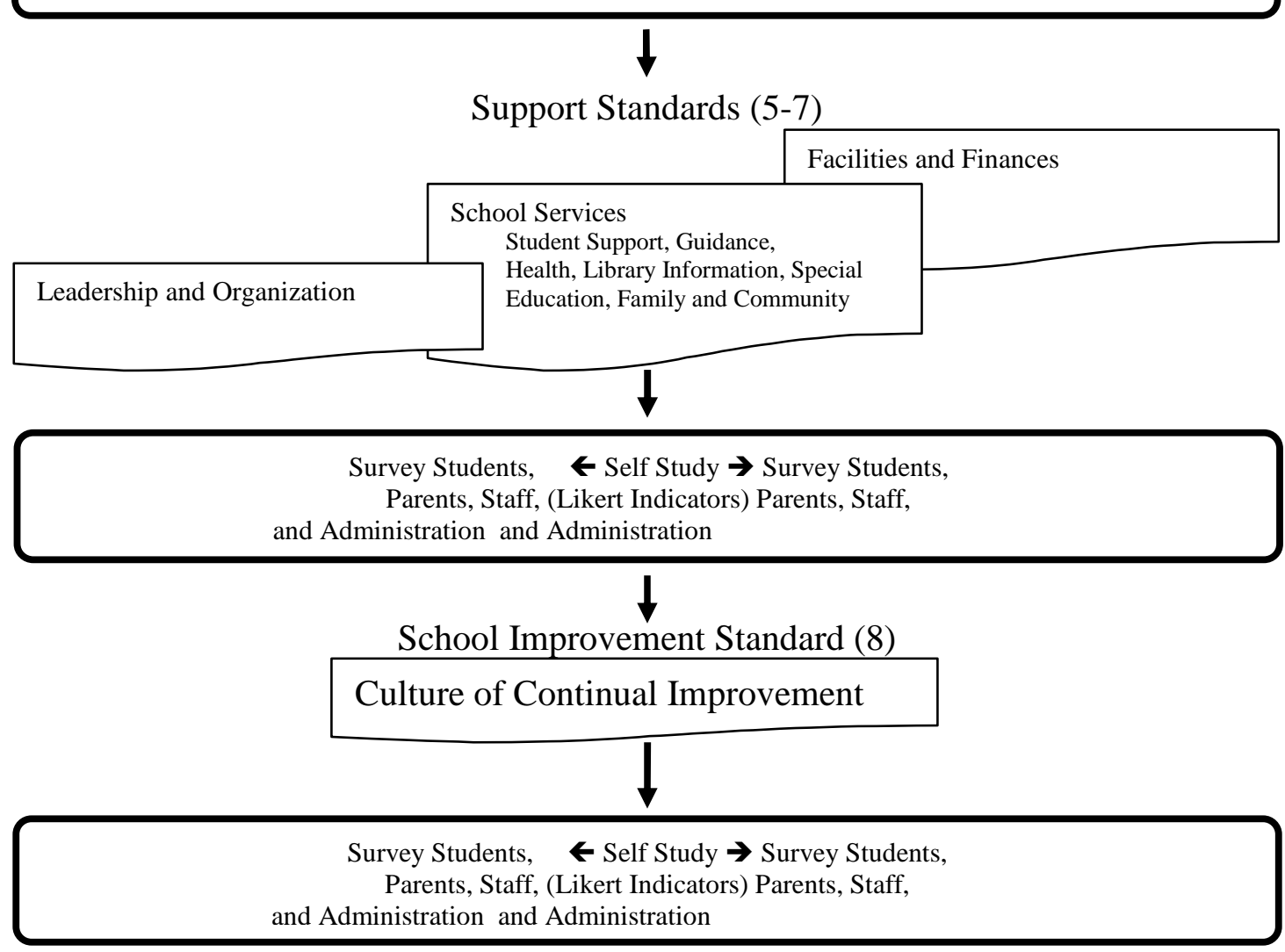

Figure 2. Evidence based school evaluation. NWAC (2011), used with permission. 
examined the reports of 100 evaluation teams and found a high level of consistency in team judgments related to strengths and weaknesses of general education program design and other institutional standards. Strong evidence-based research exists for the impact of leadership and school improvement planning, both critical standards of regional accreditation associations, on student achievement (Danielson, 2002; Marzano, Waters, \& McNulty, 2005). Regional association literature suggested "Accreditation provides general justification for public confidence in a member school" (NWAC, 2010, p. 1) and "A performance-based accreditation process that provides each institution with a more comprehensive analysis to drive continuous improvement" (AdvancED, n.d.a, p. 2). As stated previously in this section, the organization known as AdvancED has subsumed several regional associations. Perhaps AdvancED will bridge the gap in educational literature by undertaking or supporting efforts to study the efficacy of accreditation on school improvement and student achievement. Using accreditation standards as a conceptual framework to design alternative high schools may indirectly lead to research questions for further study.

The regional accreditation associations not affiliated with AdvancED include the MSACS, NEASC, and WASC. These three associations use standards similar to those of the NWAC (R. Darst, personal communication, May 10, 2012), but may use more or fewer standards to emphasize standards important to their regional commissions. The MSACS (2007, p. 7) utilizes 12 standards in two groups of six, called "Foundational Standards" and "Operational Standards" that appear to emphasize health and safety, student activities, and technology more than do current NWAC standards. The NEASC 
(2011) maintains seven standards that appear to place greater emphasis on the importance of having adequate school and community-based resources. WASC operates under categories of "School-wide Criteria" that are very similar to the teaching and learning, support, and school improvement standards of NWAC, with variations for each state (California and Hawaii) WASC (2012) serves.

As stated previously, AdvancED has recently subsumed three of the six regional accreditation associations. AdvancED has condensed the standards to five, modernized the language in them, and sought to eliminate redundancy among the standards. The AdvancED (n.d.a) standards are: (a) Purpose and Direction, (b) Governance and Leadership, (c) Teaching and Assessing for Learning, (d) Resources and Support Systems, and (e) Using Results for Continuous Improvement. As an example of new language, AdvancED (n.d.a) uses "purpose and direction" rather than "vision and mission" used by older organizations. Redundancies in the standards, such as technology under both the current instruction and facilities standards of the NWAC, have also been reduced by consolidation of standards by AdvancED.

This section argues for the use of regional accreditation standards as a conceptual framework for the design of alternative high schools. While I agree a greater efficiency and modernization of standards may be necessary, as advocated by AdvancED (n.d.a), for the purpose of school design, using a set of 10 standards or steps is appropriate in that greater attention to detail can be achieved. I believe it is important to differentiate between vision and mission (or purpose and direction) as mission is a distillation of the vision that drives the vision and makes the vision clear to stakeholders (Gabriel \& 
Farmer, 2009). Thus, a "10 step" design process that includes: Vision, mission, curriculum, instruction, assessment, leadership, organization, supports, facilities, and finance can be utilized. Plans for the future school's improvement are developed as goals for future program evaluation.

\section{Program Evaluation: Begin With the End in Mind}

The fourth topic of this literature review is program evaluation and the need to begin with the end or outcome in mind as an innovative alternative to traditional high schools is designed. Alternative high schools will be different from traditional high school, and eventually the state and school district in which it is located should want to evaluate it to determine if it is an effective model. The design of a new alternative high school will also be more successful if the designers consider from the beginning of the design process how the new school will be evaluated in its first and subsequent years of operation. Designers need to know what program evaluation is generally, and how it specifically applies or may apply to alternative high schools. Beginning with the end (an innovative school effective over time) in mind will stave off future concerns and problems when an evaluation is required.

The term "program evaluation" generally, and as it is used in education, can be defined in a multitude of ways. Worthen, Sanders, and Fitzpatrick, (1997) preferred the definition offered by Scriven, Tyler, and Gagne (1967) who defined evaluation as judging the worth or merit of something. Evaluation theorists distinguish two basic types of evaluation, formative and summative. Formative evaluation is conducted to provide information useful in improving a program, and summative evaluation is conducted to 
make judgments in relation to set criteria (Worthen et al., 1997). Program evaluation can also be formal, based on thorough and structured objectives, or informal and based on impressionistic and subjective perceptions (Worthen et al., 1997). According to Rossi, Lipsey, and Freeman (2004), different kinds of assessment may be conducted as part of a program's evaluation during different stages of a program's development. These include determining a program's cost, impact, implementation, design, and need.

Just as evaluators cannot agree on a common definition of evaluation, evaluators also do not agree as to its basic purposes, uses, and activities. Worthen et al. (1997) suggested the basic purpose or goal of evaluation "is to render judgments about the value of whatever is being evaluated" (p. 8). Scriven $(1991,2002)$ consistently proposed that the evaluation of any object, such as a school, is undertaken to identify and apply defensible criteria to determine its worth, merit, or quality. Shadish (1994) and Fetterman (1994) constructed the definition of evaluation and its purposes and uses more broadly and include the activities evaluators do. Shadish thought the definition of evaluation should include more than valuing and extend to activities of evaluators, "Such as seeing that the evaluation is used and providing recommendations aimed at program improvement" (Worthen et al., 1997, p. 9).

Considering uses of program evaluation at the beginning of the process for a team to design a new school may seem counterintuitive as there is no program to improve upon when the design process begins. Local leaders will be creatively empowered, however, by considering an inventory of school policy and practice, how the school will comply with federal and state laws, and the quality of its educational program. Within an 
evaluation context, the school design process must encourage creative thinking about what a high school can be and that there is no one best school or school system. A good program evaluation will also justify the expenditure of resources needed to enact a new school. Judging the quality of an alternative high school is the purpose of program evaluation in this dissertation as it seeks to develop a process to design such schools. Evaluation of educational programs is important as society faces modern challenges, such as the current high school dropout rate, and the need for innovative alternative high schools.

\section{Alternative High School Evaluation}

Alternative schools can be designed to serve vulnerable students who are at-risk of failing to graduate from high school, but these schools are notoriously difficult to evaluate (Barr \& Parrett, 1997; Raywid, 1994, 2001; Reimer \& Cash, 2003). Primarily, a variety of definitions as to what alternative schools are exist, and these various definitions make it difficult to determine school quality by comparison. Due to varying missions and organization of alternative schools, effectiveness is difficult to measure, and mission achievement of one alternative school may greatly differ from another alternative school (Reimer \& Cash, 2003). In the early years of alternative education, there was a strong anti-evaluation climate as alternative school leaders believed saving students from dangerous life circumstances was sufficient reason to exist (Kellmayer, 1995). More recently, leaders realize that while helping students overcome social problems is important, educating them is of more importance if they are to succeed in society. 
Because of these challenges the need for program evaluation of alternative schools has never been greater. For students at-risk of high school failure, alternative schools remain the frontline in dropout prevention. According to a director of research and evaluation for Education Northwest, when alternative schools fail because they are inadequately or inappropriately evaluated, youth fail with them $(C$. Wang, personal communication). A sizable percentage of those dropout students will wind up unemployed or underemployed throughout much of their lives. A study by a group of economists concluded that if the number of dropouts in the present cohort of 20-year-olds was cut in half, the nation would reap $\$ 45$ billion through extra tax revenues and reduced costs of public health, crime and justice, and welfare payments (H. M. Levin \& Belfield, 2007).

The difficulty of knowing what to measure and how to measure it has made it hard for school leaders to create accountability for alternative schools. Many school districts therefore seek to evaluate alternative schools by relying on informal and anecdotal information rather than data to portray their merits (Montecel, 1999). Other methods might include a summative checklist of NCLB, state, and local school district legal and policy compliance factors that are virtually useless for school improvement. State governments also impose evaluation criteria on alternative schools that compare them with traditional high schools. With a heavy reliance on standardized, literacy and numeracy test scores all schools are given a state "report card." These report cards are often misapplied to alternative high schools with missions to serve students who have dropped out and may be years behind grade level. Experienced educators agree that there 
is clearly more to schooling and measuring the success of a school's students than test scores, attendance, and graduation rates. If such simplistic measures are inadequate to fully evaluate traditional schools, as many educators contend, such methods are especially inadequate in determining the quality of alternative schools (Hinds, 2012).

Research suggests a growth model ought to be used to account for differences in student achievement from year to year. Such comparisons in student academic growth make a logical argument but lack practical application when states account for student mobility between schools and districts (Rumberger, 2002). This is especially true in alternative schools where the average length of stay could be as short as a few weeks and as long as a few years. Many alternative schools that currently receive report cards do not have an adequate data sample to result in a grade, and those that have a population large enough to be measured are sometimes identified as some of the worst schools in a state (Oregon Department of Education, 2010). Traditional forms of school accountability and comparison are not adequate for alternative schools because they do not account for differences among the student population at a given time (Hinds, 2012). Local alternative school design teams will need to understand state compliance expectations for program evaluation, such as school report cards, and be prepared to go beyond their criteria and into areas such as qualitative measures of students' affective development and personal (non-cognitive skill) growth over time.

Constructing an evaluation that goes beyond state test must begin with imagining quality outcomes and what those outcomes will be based right from the start of the design process. Barr and Parrett (1997) emphasized "How an alternative school is started may 
well be the most critical aspect of the emerging life and chance for success a new program experiences" (p. 107). Reimer and Cash (2003) concurred "Failing to spend the time, energy, and money to properly evaluate is to doom an alternative school to mediocrity or failure" (p. 35). Fifty years of evidence exist in what works in alternative schools and much of that research has not yet been applied in processes in evaluating alternative schools (Barr \& Parrett, 2001). What seems to be lacking is an adequate and reliable evaluation instrument to document the effectiveness of alternative schools (Reimer \& Cash, 2003).

States such as Florida, Kentucky, Iowa, and Tennessee have evaluation models for dropout prevention programs and alternative schools (Swarts, 2002). Drew Hinds is working at the Oregon Department of Education to research and develop an alternative school evaluation tool that goes beyond using traditional school measures. We are also collaborating in the R\&D of a design and evaluation process for Oregon alternative schools. In addition to state efforts, a small number of well-qualified researchers in alternative education have sought to develop evaluation instruments. In Iowa, Morley (2002) developed an early instrument to establish and evaluate quality alternative schools' effectiveness. Morley's “Framework for Learning Alternative Environments" includes an "Inventory of Policies and Practices Related to Student Failure and Dropping Out" and a "Checklist of Quality Indicators for Alternative Learning Environments." Gregory (2001) reviewed alternative school evaluations, through issues commonly addressed by alternative schools, and found them to be a way to improve the often weak political positions and misunderstandings about alternative schools among school district 
leaders. Scriven $(1991,2005)$ developed a key evaluation checklist of 15 points that can be used to evaluate alternative schools. The National Dropout Prevention Center/Network $(\mathrm{NDPC} / \mathrm{N})$ at Clemson University has combined the elements of effective alternative schools and accreditation standards, describe previously in this dissertation, into their own 10 essential elements: Accountability measures, administrative structure and policies, curriculum and instruction, faculty and staff, facilities and grounds, school leadership, student support services, learning community, program funding, and school climate (Reimer \& Cash, 2003). The NDPC model goes on to describe two levels of analysis, a basic or self-evaluation analysis, and a more in-depth analysis that uses a third-party evaluator in a process NDPC calls "Program Assessment and Review (PAR)" (Reimer \& Cash, 2003, p. 31).

What these evaluation efforts have in common is that educators in alternative schools work very hard every day with their students and deserve an adequate means by which to tell their stories of success and failure. It is best to make what that story will have to tell an integral part of the design process. Failure to tell an adequate or whole story of the new alternative school's successes and areas for improvement may enable the public to view the new alternative school as second rate. Given the importance of alternative schools serving our most vulnerable student population and the unknown quality of the majority of these programs, a thoughtful and effective evaluation of these programs will be important for the design and development of alternative high schools. Some features of program evaluation of alternative high schools that go beyond 
politicized test scores and legal compliance and begin to determine quality in a contextualized process are described in the next section.

\section{Evaluation Features and Questions}

The following section of the paper presents some research based features and possible questions for the effective evaluation of quality alternative education programs (C. Wang, personal communication). Key elements of effective alternative education schools are backed by 25 years of research (Barr \& Parrett, 1997; Raywid, 1991, 2002). Aligned with accreditation standards and the elements of innovative alternative schools presented previously in this dissertation, an effective design and evaluation of alternative schools needs to examine the following components of the alternative high school and consider potential evaluation questions for any new alternative high school. These features and evaluation questions are in the areas of: (a) context, (b) vision and mission, (c) governance and operation, (d) educational program of curriculum and instruction, and

(e) community involvement. The design process for alternative high schools should include a design team's consideration of the features and potential evaluation questions.

Context. Alternative education programs vary in terms of students served and approaches used in serving these students (Fizzell \& Raywid, 1997; Raywid, 2001). Even though legal definitions of alternative schools exist in many states, the term can mean different things to different people. The term has also been attached to magnet and charter schools (Molnar, 1996). Adding to the confusion is that many alternative schools do not attach "alternative" to their school names, for fear of a negative connotation often 
associated with the term. To some, dependent on local control of the school system, "alternative school" is less threatening than "charter school."

Examining the context an alternative education program is the first step toward a systemic, rather than a fragmented, evaluation. Non-systemic evaluation tends to focus on isolated outcomes such as standardized test scores without looking into the intricacies of relationships within the system. The results of non-systemic evaluation often do not reflect what is really happening and is of little use for program improvement. To enter into a systemic evaluation of an alternative education program aligned with school design, potential evaluation questions such as those that follow should be formulated.

- Under what circumstance is the alternative school being established?

- What are the characteristics of the student population the school intends to serve?

- How are students going to be recruited for the school and how are teachers going to be assigned to teach in it?

- How will this school be viewed in relationship to the school district and the community in which it is located?

- Who is going to be responsible for running the school? (Wang \& Edwards, 2009)

Vision and mission. The evaluation should examine the extent to which the program mission or purpose fits the context of the alternative school, and particularly the characteristics of the student population the school intends to serve. An effective alternative school, as does any educational institution, needs to have a clear vision and mission, a sense of community and commitment, and shared values (Hallinger \& Heck, 2002; Senge et al., 2000). Unlike traditional schools that have to cater to everyone, an alternative school could have a distinctive mission for serving a targeted student 
population with targeted needs that are difficult to meet in a traditional school setting. When developing the new school's vision and mission, potential evaluation questions such as these should be asked:

- Is the school mission relevant to students in the school?

- Does its vision and mission distinguish this school from other schools?

- Is the mission achievable given the context and the community of the school?

- Will staff members, students, parents, and other stakeholders be able to verbalize the school's vision and mission goals?

- Does the program have a list of objectives relating to the school mission and goals? Are the objectives measurable? (Wang \& Edwards, 2009)

Leadership and organization. An effective alternative education schools needs to have some degree of autonomy, which is one of the elements of effective alternative schools (Barr \& Parrett, 1997). It needs to have a separate administrative unit that can make decisions independently and quickly to meet students' needs (Chalker, 1996). When students become reengaged in an alternative education school, the school is usually characterized by a culture of concern and caring (Raywid, 2001). In this school culture, students feel they are treated with respect and given freedom to learn while being held accountable for making progress toward their learning goals (Hefner-Packer, 1991). There is a strong sense of "family" among all participants: students, teachers, counselors, support staff, and administrators (Barr \& Parrett, 2001). Potential evaluation questions that need to be conceived in this area could include:

- To what extent will the school be independent in making decisions relating to student needs?

- What will the school do to make students feel they belong? 
- To what extent will students and teachers have a real voice in the day-to-day operation of the school?

- To what extent will community members involved in the school?

- Will class size be small enough to allow students individualized learning and personal attention?

- To what extent will technology be integrated into learning, allowing students access to more learning resources and to learn at their own pace?

- Will disciplinary rules be fair and equitably enforced?

- Will the attendance policy be flexible and designed to meet student needs (Wang \& Edwards, 2009)

Curriculum and instruction. Successful alternative education programs are no different from traditional schools in trying to achieve academic goals. For example, Oregon state law provides that, "The (alternative school) program ensures that students receive adequate instruction in the educational standards adopted by the State Board of Education for the grade level(s) the program serve[s] for students to meet state and local benchmark standards" (Oregon Revised Statute 339.250). What makes alternative schools different from traditional schools are innovative approaches used to attaining these goals (Raywid, 1994; Schargel \& Smink, 2001). An effective alternative education curriculum tends to be student centered and relevant to students' academic and personal concerns, with plenty of contextualized learning opportunities or hands-on experiences (Barr \& Parrett, 1997). Some potential evaluation questions relating to alternative school curriculum and instruction include:

- Will the alternative school have a curriculum or a curriculum framework that is aligned with state and district academic standards?

- What will be innovative about the program curriculum that allows it to meet the needs of individual students (e.g., integration of academic and career 
education, differentiated instruction, contextual learning/hands-on experiences)?

- To what extent will students be able earn their credits based upon proficiency instead of "seat time"?

- How will students access curriculum to make progress toward their academic goals?

- How will individual instructional assistance be provided for students when they need it? (Wang \& Edwards, 2009)

Community involvement. No evaluation of an alternative school is complete without collecting community involvement data from both its internal (students, parents, and staff members) and external school communities (individuals and civic organizations). This feedback is typically collected via surveys or focus groups. It is important to design questions with key elements of a successful alternative education schools (such as individualized instruction, relevant curriculum, and a supporting, caring learning environment) as a framework. The following are potential evaluation questions that can be used to obtain feedback from members of an alternative school's communities:

- What is unique about the alternative education school in comparison with traditional schools?

- How does individualized instruction take place in the school?

- How do students get connected to the school?

- How does the school make learning relevant and meaningful for students?

- What strategies does the school use to deal with students' behavioral issues?

- How are parents, community members, and social service agencies involved in the school? (Wang \& Edwards, 2009) 


\section{Outcomes}

The common sense dictum of Covey (1989), that as does an effective person, an effective school has to begin with the end in mind. Eisner (1985) also asserted "One should know where one is headed before embarking on a trip" (p. 35). The major feature of an evaluation has to be the student outcomes and the measures of those outcomes which are the ends a design team must bear in mind throughout the design process. The team must ask itself from the beginning: What will the new school be like when it grows up? What are the outcomes that will be achieved, and how will these outcomes be manifested by students, teachers, and the community?

Leaders who design innovative alternatives to traditional high schools know every school should be held accountable for its student outcomes and alternative schools are no exception. Alternative schools are included in our current education environment of accountability, where student outcomes are often disproportionately focused on basic, narrowly defined academic skills. Success is often measured by how many students meet or exceeded the state benchmarks in reading and mathematics alone. By this measure, many alternative schools appear to fail their students despite significant academic progress being made in alternative schools. This single measure takes the context out of alternative schools. As mentioned above, students in most alternative school were dropouts or at risk of dropping out before they enrolled. They may enter alternative schools grade levels behind and may have to overcome a variety of other personal issues just to come to the school. Many of these students move closer to meeting academic benchmarks each year, but the simple percentage of students meeting or not meeting 
academic benchmarks will still mark them as school failures without acknowledging their academic progress. Using this indicator alone will not allow us to capture the whole picture of an alternative school, and it is incumbent upon alternative school designers to work with state and local officials from the outset to incorporate measures beyond simple math and reading scores to show success in their alternative schools. For example, for some career-related alternative schools measure students self-efficacy for employment as an appropriate indicator of a student's preparedness for work. There are many other nontraditional measures of self-esteem and social skills that could also be used to measure student growth over time. In measuring student success, multiple indicators that align with the purpose and design of individual alternative schools must be used to judge the quality and merit of each school. Designers of alternative high schools will do well to begin the design process with the end product in mind and to consider program evaluation and the outcomes they want to achieve, starting from the beginning of the design process.

\section{Summary}

In addition to understand the problems of traditional public high schools and the reasons for the current lack of innovation in education, school leaders who want to design innovative alternatives to traditional high schools will also do well to consider educational research and literature related to the assumptions and theoretical frameworks underpinning this dissertation.

It is important leaders understand the literature as it relates the historical context of the development of alternative education during the last half century and the 
descriptors and "essential elements" researchers have gleaned from the experiment in educational innovation. Many of these elements, small size, relevance and relationships, flexibility, have been adopted by traditional high schools, but as this dissertation asserts, they have too often been adopted piecemeal rather than as a whole set, and this form of incrementalism has diluted their impact. Different types of alternative schools have been identified in the literature, but too often school leaders get lost in trying to find the best model to replicate locally. This dissertation advocates for models that are "good" alternative schools as identified in the literature as schools of choice with themes and innovative programs that are attractive to all kinds of students, especially those students who have left traditional schools early because they did not find the traditionally designed school to be relevant to their needs—-both personally and academically.

An important assumption in school design is the willingness of the participant designers to agree to start over ("from scratch" or "from square one") and to set aside the personal or professional historical baggage that comes with trying to turn around an existing school that is failing. Leading researchers have recognized the difficulty of changing a system that some say is only slightly easier to change than the penal system. Starting over, and I believe the research bears this out, is more efficient in terms of time and resources. Getting a committee of committed partners to agree to start over takes a leader who has a well thought out and researched leadership approach and the ability to drive consensus as to a vision for a new school. Whether the leadership approach is through a cultural/symbolic, historical, visionary, or some other context or combination of approaches is immaterial. What is important is a leader guide a team through a design 
process that gives the team language and frameworks to achieve a shared vision through group consensus, which will result in a stronger school design.

My assertion is it can be assumed that accreditation standards, though derived for the evaluation and improvement of traditional high schools, can be used as a framework or skeleton from which to design an alternative high school. Accreditation standards make a good framework for design because they are comprehensive and cover all the basic components any school needs. Examination of standards in different parts of the country shows all regional accreditation associations have similar standards, some have more and some have fewer, but they are all basically the same. What this means is the design process being studied in this dissertation could be adapted to use any set of regional standards, though I advocate for the use of 10 standards, so as to give a broad context to the design process and its product, which is a comprehensive description of the new school.

Embedded with elements of innovation and accreditation standards that are the building blocks for the design of alternative high schools, program evaluation that considers the outcomes designers want to achieve is incorporated throughout. Prominent evaluation researchers recognize that program evaluation means different things to different evaluators, but most agree program evaluation is about rendering value judgments using criteria to determine its quality. Creating a new alternative high school without seeking quality, but merely, for example, to get the "bad kids" off the street, does a disservice to the local community and especially to the students for whom designers should have the highest expectations of service. A quality alternative school, which the 
research literature bears out, can intervene and turnaround lives that will otherwise be wasted. 


\section{CHAPTER 3}

\section{RESEARCH METHODOLOGY}

“Yet only through communication can life hold meaning." -Paulo Freire

This dissertation studies the research question: What do leaders need to know to design innovative alternatives to traditional high schools? The product of this research is the development of a design process for creating new forms of secondary schooling. This chapter discusses the research design and research questions used to evaluate the need for this product and its effectiveness in helping school leaders design an alternative high school. This chapter then explains the data collection procedures used. The data analysis section clarifies how the researcher safeguarded the research process from bias and assured the validity of the study. Lastly, this chapter describes the action plan used in field-testing the product.

As described in Chapter 1, school leaders who want to design innovative alternatives to traditional high schools, especially alternative high schools purposed to serve students at-risk of school failure, may lack experience or training in school design and a process by which to create the new school. School leaders may assume a narrow view of school design, especially as it pertains to alternative high schools, because of limited experience in knowing "what works" when educating students at-risk of school failure. School design is part of the overall school development process that fits between needs assessment and implementation.

Traditional American high schools were never adequately designed to meet the educational and social needs of every student who may enroll in them. Inadequate design 
is evidenced by an epidemic dropout rate. Also, innovation in high school education may be stifled by school leadership's regression to the status quo, or denial of the problem. Despite decades of tinkering by trying to reform existing high schools, the dropout rate among high school students has remained unchanged. Leaders in education may seek to create alternatives to traditional high schools, but are often uncertain where to begin and what process to follow. This dissertation posits four assumptions of which leaders in education need to be more aware in order to enhance their ability to design alternative high schools. These assumptions are: (a) consider all essential elements of alternative schools at the same time, (b) start over when designing a new school, (c) use accreditation standards as a framework for school design, and (d) begin with the end in mind for program evaluation. Greater knowledge of these areas through a professional development process of innovative school design will help leaders overcome barriers in the development of new and innovative alternative high schools.

Based on my experience using preliminary versions of a design process and responses received when presenting on alternative school design at conferences, I believe there is a need for such a process. In my opinion, professional development for school leaders who want to design alternatives to traditional high schools is sorely needed. A facilitated process will help school leaders avoid the pitfalls and mistakes others have made when creating alternative schools. Finally, the development of a field tested process for designing alternative high schools will lead to better designed alternative high schools, and save resources that would otherwise be lost through the use of poor and inadequate design processes. 


\section{Research Design}

The research design I identified as most useful for collecting data for this study is a PBL approach utilizing an R\&D process (Borg \& Gall, 1989; Bridges \& Hallinger, 1995). PBL is a project development practice and its research model is R\&D described by Borg and Gall (1989) as "a process used to develop and validate educational products" (p. 782). PBL consists of addressing an educational problem demanding knowledge acquisition, problem-solving, self-directed learning, and team participation skills. A systematic approach to problem solving and overcoming challenges encountered during the career of an educator characterize the PBL approach (Bridges \& Hallinger, 1995). Bridges and Hallinger have also identified PBL as a strategy for doing doctoral work, especially among students seeking an EdD in administration, as participation in PBL will become important during their careers.

This study uses PBL as its research method. PBL provides an R\&D model (Borg \& Gall, 1989) that enhances my research goal. This R\&D cycle enables researchers to develop, field test, and refine educational products so they are ready to be implemented in schools. This cycle enables development and field testing of a process for school design teams that will be used to create new schools. As a result of the R\&D process school leaders will have a product that has been tested for use in school systems. This design process is guided by the question: What do leaders need to know to design innovative alternatives to traditional high schools? The benefit to school leaders will be having a process available to guide a local team through the design of schools that are based on elements of effective alternative schools that will engage all youth in learning. This study 
has practical value to school leaders seeking to design alternative high schools that may be designed to engage and re-engage students at-risk of dropping out.

For the purposes of this study, I plan to follow first seven steps in Table1 as delineated by Borg and Gall (1989, pp. 784-785).

Step 1 (research and information collecting) is accomplished through the research and information collected for literature review, chapter 2, of this dissertation. This step is also accomplished through information and feedback collected while presenting on alternative school design and evaluation at state and national conferences. Conferences recently presented at are listed in Table 4.

At these conferences I had the good fortune of co-presenting with Dr. Changhua Wang, Director of Research and Evaluation at Education Northwest; Dr. Richard "Dick" Darst, Oregon Director of the NWAC, a division of AdvancED; and Drew Hinds, Specialist in Alternative Education for the Oregon Department of Education. During most of the conferences I co-presented with Mr. Hinds, who is also a member of my doctoral program cohort and our research is similar as he is studying the evaluation of alternative schools in Oregon. Further information regarding coordination of our research is presented later in this chapter. Gathering research and information has been ongoing step as my study uses the R\&D cycle. 
Table 4

Presentations of School Design Process Prototype

\begin{tabular}{|c|c|c|c|}
\hline Title of Presentation & Event & Location & Date \\
\hline $\begin{array}{l}\text { An Innovative School } \\
\text { Design Process }\end{array}$ & $\begin{array}{l}\text { Annual Conference of the Oregon } \\
\text { Association for Comprehensive } \\
\text { Education }\end{array}$ & $\begin{array}{l}\text { Seaside, } \\
\text { Oregon }\end{array}$ & $\begin{array}{l}\text { January } \\
2012\end{array}$ \\
\hline $\begin{array}{l}\text { Designing and Evaluating } \\
\text { Innovative Schools }\end{array}$ & $\begin{array}{l}\text { Podcast, National Dropout Prevention } \\
\text { Center/Network }\end{array}$ & $\begin{array}{l}\text { Oregon } \\
\text { Public Radio }\end{array}$ & $\begin{array}{l}\text { November } \\
2011\end{array}$ \\
\hline $\begin{array}{l}\text { Designing and Evaluating } \\
\text { Innovative Schools }\end{array}$ & Oregon Innovative Schools Conference & $\begin{array}{l}\text { Gervais, } \\
\text { Oregon }\end{array}$ & $\begin{array}{l}\text { October } \\
2011\end{array}$ \\
\hline $\begin{array}{l}\text { Designing and Evaluating } \\
\text { Innovative Schools }\end{array}$ & $\begin{array}{l}\text { National Dropout Prevention } \\
\text { Center/Network Annual Conference }\end{array}$ & $\begin{array}{l}\text { Chicago, } \\
\text { Illinois }\end{array}$ & $\begin{array}{l}\text { October } \\
2011\end{array}$ \\
\hline $\begin{array}{l}\text { Design and Evaluation of } \\
\text { Innovative Alternative } \\
\text { Programs }\end{array}$ & $\begin{array}{l}\text { Confederation of Oregon School } \\
\text { Administrators (COSA) Annual } \\
\text { Conference }\end{array}$ & $\begin{array}{l}\text { Seaside, } \\
\text { Oregon }\end{array}$ & June 2011 \\
\hline $\begin{array}{l}\text { Designing Innovative } \\
\text { Schools }\end{array}$ & $\begin{array}{l}36^{\text {th }} \text { Annual Conference of the } \\
\text { Washington Association for Learning } \\
\text { Alternatives (WALA) }\end{array}$ & $\begin{array}{l}\text { Ocean Shores, } \\
\text { Washington }\end{array}$ & $\begin{array}{l}\text { March } \\
2011\end{array}$ \\
\hline $\begin{array}{l}\text { Design and Evaluation of } \\
\text { Alternative Programs }\end{array}$ & $\begin{array}{l}\text { Oregon Association for Comprehensive } \\
\text { Education Conference (OACE) }\end{array}$ & $\begin{array}{l}\text { Seaside, } \\
\text { Oregon }\end{array}$ & $\begin{array}{l}\text { January } \\
2011\end{array}$ \\
\hline $\begin{array}{l}\text { Program Evaluation in K- } \\
12 \text { Schools }\end{array}$ & $\begin{array}{l}\text { Oregon Program Evaluators Network } \\
\text { (OPEN) Annual Conference }\end{array}$ & $\begin{array}{l}\text { Portland, } \\
\text { Oregon }\end{array}$ & $\begin{array}{l}\text { September } \\
2010\end{array}$ \\
\hline $\begin{array}{l}\text { Alternative Education } \\
\text { Programs: Review Teams } \\
\text { and Evaluation }\end{array}$ & $\begin{array}{l}\text { Confederation of Oregon School } \\
\text { Administrators (COSA) Annual } \\
\text { Conference }\end{array}$ & $\begin{array}{l}\text { Seaside, } \\
\text { Oregon }\end{array}$ & June 2010 \\
\hline $\begin{array}{l}\text { Tools for District Review } \\
\text { of Alternative Education } \\
\text { Options }\end{array}$ & $\begin{array}{l}35^{\text {th }} \text { Annual Conference of the } \\
\text { Washington Association for Learning } \\
\text { Alternatives }\end{array}$ & $\begin{array}{l}\text { Ocean Shores, } \\
\text { Washington }\end{array}$ & $\begin{array}{l}\text { March } \\
2010\end{array}$ \\
\hline $\begin{array}{l}\text { Effective Evaluation of } \\
\text { Alternative Education } \\
\text { Programs in Oregon }\end{array}$ & Superintendent's Summer Institute & $\begin{array}{l}\text { Eugene, } \\
\text { Oregon }\end{array}$ & July 2009 \\
\hline
\end{tabular}

Step 2 (planning, objectives, learning activities, and small scale testing) came about through conversations with school leaders with interest in alternative school design. At conferences and through visits with school administrators and staff I began to 
understand the barriers they faced, what understanding they lacked, and what they would need to know to create innovative alternative high schools.

Step 3 (develop a preliminary form of the product) began when I was invited to help a group of school districts in the South Coast region of Oregon to design a new alternative school. I worked primarily with the two local school district superintendents and a design team they put together. I facilitated a series of meetings and writing activities that resulted in a preliminary product or prototype version of my alternative school design process.

During Step 4 (preliminary field testing) this study conducted a quantitative and qualitative survey of high school administrators who have demonstrated interest in designing alternative high schools. After presenting and discussing my school design process with participants in a session at the Northwest Innovative Schools Network Annual Conference in October 2012, I surveyed session participants using a survey instrument (See Appendix A). I also used a questionnaire with selected school leaders who have already designed innovative schools in order to compare the process they used to design their schools with my process. I simply asked the participants who have school design experience to describe the process they used to design their schools and to share any extant documents pertaining to their school's design. Survey questions and interview protocols are further discussed in the data collection section of this chapter. Table 5 is a preliminary list of innovative school designers who have tentatively expressed interest in my school design process and are being considered for participation in this study. 
Table 5

Preliminary List of Innovative School Designers and Schools

\begin{tabular}{ll}
\hline School Leader & School Name \\
\hline Terrance Smyth & Oregon Trail High School \\
Ginger Redlinger & Clackamas Academy of Industrial Sciences \\
Steve Rutherford & Alliance High Schools of Portland Public Schools \\
Adam Reid & Leadership and Entrepreneurship (LEP) HS \\
Jill Mohr & Alliance Charter High School \\
Mike Englen & New Urban High School \\
\hline
\end{tabular}

Step 5 (main product revision) used the survey and interview data collected in Step 4 to revise and refine the alternative school design process.

Step 6 (main field testing) was conducted, in coordination with Drew Hind's research on alternative school evaluation, in an Oregon school district. Our goal was to design and evaluate an alternative high school. Main field testing resulted in educational products that can serve both for alternative high school design and evaluation of alternative schools throughout the state of Oregon and beyond the state.

Step 7 (operational product revision) resulted in a fully detailed process, in the form of an electronic and printed notebook that will be edited, refined, and made ready for dissemination as detailed in PBL research by Lorenz and Pichert (1989). The R\&D process provided the information needed to create a product that was needed and is beneficial to school leaders.

Steps 8-10 (see Table 1) are post dissertation activities. 


\section{Research Questions}

My research is guided by this central question: What do leaders need to know to design innovative alternatives to traditional high schools? Related research questions that will help evaluate a school design process are presented below. These research questions were developed based on questions important to the R\&D cycle and used to determine the future usefulness or effectiveness of the educational product, which is a structured process for alternative high school design. The school design process is intended to provide school leaders with the knowledge they need to successfully design an alternative school. The research questions follow:

1. Is the process under development an effective process for designing innovative alternatives to traditional high schools?

2. What obstacles have school leaders experienced when attempting to design an alternative school? How well does the proposed process address those obstacles?

3. How essential are the four assumptions imbedded in the process regarding what leaders need to know?

4. How does using a design team impact or improve the school design process?

5. What impact can this process potentially have on students at-risk of high school failure?

Using feedback from the research questions above, I refined and more fully developed the process. As that refinement took place, I expected other research questions to arise that allowed me to further revise the process. Further research added to my 
knowledge as to what school leaders need to know and to assist them in obtaining that knowledge. My hope is school leaders will use the process to add to the diversity of schools offered by school district so as to meet the educational needs and interests of all students.

\section{Data Collection Procedures}

School leaders, especially superintendents and high school principals, are aware of the crisis in dropouts and want to create alternatives to traditional school settings. Educational books and articles contained helpful hints and lists of elements that partially enable alternative high schools to be successful, but there appears to a lack of a comprehensive process for designing alternatives. While assisting school districts to design such schools, I have been able to create a preliminary design process. In this section I discuss the data collected and how it was collected with the aim of analyzing the data to improve the alternative high school design process.

When beginning research it is important to consider what kinds of data will be useful to addressing the problem statement and answering the research questions posed previously in this chapter (Gay et al., 2009). Gay et al. (2009) recommended the use of multiple methods of data collection to overcome the limitations of each. Triangulation, three of more sources of data enables the researcher to gain multiple perspectives, thereby increasing the validity of the data. Since the process for designing alternative high schools is a resource for school leaders, data collected was from school leaders in the form of surveys and interviews, and through reflections on the facilitation of a design 
leadership team as an actual school is designed. A survey of school leaders is presented in Appendix A.

Standardized testing is an example of one type of quantitative research, but as Gay et al. (2009) noted, quantitative research may also take the form of survey research which “involves collecting data to answer questions about people's opinions on some topic" (p. 175). Survey research may be used to collect data about survey participants and used quantitatively by analyzing participants' ratings of statements based on research questions. Some generalizations about alternative school design could be derived from this type of research. Quantitative data based on participants' opinions will constituted only a part of my research, as I believe it is important to conduct field research with practitioners who have experienced a school design process. This research contributes to Steps 4 and 5 of the R\&D cycle (Borg \& Gall, 1989), discussed previously in this chapter. Specific research instruments are discussed later in this section.

The central focus of qualitative research is to provide an understanding of an activity from the perspective of research participants (Gay et al., 2009). Types of qualitative research include group surveys, case studies, interviews, and questionnaires. Surveys and questionnaires may also be quantitative. Gay reported questionnaires are less time-consuming than face-to-face interviews, but that researchers often conduct followup interviews when participant feedback warrants further investigation. A "Comments" section should be part of a questionnaire whenever possible.

In my research, I collected responses to a self-reporting question from a select group of research participants who have already designed non-traditional high schools. I 
planned to define for participants the meaning of "design" in the context of new school development (see Figure 1) and simply pose the question: What process did you use to design (your school)? As a part of my field work I followed-up the collection of written responses to the question with interviews of participants when further investigation was warranted. Overall, this method allowed access to experienced school designers so as to gain the information needed to improve the effectiveness of the school design process under development. The primary focus of the questionnaire was to understand how participants' schools were initially designed, so analysis of responses could be used in comparison to the design process under development. Field notes taken during the follow-up interviews were summarized as data for further analysis. This research contributes to the fulfillment of Steps 4 (Preliminary field testing) and 5 (Main product revision) of the R\&D cycle (Borg \& Gall, 1989). Participants were assured of confidentiality and participation at no risk during every step of the R\&D cycle.

Bridges and Hallinger's (1995) PBL employs an R\&D cycle (Borg \& Gall, 1989) well suited to the $R \& D$ of an educational product, in this instance a process for designing alternative high schools. Step 6 of the R\&D cycle research is main field testing, during which further evaluation of the product's efficacy and may rely on quantitative evaluation design that assesses implementation of the product and creates a summative evaluation. Main field testing took place with an alternative high school design leadership team that is using the process to design an actual school. Main field testing was done in collaboration with Drew Hinds, who is concurrently researching evaluation methodology of alternative schools in Oregon. Quantitative surveys of design team members were used 
to evaluate the efficacy of the design process during the implementation of the process.

When conducting this research, I played the role of researcher-facilitator.

\section{Sources of Data Used in This Study}

- Quantitative survey of participants in a state-wide (Oregon) alternative education conference who have demonstrated interest in alternative school design, approximately 20 participants. Fulfills Step 4 (preliminary field testing) of $R \& D$ process.

- Qualitative questionnaire with self-reported responses and follow-up interviews, when warranted, of school leaders who have designed existing alternative high schools, approximately six participants. Fulfills Step 4 (preliminary field testing) of $\mathrm{R} \& \mathrm{D}$ process.

- Field notes from follow-up interviews and school visits with questionnaire respondents. Fulfills Step 4 (preliminary field testing) of R\&D process.

- Surveys and debrief field notes from main field testing during and following research-facilitation of a leadership design team to design an alternative high school, approximately 10 participants on the team. Fulfills Step 6 (main field testing) of $\mathrm{R} \& \mathrm{D}$ process.

School leaders who have demonstrated an interest in alternative school design,

practitioners who have already designed innovative alternative high schools, and a group of local school leaders working to design such a school, were part of my research. Some participants were invited to participate, and others volunteered. All participants were assured that their participation was completely voluntary. In addition, participants' decisions to participate did not have any effect on their relationship with me as a researcher, their school or school district. The participants were not offered, nor were non-participants be denied, any financial compensation. The participants were advised that they could withdraw from the study at any time without any negative effect on their relationship with me as a researcher, their school, or school district. The participants were assured that their responses and the information gathered would be kept confidential. The 
focus of this work was developing an educational product which is a process for designing alternative high schools, and not evaluating participants or their work.

The data collection process $(\mathrm{R} \& \mathrm{D})$ methods that have been covered in this section are all methods that contributed to creating a quality process for the users of the product. One key factor taken into account pertinent to this study is that research findings and product revisions would be presented and discussed with participants to identify any inaccuracies or oversights. Primarily, the participants validated the strength and effectiveness of the alternative high school design process and their insights in the study.

\section{Data Analysis Strategies}

Collecting and analyzing the data necessary to conduct a reliable study requires using valid research methods. A variety of research methods could be selected and used to study a school design process, but whichever method is chosen the researcher needs to consider whether or not it will answer the primary research question, if secondary questions are comprehensive enough to give a broad perspective, and when it is appropriate to stop collecting data. School design is a complex process, and a framework for data collection and analysis must be carefully defined. Analysis of data must be conducted in a way that answers this primary research question: What do leaders need to know to design innovative alternatives to traditional high schools?

The surveys to be conducted during Step 4 (preliminary field testing) and Step 6 (Main field testing) of the R\&D process, the research design of this study, were given through a paper-and-pencil format that I facilitated through face-to-face interaction and/or through email correspondence. In collecting data I used Survey Monkey. To 
analyze the data, I used Excel spreadsheet software to summarize survey results and gather information such as participant quantitative ratings and qualitative comments received. Spreadsheet collection of data enables it to be generated in table forms. I was able to view chart view each question for side-by-side comparison. The data analyzed informed revisions of the alternative school design process. A scale that evaluated the effectiveness of the school design process was predicated on statements related to the primary and secondary research questions. A draft of a survey to be used in Step 4 (preliminary field testing) of the R\&D process is presented in Appendix A. A similar survey was developed and used in Step 6 (Main field testing). Participants used numerically rating statements: 1="Not Essential," 2="Somewhat Essential," 3="Moderately Essential," and 4="Absolutely Essential." Scores and comments were analyzed to improve the school design process in all areas based on participant ratings. The intent of this study is for refinement to continue until aspects of the process achieve the equivalent of an "absolutely essential" rating.

Qualitative follow-up interviews of participants were conducted when further information was needed during main field testing. Data were analyzed for frequency of occurrence and reoccurring trends in responses. Interviews were transcribed and coded for analysis. When conducting interviews I was viewed as a peer by administratorparticipants, which was designed to minimize personal bias as I had no power over the interviewees. Participants were told my only interest was in improving the school design process in question. For the most part, I had some knowledge of the non-traditional schools whose administrators I surveyed, but I had no other connection or importance to 
the operation of their school. Data were only collected by me in a role as an outside observer or facilitator of the school design process being studied.

During main field testing a local alternative high school design leadership team was created a design for a new school. I assumed the role of a facilitator who guides the team through the design process. In that role I worked to avoid weighing in on discussions or giving my opinion. At the conclusion of team meetings surveys of team members were conducted to collect data analyzed and used to guide the improvement of the school design process. My experience as a perceived expert in alternative school design may have influenced team members' behaviors, but I am unable at this time to say how much their behaviors were affected.

\section{Work Plan}

This research plan was submitted to Portland State University's Human Subjects Department along with the informed consent document, formatted survey questions, and interview questions. In this section more detailed information on the work plan and timeline to be follow as I conducted this research study is presented.

Initial research and information collecting for the development of a process to design new and innovative alternative high schools began many years ago during my career when I was Director of Education Options for the Portland (Oregon) Public Schools. More recently, beginning in July 2009, planning objectives, learning activities, and small scale testing became more formalized as I chose alternative school design as a research topic for this dissertation, and was engaged as a consultant by three small school districts in the South Coast region of Oregon to help the create a new alternative school. 
During that consultancy I took informal field notes of design team meetings and conducted unstructured interviews of design team members. Those experiences led to the development of a preliminary form of the school design process being studied here. This preliminary data, combined with my review of existing literature provided me with enough information to create a prototype process. Beginning October 2012, I began conducting preliminary field testing for the further development and effectiveness of the process to design innovative alternatives to traditional high schools. The school design process was revised through each step in the R\&D cycle: preliminary field testing, main field testing, and operational product revision. I did this research in collaboration with Drew Hinds, a member of my doctoral cohort who studied program evaluation of alternative schools in Oregon.

Actions taken to conduct this research were as follows:

- In October 2012, Mr. Hinds and I co-presented at a conference of Oregon alternative school leaders. As part of Step 6 (preliminary field testing) of the R\&D process, voluntary participants in our conference session were briefed on the school design process, as well as Mr. Hinds evaluation plan, then asked to complete a survey (See Appendix A). As researchers we informed participants about the nature of our research and our data collection activities. Participation was completely voluntary and a consent form was included. Contact information was provided participants in case any want to revoke consent. Participants were notified that their identities would be held in strict confidence.

- During October and November 2012 survey questionnaires and interviews of school leaders who have successfully design non-traditional schools were conducted, also as part of Step 6 (preliminary field testing). The same research protocols as applied to conference survey participants also applied to these participants.

- From November 2012 through April 2013, research was conducted during main field testing. Main field testing consisted of facilitating the design of an innovative alternative high school in the Portland, Oregon metro-area. Surveys 
of design leadership team members were conducted and analyzed. Survey results and field notes were used to improve the effectiveness of the school design process being studied. Drew Hinds collaborated with me in this effort as he studied alternative school program evaluation.

Research activities and a proposed timeline for this research are represented in Table 6, which also includes a timeline for revising the product.

Table 6

Proposed $R \& D$ Timeline

\begin{tabular}{lll}
\hline Month/Year & Activity & Action \\
\hline October 2012 & $\begin{array}{l}\text { Present to State } \\
\text { Conference Participants }\end{array}$ & Survey Participants with Consent \\
October 2012 & Analyze Data & Use Data to Conduct Product Revision \\
$\begin{array}{l}\text { October-November } \\
2012\end{array}$ & $\begin{array}{l}\text { Request Data for } \\
\text { Successful School } \\
\text { Designers }\end{array}$ & $\begin{array}{l}\text { Collect Question Responses \& Conduct Follow-up } \\
\text { Interviews }\end{array}$ \\
November 2012 & Analyze Date & Use Data to Conduct Product Revision \\
$\begin{array}{l}\text { November 2012 }- \\
\text { April 2013 }\end{array}$ & $\begin{array}{l}\text { Facilitate School } \\
\text { District Design Team }\end{array}$ & $\begin{array}{l}\text { Survey Participants, Conduct Follow-up Interviews, } \\
\text { and Take Field Notes }\end{array}$ \\
May 2013 & Analyze Data & Main Product Revision \\
\hline Source: Borg and &
\end{tabular}

Source: Borg and Gall (1989)

\section{Summary}

This chapter outlines the methodology by which a problem in education was identified, arguing that school leaders often lack the knowledge embedded in a process to design alternative high schools. Next it discusses the research design of the study, defining the PBL approach that combined with an R\&D process provided a tangible method for data collection and analysis for this study. Research questions are presented that created a broad perspective as to the effectiveness of the educational product under 
development, which is a process to design innovative alternatives to traditional high schools. Next, this chapter clarifies how data were gathered and analyzed, including how bias and undue influence on the part of the researcher was avoided or minimized. Finally, this chapter presented a work plan and timeline for carrying out this research. The result of this research was revisions of the school design process.

Educational research employing an R\&D cycle to address a question of PBL is an application to practice suited to a doctorate in education, rather than perhaps is abstract educational research that Wilson and Daviss (1994) criticized as often going unused at the school level. This dissertation seeks to learn what school leaders need to know to design alternatives to traditional high schools. Solving the dropout crisis is an important educational need, and may be one application of this product. There were sufficient human resources available, with the knowledge and skills, to conclude that a successful product can be built. We know what to do, and there is no time like the present to do it. 


\title{
CHAPTER 4
}

\author{
ANALYSIS \\ "If you will it, it is no dream." -Theodor Herzl
}

What do leaders need to know to design innovative alternatives to traditional high schools? This question assumes leaders in education often do not know what to do to design innovative alternative high schools and is the basis for the PBL research described in chapter 3. This chapter analyzes of the results of a $R \& D$ process used to improve an educational product, in this case a process to help teams of leaders design new forms of secondary schooling. This chapter also reviews the research questions and the general design of this PBL project. It then reviews the development and implementation (field testing) of the project based on my experience and steps 1 through 7 of the $R \& D$ process. Summative and formative results of PBL project implementation were evaluated and are presented. This chapter concludes with discussions of final product revision and the challenges encountered during field testing.

Participants in this research project were school leaders with a wide array of educational backgrounds and experiences. All participants were selected because they demonstrated an interest in alternative high school design. Each participant reacted differently to the school design process and openly shared their views with the researcher in varying degrees. Care was taken to gain greater understanding throughout the field research as to the effectiveness of the school design process in order to improve the overall usefulness of this product. The researcher utilized common trends and themes in the data collection and analysis process to achieve this goal. The development of the 
alternative high school design process was related to four key design process recommendations: 1) consider all essential elements of alternative schools at the same time; 2) start over when designing a new school; 3) use accreditation standards as a framework for school design; and 4) begin with the end in mind for program evaluation. Improving the design process to increase knowledge in these areas will help leaders create better alternative high schools in the future.

This chapter explains steps 1-7 of the R\&D process, describing what was done and what was learned at each step. Research questions that guided this study are then reviewed. The chapter also explains the research design used in this study. It then describes the development and field testing of the design process (product), as well as the researcher's experience progressing through the first seven steps of the R\&D process. Lastly, it explains the results and findings of the first seven R\&D steps.

The following section of this chapter outlines the research design and research questions used to answer the question: What do leaders need to know to design innovative alternatives to traditional high schools? This research also leads to the further development of an alternative high school design process called "Designing Innovative Alternatives to Traditional High Schools."

\section{Research Questions and General Design}

The primary research question (What do leaders need to know to design innovative alternatives to traditional high schools?) led to the development of secondary research questions. These five questions are aimed at determining the effectiveness of the educational product to be used for designing an alternative high school. The school 
design process is intended to provide school leaders with the knowledge they need to successfully design an alternative school.

\section{Research Questions}

1. Is the process under development an effective process for designing innovative alternatives to traditional high schools?

2. What obstacles have school leaders experienced when attempting to design an alternative school? How well does the proposed process address those obstacles?

3. How essential are the four assumptions imbedded in the process:

- Consider all essential elements of alternative schools at the same time.

- Start over when designing a new school.

- Use accreditation standards as a framework for school design.

- Begin with the end in mind for program evaluation.

4. How does using a design team impact or improve the school design process?

5. What impact can this process potentially have on students at-risk of high school failure?

Using feedback from the research questions above, a more fully developed design process was created. As the alternative high school design process refinement took place, differences from prototypical processes were noted and further developed as needed.

Data collection and application of the product added to the extant knowledge base about what school leaders need to know regarding the alternative high school design process as well as how to impart that knowledge. Benefits of the design process were noted during its applications by carefully following steps 1-7 of the R\&D process. These benefits of the alternative high school design process, such as increased innovation in education, 
more efficient use of resources to start new schools, and staff buy-in are documented as part of conclusions drawn in chapter 5. Ultimately, school leaders have a new design process to facilitate the creation of alternative high schools that meet the future educational needs and interests of all students.

\section{Research Design}

PLB employing R\&D was used as the research design for this study. Borg and Gall (1989) depicted educational R\&D as "a process used to develop and validate educational products" (p. 782). Researchers engage in R\&D and use findings to create a product that is ready to be implemented in real world educational applications. The full R\&D model is a 10 step process leading to full dissemination of the educational product under development. For the purposes of this dissertation, the first seven steps in the R\&D cycle are followed to develop, field test, and refine a process for designing innovative alternative high schools. The first seven steps in the R\&D process were implemented to ensure that the product is ready to assist practitioners in the field. The next section of this chapter provides information on the researcher's experience in the development, field testing and refinement of the product during each of the seven steps in the process. Steps 8-10 are also presented and further addressed in conclusions drawn in chapter 5 of this dissertation. As shown previously in Table 1, Steps in the R\&D process are:

1. Research \& information collecting

2. Planning, objectives, learning activities, and small scale testing

3. Develop preliminary form of the product

4. Preliminary field testing 
5. Main product revision

6. Main Field testing

7. Operational product revision

8. Operational field testing

9. Final product revision

10. Dissemination and implementation

\section{Development and Implementation}

\section{Step 1. Research and Information Collecting}

The need for a process to design innovative alternatives to traditional high schools was identified as a result of the literature review and the lack of such a process. The literature review exposed the need of school leaders for a guided process to assist them in the development of new forms of secondary schooling that are standards based, but provide the flexibility to be innovative. The literature review served to demonstrate not only the lack of information on how this organizational change can be accomplished, but it also highlighted that high school leaders may lack comprehensive knowledge associated with what makes alternative education effective and the ability or power to start over when conceptualizing the possibilities of what a new school of the future can be (Wilson \& Daviss, 1994).

Additionally, the literature review served to demonstrate that the need for designing alternatives to traditional high schools is becoming increasingly more crucial as high schools seek to adapt to the changing needs of student demographics and cultures (Barr \& Parrett, 1997). The speed and scope of changes occurring in society further 
exacerbates the need for leaders to have the skills and knowledge to change high schools so they will benefit all students in the future. High schools are continually challenged to work with scarce resources. To adapt, high school leaders need a process to help them design schools within a framework, while also freeing them to think creatively about what an ideal high school could be. There is a need for a new high school design process that will guide school leaders and enable them to use available resources to create successful high school environments.

The only processes readily available to high school leaders are limited to those provided in some states that have legal requirements for alternative education or charter schools. A review of the literature revealed that these processes are either inadequate to fully design a school, or so complex as to create barriers to new high school development. Some regional and national education organizations and authors offer advice as to how to design alternatives to traditional high schools, but these seem to lack a complete process for school design. Existing information may not relate to real world situations, or may only be conceived as replication of pre-packaged educational programs that may or may not meet local needs and interests (Raywid, Schmerler, Phillips, \& Smith, 2003). Given this environment, many high school designers may be unsuccessful in their efforts to develop innovative alternatives. The lack of a design process made it evident that there is a fundamental need for high school leaders to have access to a process for designing alternatives to traditional high schools that informs them as to what they need to know and how to do it. The success or failure of designing new high schools is currently trial-and-error, and high school leaders with whom I communicated wanted a 
better process as they embarked on their journey to create high schools of the future.

Provide a better design process has been the main work of my career, as prototypes were developed and tested in practice then researched through this dissertation and the use of an $R \& D$ process.

\section{Step 2. Planning, Objectives, Learning Activities, and Small Scale Testing}

A review of the literature exposed a lack of clear and comprehensive resources needed by school leaders who want to design innovative alternatives to traditional high schools. In addition, extensive professional experience in alternative education enabled me to begin to determine key assumptions to which leaders need to pay attention. To test these ideas I began to make presentations about alternative school design at local, state, and national educational conferences and gather feedback from school leaders who attended these forums. A list of these presentations is provided in Table 4. During these sessions I learned there was a considerable interest and need for a process leading to the creation of alternative high schools, but school leaders lacked a comprehensive and effective process to design such schools. Gradually a more complete picture of an alternative school design process emerged. There was a need for a planning or design process, and objectives activities for instructing leaders as to what they would need to know began to take shape. Small scale testing took the form of trying learning activities, such as discussion of the meaning of school choice, for example, helped to refine the objectives and activities. These activities took the form of presentation outlines and PowerPoint illustrations used to take school leaders through prototypes of the alternative high school design process. Information gathered about other alternative high school 
design processes, through discussions with school leaders with school design experience, and applications as described in Step 3, allowed improved planning of the design process, its objectives, and activities from which school leaders could learn to design their own alternative high schools.

\section{Step 3. Develop Preliminary Form of the Product}

In Spring of 2011, I was employed by several small school districts in the South Coast region of Oregon to assist them in designing a regional alternative high school. This experience is characterized in the preface of this dissertation. It became apparent from initial meetings with superintendents that they were aware of the needs of out-ofschool youth in the area, but were uncertain as to where to begin and what steps to follow to meet youth's needs. Because of my experience in alternative education I was recommended to the superintendents by the state department of education. An existing alternative program was being discontinued for poor performance and the resources that had been used for it were available for planning and implementation purposes. Design process objectives emerged from the situation, which in effect became small scale testing of a prototypical design process. The first objective was identification of a local design leadership team composed of internal and external school community stakeholders. Team members included superintendents, principals, teachers, parents, students, and other local community members. The second objective was to create learning activities from which team members could obtain common knowledge about the key assumptions they would need to know to design an innovative alternative to their local traditional schools. The third objective was to create a "program description" that served as a blueprint for the 
new school and was based on the learned assumptions. All objectives were achieved prior to the implementation of the new alternative high school and meeting these objectives served to develop a preliminary form of the product, which is a process to design innovative alternatives to traditional high schools.

\section{Step 4. Preliminary Field Testing}

To fully realize potential of the design process and its applications, more formal research was needed. The purpose of preliminary field testing was to obtain an evaluation of the effectiveness of the initial product (Borg \& Gall, 1989). As the prototypical design process evolved through presentations to different professional audiences and critiques by various colleagues, its title also changed from "Designing Innovative Schools," reflecting a universal application to any school anywhere, to "Designing Innovative Alternatives to Traditional High Schools," which provided a more targeted focus and tighter application to a more specific educational problem.

For a first preliminary field test of the proposed design process, nine school leaders who attended Northwest Innovative Schools Conference in October 2012 were asked to complete an Alternative High School Leadership Survey (see Appendix A) after attending my presentation, which included discussion about the prototype design process. The school leaders who attended included principals, other school administrators, and teachers. These alternative school leaders completed a survey about the effectiveness of the prototype design process, based on my research questions that asked them to rate how essential to the process various indicators were. Results of these ratings showed most respondents understood and agreed with the importance of comprehensively attending to 
the concepts of starting the design process over, understanding elements of effective alternative education, following pre-existing or developed standards, and thinking of the end in mind through program evaluation when designing an alternative high school. A comments section was also provided but was not used by most respondents. Their responses confirmed that the prototypical process appeared to be useful and an effective process for designing innovative alternatives to traditional high schools.

A second preliminary field test involved requesting written responses from six leaders who had previously designed innovative alternatives to traditional high schools. These leaders were asked to describe the process they used to design their schools. Anonymity was maintained in that responses were received in a way that individual schools could not be identified. Surveys were conducted and guiding questions were provided in a letter requesting research information (see Appendix B). Five of six (83\%) school leaders from whom data were requested responded. These school leaders included principals of existing alternatives to traditional high schools. Table 7 lists the school leaders from whom information was requested, and the name of the school they were involved in designing,

Responses to the research questionnaire from leaders who had designed innovative high schools were based on these guiding questions:

1. What was the position of the person who initiated or led the design process for your innovative high school?

2. What obstacles did you experience when designing your innovative high school? 
3. What conceptual framework(s) did you use when designing your innovative high school?

4. Was a team approach used to design your innovative high school? If so, what was the general composition of the team? How effective was the team approach?

5. What impact, if any, did the results of your design process have on students at-risk of high school failure?

Table 7 lists innovative high school leaders who were surveyed as part of the R \& D process.

\section{Table 7}

Innovative Alternative High School Designers Surveyed

\begin{tabular}{ll}
\hline School Leader & School Name \\
\hline Becky Lukens & $\begin{array}{l}\text { Pacific Crest Community School, Portland, Oregon } \\
\text { Clackamas Academy of Industrial Sciences, Oregon City, } \\
\text { Oregon }\end{array}$ \\
Steve Rutherford & $\begin{array}{l}\text { Alliance High Schools of Portland Public Schools, Portland, } \\
\text { Oregon }\end{array}$ \\
Noel Hygelund & Ackerman Center High School Academy, Canby, Oregon \\
Jill Mohr & Alliance Charter High School, Oregon City, Oregon \\
Mike Englen & New Urban High School \\
\hline
\end{tabular}

The responses were coded and analyzed to create the following common categories and themes: 
1. Initiation of Design. Leadership for designing innovative alternatives to traditional high schools can come from various stakeholders. Some alternatives arise from nontraditional schools or educational programs that are discontinued due to poor performance. At other times a school district superintendent or senior central office staff perceive a need, such as a high dropout rate, and may initiate school district efforts and seek to open an alternative education program to attract dropouts back into the school system. In my experience, a school system may be motivated to start an alternative school by loss of revenue and other resources when students dropout. Though the design process, based on a perceived need, may be initiated by a senior school district leader, it is often assigned to a less senior administrator, such as a high school vice principal, to implement. Charter school alternative high schools may be initiated by an individual or small group of likeminded individuals based on a perceived community need or in opposition to constraints put on traditional public schools (Finnigan, 2007). Federal or state "start-up" resources can motivate groups or individuals to seek to start charter schools. It is important to understand that design processes are often driven inconsistently or haphazardly, and adequate time may not be given to creating an adequate design.

2. Obstacles to Design. Administrative staff assigned to lead the design process often had no experience in creating a new alternative high school. Leaders had little awareness of model schools, and finding information about alternative 
school models was often challenging. Financing and other resource support from the local school district may be an obstacle due to budget constraints. As stated previously, temporary or start-up resources typically are available, but sustaining a new school once temporary resources go away is often problematic. Inadequate or inappropriate staffing, especially when competing with other schools for assignment of highly qualified staff, is also a common obstacle. Groups and individuals outside school systems may seek to design and implement alternatives to traditional high schools, but school districts typically lack a process that would support, with a comprehensive design process, innovations and ideas from outside the internal school district community. School districts that have an application process for external community stakeholders to submit ideas for new kinds of schooling often lack a design process, to precede the application, to help applicants. Such obstacles are important to understand and change, because they often impede new ideas that could be brought into improve traditional school systems.

3. Conceptual Frameworks. Rather than having a consistently larger conceptual framework for school design, the conceptual frameworks used to design the innovative high schools of the leaders who responded varied from school to school and were dependent on the type of educational program the design leaders were developing. These "frameworks" ranged from strict behavioral/levels based classrooms to student-centered instruction, personalized learning, and curricular themes. In other words, frameworks for 
design were often student-centered, which is appropriate, but limited to curriculum, instruction, and student management. Conceptual frameworks for alternatives were often based on replicating other alternative schools. A broader conceptual framework that takes into account a vision and mission, supports for learning, and elements of effective alternative schools is needed.

4. Team Approach. A team or committee approach was used to design each of the innovative high schools by the leaders who responded to this survey. The general composition of the teams was also generally aligned with the educational program being developed. For example, a school for home schoolers included parents of home schoolers, and a school associated with the manufacturing sector where students would apprentice had manufacturer representatives on its team. Respondents generally did not comment on the effectiveness of using a team approach. This was surprising given that schools state a collaborative team approach was used in most cases. Perhaps leaders of design efforts were not satisfied with their teams' work in that possibly could have impeded the leaders' vision of what the new school should become.

5. Impact on At-Risk Students. School leaders who designed new alternatives responded that the schools they developed had an impact on students at-risk of high school failure by providing new opportunities for them to learn in new kinds of school settings. Quantitative achievement data were not discussed in participating leaders' responses, but most leaders indicated that students atrisk of school failure often experienced positive behavioral changes as a result 
of attending a school designed to meet their needs and interests. This is important because in time at-risk students who become more engaged in schooling should produce better achievement.

This analysis revealed that the school designers who responded to the questionnaire would have benefited from having a comprehensive process for designing an innovative alternative high school, especially in having a consistent conceptual framework to follow. The design processes used to establish alternatives to traditional high schools were at times haphazard or only partially thought out. Sometimes they were assigned to an individual school administrator to lead. A team approach was often used, but the composition of the team was often limited to those with the most vested-interest in the design of the new school. Often a new alternative high school got underway before many of the operational details were determined. Using the alternative high school design process under development and studied in this dissertation, may have led to a more efficient implementation and operation of a new alternative high school.

\section{Step 5. Main Product Revision}

Preliminary field testing revealed that the educational product, in this case a design process for creating innovative alternatives to traditional high schools, was sufficiently developed and useful. The preliminary form of this product was developed based on a review of the literature and an actual application during the development of the South Coast high school described in Step 3. Revisions based on preliminary field testing centered on using preliminary field test data to improve the process in preparation for the exigencies of the main field test. Based on the data collected from surveys, 
presentations, and discussions, several revisions were made to the process for "Designing Innovative Alternatives to Traditional High Schools.”

Key revisions made to the high school design process as a result of preliminary field testing are as follows:

1. Vision Development. To fully develop a shared vision as the initial state of alternative high school design, it is important for design team members to understand regional accreditation standards as a framework for design, all of the elements of effective alternative schools, program evaluation, and the concept of starting over from scratch when design an innovative alternative high school. During the development of the prototype of the alternative school design process, design team members were left on their own to develop categories with which to develop a vision statement. This led to confusion and a breakdown in participants understanding of the creation of a shared vision. As a result of preliminary field testing, greater care is given to assisting team members to create a shared vision by providing key categories, such as “Teaching and Learning, "Beliefs," and "Community," during the protocol to create a shared vision statement. Fidelity to protocol in the development of vision was needed (Chenoweth \& Everhart, 2002).

2. Understanding the Elements of Effective Alternative Schools. To enhance the understanding all of the elements of effective alternative high schools, (see Table 9), preliminary field testing responses and discussions revealed that two activities needed to occur. The first is to hear "student voices" prior to the 
development of a shared vision. This consists of having prospective students on the design team itself, and having students who have experienced traditional and alternative high schools discuss their school experiences with designers. Secondly, once a shared vision is derived, field visits to existing alternative schools also increases understanding of the elements that make them effective. It was determined that revising the school design process to include student voice and an observation of model schools will increase the level of practical as well as theoretical relevance and awareness among design team members.

3. Program Evaluators. Following the design of the alternative high school, the design team may be used as a program evaluation team, as they are already most familiar with the expectations of the new school. Part of the process leading up to the formation of such a team is explaining program evaluation models and definitions of terms associated with program evaluation. These explanations should be presented in ways that are not too complex or obscure for design team members, as was observed in preliminary field testing. A logic model, for example, which begins with obvious statements of successful outcomes that are addressed by inputs and outputs seemed too theoretical to some participants during preliminary field testing. Terms such as "formative" and "summative" seemed familiar to most preliminary field test respondents, but further discussion revealed common definitions of such terms were 
sometimes lacking or misinformed. Care was taken to revise the high school design process in the area of program evaluation to define key terms.

4. Clarify Starting Over. A key aspect or assumption of the design process is that it is more efficient to start over from the beginning when designing an innovative alternative high school. Preliminary field test participants provided mixed responses when asked how essential this assumption was in the design process. Negative responses may have had to do with the extent to which school leaders were already invested in a model of traditional or alternative education when they began learning about the design process or as they began the design process. A key revision of the design process was to better define where leaders are in a school development process and if they are bound to a particular model of high school. The process was revised to carefully define what starting over means. Some leaders may have little concept of what they want and will readily agree to start over from the beginning to create something new; others may have solid mental models or even existing schools, which they seek to protect. Product revision allowed for a more clear definition of start over.

\section{Step 6. Main Field Testing}

In Fall 2012, I began collaborating with Drew Hinds, doctoral cohort member studying alternative school evaluation, to find a school district that would allow us to conduct research on designing and evaluating an alternative high school for implementation in fall of 2013. As researchers we quickly realized that due to severe 
budget constraints, school districts were currently challenged to find scarce resources to develop new alternative high schools. We were successful, however, in identifying Zeeland School District [pseudonym] in Oregon that had an existing alternative high school, Whyland School [pseudonym], which was interested in using our school design and evaluation processes. The Zeeland School District superintendent understood that going through the design process would clarify the vision and purpose of Whyland School and would increase communication between central office, the traditional high school, and Whyland staff. Zeeland School District is a mid-sized, suburban district located in a suburb of an urban area and representative in demographic composition of many other school districts. Zeeland was also very interested in utilizing Drew Hinds program evaluation process to determine the effectiveness of Whyland School. Zeeland's superintendent and senior central office staff members were very enthusiastic about using the design and evaluation processes. In conversation, the Whyland School's principal, who had led the school for many years and was nearing retirement, seemed less certain about the purpose of the processes. A decision was made to proceed and agreement was reached to begin main field testing in January 2013.

Under the auspices of the Zeeland School District superintendent, a design team for Whyland alternative school was identified. Design team membership was critical to the success of the design process and research into the process's improvement. Table 8 lists design team members by role or position and indicate members' experience in education. Attendance at meetings is noted by meeting dates. Except for the researcher/facilitators, names have been altered to protect anonymity. 
Table 8

Whyland School Design Team Membership

\begin{tabular}{|c|c|c|c|c|c|c|c|}
\hline & Name & Role & $1 / 23$ & $2 / 6$ & $2 / 20$ & $2 / 27$ & $3 / 13$ \\
\hline 1. & Drew Hinds (Facilitator) & Evaluation Consultant & $X$ & $\mathrm{X}$ & $\mathrm{X}$ & $\mathrm{X}$ & $\mathrm{X}$ \\
\hline 2. & $\begin{array}{l}\text { Chet Edwards } \\
\text { (Facilitator) }\end{array}$ & Design Consultant & $X$ & $\mathrm{X}$ & $\mathrm{X}$ & $\mathrm{X}$ & $\mathrm{X}$ \\
\hline 3. & James Jones & Whyland School Principal & $X$ & $\mathrm{X}$ & $\mathrm{X}$ & $\mathrm{X}$ & $\mathrm{X}$ \\
\hline 4. & Brewster McCloud & $\begin{array}{l}\text { Zeeland School District } \\
\text { Superintendent }\end{array}$ & $\mathrm{X}$ & $\mathrm{X}$ & $\mathrm{X}$ & $\mathrm{X}$ & $\mathrm{X}$ \\
\hline 5. & William Jameson & District Curriculum Director & $X$ & & $\mathrm{X}$ & $\mathrm{X}$ & $\mathrm{X}$ \\
\hline 6. & Sarah Silverman & District Services Director & $\mathrm{X}$ & $\mathrm{X}$ & $\mathrm{X}$ & $\mathrm{X}$ & $\mathrm{X}$ \\
\hline 7. & Rick Nelson & $\begin{array}{l}\text { Zeeland High School } \\
\text { Principal }\end{array}$ & $\mathrm{X}$ & $\mathrm{X}$ & $\mathrm{X}$ & & $\mathrm{X}$ \\
\hline 8. & Gilda Radner & Whyland Teacher & $\mathrm{X}$ & $\mathrm{X}$ & $\mathrm{X}$ & $\mathrm{X}$ & $\mathrm{X}$ \\
\hline 9. & Simon Garfunkel & $\begin{array}{l}\text { Teacher (Evening Program } \\
\text { Coordinator) }\end{array}$ & $\mathrm{X}$ & $\mathrm{X}$ & $\mathrm{X}$ & $\mathrm{X}$ & $\mathrm{X}$ \\
\hline 10. & Citizen Kane & $\begin{array}{l}\text { Neighboring District } \\
\text { Alternative High School } \\
\text { Principal }\end{array}$ & $\mathrm{X}$ & $\mathrm{X}$ & $\mathrm{X}$ & & $\mathrm{X}$ \\
\hline 11. & Jackie Onassis & Parent/Community Member & & $\mathrm{X}$ & & & \\
\hline 12. & Calvin Kline & Parent/Community Member & $\mathrm{X}$ & $\mathrm{X}$ & & $\mathrm{X}$ & \\
\hline 13. & Whyland Student & $\begin{array}{l}\text { Academy Program (Latino- } \\
\text { American Male) }\end{array}$ & & $X$ & & & \\
\hline 14. & Whyland Student & $\begin{array}{l}\text { Option Program } \\
\text { (Asian-American Female) }\end{array}$ & & $X$ & & & \\
\hline
\end{tabular}

The Whyland School principal was already familiar with regional accreditation standards and elements of effective alternative schools, and the principal agreed to use 
the design process as a means to create a description of an alternative high school, which in this application would be the product of the innovative alternative high school design process. The final program description for Whyland School is presented in Appendix C.

Development of the new description of Whyland School was the result of a series of five 2-hour meetings held in collaboration with myself, Drew Hinds, staff from Zeeland School District and external team members representing the parents of Whyland School. The first two meetings were led by me and devoted to the design process, and the third and fourth meetings were led by Mr. Hinds and used to develop an evaluation plan. The fifth meeting was used jointly by both Mr. Hinds and me to conclude this application of our prototypical design and evaluation processes and to collect final research data from the design team.

The first team meeting was used to create a common vocabulary or lexicon that would be useful in future discussions among disparate design team members. An annotated agenda showing this beginning stage of the school design process is presented in Appendix D. The second session of the Design Leadership Team was conducted 2 weeks after the first session. It was used to create a shared school district vision for Whyland School, based on knowledge gained by team members during the first session. That vision is presented on pages 3-4 of the "Program Description" (see Appendix C.) As previously stated, sessions three and four were used by Mr. Hinds to develop an alternative school evaluation process. During those sessions the team learned about program evaluation strategies, a key aspect or assumption of the school design process. Also during the time sessions three and four were being conducted, the Whyland School 
principal and I developed a draft program description that was presented to the design team at the conclusion of session four and briefly discussed. The description of Whyland School is based on an existing alternative school, except for the "vision statement" and "program evaluation" sections, which were newly created during this field test. In this research the full innovative alternative high school field test was truncated to the foundational steps of establishing a shared vision among school district staff and school community members. A full design process would involve 6-10 sessions during which subgroups would, in collaboration with the school principal and design process facilitator, create various subsections of the program description, such as a description of curriculum and instruction, which would serve as a "blueprint" for the alternative high school under development. Although the design process was abbreviated in this field test, team members were fully aware they were piloting a design process field test and they were also fully aware of the research questions being explored. Session five was used to debrief the design and evaluation team. After debriefing and discussion a survey (see Appendix A.) was given to team members. The results of that survey are presented in the "Evaluation Results" section of the chapter.

\section{Step 7. Operational Product Revision}

Operational revisions of "Designing Innovative Alternatives to Traditional High Schools" design process were based on the results of the main field test pilot, which took place over a 4-month period at "Whyland School." Feedback from school design team members was analyzed and taken into consideration for the operational revisions. Data included quantitative scores and qualitative comments in response to research questions. 
The design team was composed of a school district superintendent, district student services director, district curriculum director, traditional high school principal, alternative school principal, evening program coordinator, a teacher, and two parents. Students were interviewed by the team during the field test and their remarks contributed to the development of a vision statement. Revisions were made based on the researcher's field notes and discussions with team members. Suggestions for improvement were documented in debriefing discussions with the team after reflection on the process. The data collected was summarized to provide information about the potential effectiveness of the design process and to determine whether or not it would be a useful process for leaders in education who want to develop innovative alternatives to traditional high schools. Lessons learned and used to improve the design process from the data are presented in the next section of this chapter. Adjustments were made to the design process based on the team's experience and feedback. Areas in need of improvement were identified during main field test and based on research questions. Based on discussion with the team and with Drew Hinds, my collaborator in this research, this researcher was left with the ultimate decision for determining whether or not areas of concern about the process were generated by an issue with the process, or were only specific to the school situation in which the field test was conducted.

\section{Evaluation Results}

Gay et al. (2009) advised that results of a survey "should include the total sample size and the overall percentage of returns along with the response rate for each item because not all respondents will answer each question" (p. 185). Effort has been made to 
follow this direction throughout this section. Gay et al., (2009) elaborated data interpretation answers the questions: "What is important in the data? Why is it important? What can be learned from it? So what?" (p. 456). This section also addresses these questions.

At the conclusion of the fifth of five 2-hour sessions on designing and evaluating alternatives to traditional high schools, design team members were surveyed to collect data regarding the design process. Eight of $10(80 \%)$ team members were present for the fifth meeting. Mr. Hinds and I, as facilitator/participants and the two students who participated briefly in the design and evaluation sessions are not included in the pool of 10 potential survey participants. Unfortunately, the two parent team members were unable to attend the fifth session, during which the survey was conducted. During the first hour of the fifth session the design and evaluation processes were reviewed, followed by an hour for the team members present to complete the survey. Survey Monkey was used to administer the survey and collect quantitative and qualitative data into Excel spreadsheets.

Among the eight design team members who responded to the survey:

- All (100\%) were from the Portland Metro-Area

- All (100\%) were professionally involved with high schools (Grades 9-12)

- All (100\%) were experienced with small schools (enrollment approx. 150)

- All (100\%) were experienced with schools housed in their own building

- All (100\%) were experienced in working with small teaching staffs (10-15 FTE)

- All $(100 \%)$ were familiar with alternative and traditional high school environments 
Among the eight design team members who responded to the survey:

- Two were teachers, two alternative high school principals, two central office directors, one a traditional high school principal, and one a superintendent

- All eight had a combined total of 134 years of administrative experience

- Six of eight $(75 \%)$ held administrative licenses

- Six of eight (75\%) had had some prior participation in a design process leading to a vision statement and program description

Responses from survey respondents to research questions and results of the survey at the conclusion of the main field test are as follows:

\section{Research Question 1}

Is the process under development an effective process for designing innovative alternatives to traditional high schools?

Four of eight (50\%) participants responded positively to this question; two (25\%) had no response; two (25\%) had negative responses.

Participants who responded positively commented:

Yes this is a good process. The struggle is designing or redesigning when there is an existing school with a certain level of success. Questions arise: are we starting from scratch with a new plan? Changing what we have already built? The process is fully capable of creating innovative schools.

"Possibly, if truly designing from scratch."

"It was difficult to analyze in our context since we were attempting to lay it over an existing school and this was only partially successful.”

"If starting from scratch. More difficult to adapt to an existing school."

Participants who responded positively, above, recognized that the design process has the potential to assist teams such as theirs to create innovative alternatives to 
traditional high schools. What is important in their responses is that they also recognize that the design process was being applied to an existing alternative school, and the part of the process for starting over from scratch could not be used in this case. This is important because the design process was developed to help design new schools and not redesign existing schools. These respondents confirm, however, that the design process will be successful if applied to a new school. What can be learned from this is the importance of assuring that the design process is only applied to new school development in the future.

Participants who made no response, neither positively or negatively, also made no comment as to the effectiveness of the innovative alternative high school design process.

Participants who responded negatively commented:

It has potential, to be sure. But to be a realistic approach to developing a school, much more time should be invested and a more genuine effort to include a wider group of stakeholders (more teachers, other school staff, students, parents, community members) would be important. Not everyone needs to be involved at every level...

"The process did not capture key elements of an effective program. The steps we went through did not add any significant learning to the group."

Some important concerns are addressed in these comments. More time, perhaps 6-12 two-hour meetings, rather than two or three as was the case here, need to be devoted to the full design process. Greater involvement of stakeholders at different levels also needs to be part of the design process. Subsequent to creating a shared vision, different aspects, such as the development of the curriculum and instruction, or finding facilities, could be assigned to subgroups of the design team to accomplish and report back to the 
whole team. What can be learned is that engaging every team member requires rigorous design process planning and execution.

Overall, analysis of these responses shows mixed results, with some respondents indicating the process was effective or potentially effective, and some indicating the process was ineffective. The major sticking point throughout was a lack of agreement or understanding of the assumption that it is more efficient to start over from scratch when designing an alternative high school. These responses indicate a lack of clarity regarding the purpose of the design process when it was applied to this situation. Was the process being used to design a new alternative high school or redesign an existing school? Most responses indicate the alternative high school design process would be effective if applied, as it was conceived, to starting over from scratch to design a new alternative high school, rather than redesign an existing alternative high school.

\section{Research Question 2}

What obstacles have school leaders experienced when attempting to design an alternative school? How well does the proposed process address those obstacles?

All eight participants (100\%) responded that they had experienced obstacles when designing an alternative school. Six of eight (75\%) of respondents who experienced obstacles chose to comment about the process under development:

"I understand the purpose of "starting over", (sic) but significant work has been

done at this school and I found it frustrating that we didn't have an opportunity to discuss that first." 
"The process stunted.key (sic) discussions which would have broughtvforth (sic) key information."

As above, when to jump in the design loop-new school design or changing existing practices and systems. The other challenge is getting a good cross section from the community to help with the process. A question that kept coming to my mind was: What are the district's student needs?

"Poor match between participants expectations of process and that of facilitator. A bit of trying to fit a square peg into a round hole."

"Yes, but because of the context, not the tool."

"School has an existing design."

As in Research Question 1, the obstacle was the lack of agreement or understanding about the concept of starting over which led to frustration among participants. Though respondents seem to agree the design process would be effective in starting a new alternative high school, the context of applying the design process to an existing alternative school created an obstacle to meeting participants' needs. It appears to be clear from these responses that future usage of the alternative high school design process should only be applied the development of new and innovative alternative high schools, and not to existing alternative high schools.

As an alternative lesson that can be learned from these responses, consideration should be given to de-emphasizing the start over aspect of the design process when applying the design process to existing alternative schools. The idea of starting over was meant to give team participants the opportunity to set aside past history of the existing school and to start fresh and to encourage innovation in team members' thinking. A facilitator of the design process will have to deal with the fact that some team participants 
will like the current school and will not be ready to start over. A protocol to address these kinds of concerns among participants who are not bought into the start over concept must include a leadership strategy that causes team members to achieve a share vision based on school symbols and complete understanding of the school's culture. In an existing school that wants to use the process to redesign, a vision that has already been created could be shared in creative ways with new team members and "refreshed" or restarted. Perhaps the concept of "restarting," rather than starting over would have been more acceptable to participants in the main field test. Restarting honors the successes of the existing alternative school, rather than offending its leaders.

Overall, it is my view that the alternative high school design process will be best applied when starting a new alternative high school from scratch. As discussed previously in this dissertation, I believe it is more efficient to begin from the beginning when designing a new alternative highs school.

\section{Research Question 3}

How essential are the four assumptions imbedded in the process regarding what leaders need to know?

This section is expanded to show survey results, both quantitative and qualitative, regarding the importance of the four assumptions upon which the innovative alternative high school design process being studied is based

To introduce these tables, it is important to know that the first 2-hour meeting of the design team was devoted to helping its members construct a common language or lexicon about the assumptions embedded in the school design process. Team members 
learned by defining and discussing each of the 10 accreditation standards and elements of effective alternative schools discussed in the review of the literature. The concept of starting over was also introduced. Program evaluation was thoroughly discussed as part of Mr. Hinds presentations in the third and fourth 2-hour meeting of the alternative high school design team and as part of the main field test.

Tables 9, 10, 11, and 12 present data related to Research Question 3. Analysis of responses is presented after each of the following tables.

Table 9 reflects participant responses to their understanding of considering all of the essential elements of effective alternative schools when designing innovative alternatives to traditional high schools.

Table 9

Essentialness of Elements of Effective Alternative Schools

\begin{tabular}{lll}
\hline Respondents' Scores & Rating & Respondents' Comments (Optional) \\
\hline $\begin{array}{l}\text { How essential is considering all of the elements of effective alternative schools simultaneously when } \\
\text { design an innovative alternative high school? } \\
4\end{array}$ & Absolutely Essential & \\
3 & Moderately Essential & Needs to have a clear understanding by \\
& all of who is served. \\
4 & Ao Response & \\
2 & Absolutely Essential & \\
4 & Somewhat Essential & \\
4 & Absolutely Essential & \\
4 & Absolutely Essential & \\
\hline
\end{tabular}

Average Score

$(n=7$ of 8$): \mathbf{3 . 5 7}$ 
Scores indicate that most respondents agreed with the necessity of considering all elements of effective alternative schools when designing alternative high schools. The comment indicated that a clear assessment of student needs should be completed prior to the design process so that the elements have a context and meaning to design team members.

Table 10 reflects participant responses to their understanding of using effective leadership strategies to start over when designing innovative alternatives to traditional high schools.

Table 10

Leadership and Starting Over

\begin{tabular}{lll}
\hline Respondents' Scores & Rating & $\begin{array}{l}\text { Respondents' Comments } \\
\text { (Optional) }\end{array}$ \\
$\begin{array}{l}\text { How essential is using effective leadership strategies to start over } \\
\text { alternative high school? }\end{array}$ & \\
2 & Somesigning an innovative \\
1 & Not Essential & We were offended by the term \\
No Response & "starting over." \\
2 & Should have strong leadership. \\
No Response & \\
2 & Somewhat Essential & \\
No Response & & \\
2 & Somewhat Essential & \\
\hline $\begin{array}{l}\text { Average Score } \\
(n=5 \text { of } 8): \mathbf{1 . 8 0}\end{array}$ & &
\end{tabular}

As in previous research questions, these scores and comments indicate that applying the concept of starting over in the wrong context can create a barrier to school 
design. One respondent was offended by the notion that the school studied would consider starting over and re-conceptualize its purpose. This participant assumed that starting over implied there was something wrong with the existing school, or that it needed to be "fixed." This comment is significant in that despite the efforts of the process facilitator to explain that start over was about conceptualizing the school design from its beginning, the participant heard the concept as an insult to the existing school. An assumption that the school was failing was never made or implied when discussing the design process. A leadership strategy that may have ameliorated this perception would have been to ask design team members to think about "restarting" rather than starting over, which some design team members perceived as disrespectful of the existing alternative school and its perceived successes. Sharing an established vision may have been more effective in this context. Or, this concern may be less complex. Some people simply like the status quo and the language of starting over was perceived as an external threat.

Table 11 reflects participant responses to their understanding of using accreditation standards as a framework for designing innovative alternatives to traditional high schools. 
Table 11

Using Accreditation Standards as a Framework for Design

\begin{tabular}{|c|c|c|}
\hline Respondents' Scores & Rating & Respondents' Comments (Optional) \\
\hline \multicolumn{3}{|c|}{$\begin{array}{l}\text { How essential is using accreditation standards as framework for designing an innovative alternative } \\
\text { high school? }\end{array}$} \\
\hline 3 & Moderately Essential & \\
\hline 4 & Absolutely Essential & \\
\hline \multicolumn{3}{|l|}{ No Response } \\
\hline 3 & Moderately Essential & \\
\hline 2 & Somewhat Essential & $\begin{array}{l}\text { Need to follow IF current and up to } \\
\text { date. Standards used in this process } \\
\text { were dated. }\end{array}$ \\
\hline 4 & Absolutely Essential & $\begin{array}{l}\text { You should align all of your supports to } \\
\text { your mission if you would like to be } \\
\text { successful. }\end{array}$ \\
\hline 3 & Moderately Essential & \\
\hline 4 & Absolutely Essential & \\
\hline
\end{tabular}

Analysis indicates somewhat favorable responses to the assumption of using accreditation standards as a framework for alternative high school design. Regarding the comment about dated standards, as a certified Lead Evaluator for AdvancED, I can report that the NWAC was recently subsumed by AdvancED, which uses virtually the same standards as NWAC, but reorganized for efficiency. Therefore, the use of NWAC standards as a framework for alternative high school design remains valid. The comment about aligning supports for learning with the mission or purpose of the school being designed is important and should be applied as a design team works through supports in creating the description of a newly designed alternative high school. The accreditation standards are universal, but different combinations or variations of standards, such as 
discussing Purpose and Direction, rather than "Mission and Vision," may be more successful and perceived as more modern. What is important from analysis of this information is to recognize the situational or contextual preparation that needs to occur prior to implementing the alternative school design process.

Table 12 reflects participant responses to their understanding of planning for program evaluation from the beginning when designing innovative alternatives to traditional high schools.

Table 12

Program Evaluation That Begins With the End in Mind

\begin{tabular}{|c|c|c|}
\hline Respondents' Scores & Rating & Respondents' Comments (Optional) \\
\hline \multicolumn{3}{|c|}{$\begin{array}{l}\text { How essential is planning for program evaluation from the beginning of the process for designing an } \\
\text { innovative alternative high school? }\end{array}$} \\
\hline 3 & Moderately Essential & \\
\hline 3 & Moderately Essential & \\
\hline \multicolumn{3}{|l|}{ No Response } \\
\hline 3 & Moderately Essential & Probably a good idea. \\
\hline 3 & Moderately Essential & \\
\hline 4 & Absolutely Essential & $\begin{array}{l}\text { It is imperative that the design will be } \\
\text { carried through from inception to } \\
\text { implementation. Often what is said is not } \\
\text { done. }\end{array}$ \\
\hline 4 & Absolutely Essential & \\
\hline 4 & Absolutely Essential & \\
\hline
\end{tabular}

Average Score

$(n=7$ of 8$): \mathbf{3 . 4 3}$

Respondents scored this section between moderately and absolutely essential, indicating agreement with the assumption that consideration of program evaluation throughout the design process is probably important. Comments showed agreement with 
the overall score. The second comment suggested fidelity to the evaluation plan, as it is conceived during the alternative high school design process, must be maintained throughout the stages of development of a new school, otherwise, assessment may be sought for events that do not occur.

\section{Research Question 4}

How does using a design team impact or improve the school design process?

Among the eight participants in the survey, four (50\%) responded positively, two (25\%) responded negatively, and two $(25 \%)$ made no response.

Among the four who responded positively, three commented:

"Good ideas, but needed to be a more well-rounded team with more time to work together."

"They are a very knowledgeable group with a vested interest in student success."

"Will work well if starting from ground up."

These comments are important because they recognize that a well-developed team that works together as team has the ability to design innovative alternative schools. Knowledge exists within a group that is fully committed to the process. Part of that process could be a team that is also committed to starting the design process for a new school, from scratch.

Those who responded negatively commented:

"The design team did not feel the process was supportive of the outcome the team was working toward."

"Not clear how this information will be used or incorporated into the school." 
These responses indicate the importance of making certain every design team member understands the intent of the process. In this case research was being conducted about a new alternative school design team, but applied to an existing alternative school. As discussed previously, clear outcomes may be better situated in a context in which a design team is formulating a new alternative high school from "square one" or its initial conception.

Overall, participant feedback indicates a team approach is desirable when designing an alternative high school. A clear purpose, a well composed and knowledgeable team, adequate time to work together, investment in student success, and team consensus or agreement about starting from scratch are desirable components for fostering teamwork leading to the design of an alternative high school.

\section{Research Question 5}

What impact can this process potentially have on students at-risk of high school failure?

Among the eight participants in the survey, three (37.5\%) responded positively, three $(37.5 \%)$ responded negatively, and two (25\%) made no response.

Those who responded positively commented:

"Allowed for parent and student voices to be heard."

"I believe it is possible. In my years working with at-risk youth, I have found alternative schools are the last hope for the disenfranchised."

"Potentially, yes. To be determined." 
These responses are important because they recognize that the design process has the potential to have an impact on students at-risk of high school failure, though further research would be necessary to determine the design process's impact on student achievement, for example. Student and parent voices need to be heard in all instances of designing alternative high schools, but student and parent voices may be particularly important in designing alternative schools specifically for at-risk youth. As it may be assumed many leaders want to design alternatives specifically for youth at-risk of failing to complete high school, future applications of the design process may focus on that student population, their needs and their interests.

Among the three respondents who responded negatively, two commented: "no (sic) way to judge that yet!"

"No data or knowledge of how this will be used to be able to respond."

These respondents recognize the need for quantitative data on student achievement to determine over time if a newly design alternative high school will have a positive impact on youth at-risk.

Overall, some responses indicate potential for the design process to lead to the development of alternative high schools that will have success with students at-risk of school failure. Other responses indicate it was unclear at the time the survey was given as to how the design would be used specifically to meet the needs of at-risk youth. The work of the design team was to create a shared vision for the ideal school for students served by Whyland School. Though many students at Whyland were at-risk, and parents and 
students were interviewed as part of creating a shared vision, although the label "at-risk" was not specifically used or discussed.

\section{Final Product Revision}

"Designing Innovative Alternative High Schools" was developed to provide a facilitated guide for school leaders who need a process to create alternatives to traditional high schools. The process was developed using an R\&D process, which included a review of the literature and preliminary and main field testing as a means to validate and improve the process through iterative revisions. The school design process followed the first seven steps of the $R \& D$ process as presented previously in this chapter. The process was reviewed by 22 "experts" in alternative education who provided feedback and data for formative evaluation of the process's content and usefulness. All suggestions, notes, and comments were considered for improvement of the process. The school leaders surveyed provided valuable information on the design process, especially during the main field test, as the facilitator used the design process to guide a team of internal and external community stakeholders through a process that resulted in a description of an alternative high school. The researcher used five research questions as the means for sharing the design team's experience as the process was tested. The PBL and R\&D process resulted in the development of an alternative high school leader's design process that will be ready for dissemination and implementation in a school setting after further revision, which is discussed in chapter 5 of this dissertation.

Key revisions were presented previously in the Step 5, "Main Product Revision," of this chapter. Briefly stated, those revisions were: (a) recognizing the criticality of 
having a shared vision among design team members and devoting enough time and guidance for the development of a vision statement; (b) understanding the elements of effective alternative high schools by having team members hear from students with experience in traditional and alternative high schools, and by visiting existing alternative high schools; (c) better defining key terms used in the area of program evaluation; and (d) carefully defining what is meant by starting over when working with a design team.

Although some of the above revision improved the innovative alternative high school design process, additional revisions or modifications were needed as a result of preliminary and main field testing. Those revisions are as follows.

Ample time, approximately four hours, and adequate facilitation was devoted to developing a shared vision during the main field test. A lexicon of common terminology was pre-learned and a creative process for developing a written shared vision statement was facilitated by the researcher as a facilitator/participant. As previously explained, the facilitator guided and instructed the design team through the assumptions and their related concepts prior to the development of a shared vision statement. Due to the way the main field test was established, however, a fully creative environment for innovation was never achieved. Greater leadership efforts need to be made in future application of the design process to ensure team members have established trust and communication, as well as a common language, as they work together to create a shared visions. Forms of leadership that may be conducive to building common bonds among design team members are explored in the literature review of this dissertation, and include cultural and symbolic, visionary, and historical leadership. For example, meaningful symbols for the 
school can be created and shared that will increase team bonding and cohesiveness prior to starting the vision development part of the process. Concepts associated with such leadership strategies could be better employed during future applications of the design process.

During implementation of the design process, the design team learned and internalized the importance of considering all elements of effective alternative schools. Hearing "student voices" reflecting on some of the elements during the development of the team's shared vision reinforced team members' learning. This is reflected by relatively high average score shown in Table 9 in which team members were asked about the importance of incorporating all elements simultaneously into the design of an innovative alternative high school. Time did not allow, however, the opportunity to visit other existing innovative alternative high schools which would have given the team different perspectives on the possibilities of what a high school can be. Such visits may have also reinforced team bonds and communication, the need for which was explored in the preceding paragraph of this chapter.

Considerable time was used by Mr. Hinds during his portion of team meeting to discuss terminology associated with program evaluation. The design team became well grounded in program evaluation at different levels and views and segued into an evaluation team by the end of our series of five team meetings. Basically, Mr. Hinds addressed aspects of program evaluation that align with the accreditation standards and elements of effective alternative schools. These concepts were: Shared vision and mission, curriculum, instruction, assessment, structures, engagement, and leadership. 
Rather than being discouraged by the low ratings shown in Table 10, the response demonstrated the criticality of having consensus among team members regarding starting over when designing an innovative alternative high school. This is very important finding and there is no need to see the low rating on Table 10 as a failure. It reinforced the knowledge that some people will tend to defend elements of a system even when they think it is not working well. What was found was that in the system studied there was not a unanimous readiness to start over by moving away from current practice. Despite the facilitators efforts to encourage participants to think out of the box some perceived the same language as an outside threat. In the case of Whyland School" specifically, it appears central office staff wanted a fresh idea of what the school had to offer, but school staff did not want to start over, but perhaps wanted to build on what they had. Although considerable effort was made to establish a common definition and agreement to start over when conceptualizing an ideal alternative school, some individual team members were unable to let go of their mental constructs and personal territories or histories as to what an alternative high school can be. In the future more time must be given to establishing an early agreement among team members that they will trust that the school design process will lead to a mutually satisfactory outcome. A common belief must be established early that starting over when conceptualizing an alternative high school will encourage open discussion and spur creativity and innovation.

In addition to the expanded and updated revisions originally delineated in Step 5, above, another critical other needed revision emerged from field testing. At the beginning of this dissertation I described four simple phases of overall new school development: 
Needs $\rightarrow$ DESIGN $\rightarrow$ Implementation $\rightarrow$ Improvement. The design phase is the focus of this dissertation. However, a key revision of the design process in the future is to assure an adequate needs assessment that ascertains the culture (and politics) of the organization around key concerns is developed first, so as to be certain a new design is needed. Once the need is described, part of the process should be for a key leader, hopefully a school district superintendent, to deliver a "charge" to that team that will set the stage for collaboration toward the goal of an innovative design.

Similarly to an adequate needs assessment, greater consideration of the composition of the design team needs to be not only delineated but achieved. Considerable care went into defining the original composition of the design team for the main field test, for example, to include both internal and external stakeholder, and especially parents and youth. As the main field test sessions progressed, however, team composition devolved into primarily internal stakeholders. Agreement must be achieved at the initial meeting of a design team that each member is committed to attendance at all meetings for the duration, and that additional members, who have not been adequately brief, may not join the team once it is underway. Careful team composition is essential to achieving the desired outcome of any change process; in this case a process for designing innovative alternatives to traditional schools (Chenoweth \& Everhart, 2002).

\section{Field Testing Issues/Challenges}

In some cases during preliminary field testing involving school leaders experienced in designing alternative high schools, it was difficult to help them understand the time and effort necessary to complete the survey and some were reluctant to complete 
it. Phone conversations and personal visits to explain the extent of the commitment to completing the survey were conducted by the researcher. This extra assistance did not affect the anonymity of the completed surveys, however, as no identifiers of specific schools were indicated in written responses.

Regarding the main field test, as in all other areas of education, preparation is everything. A "Scope of Work" was created prior to main field testing sessions, but it should have more fully address the concerns that resulted in the process revisions discussed previously in this chapter. Greater care should have been taken in preparing and achieving a complete understanding through a more accurate written agreement as to the goals of the project. A better assessment of student needs could have been conducted prior to the design process, although the scope of the research was limited to the application of the process itself. As alluded to in the previously in this chapter, the context and circumstances of the main field test were less than ideal, resulting in a somewhat truncated process. More time and preparation as to the goals or purpose of the project would have increased participation and understanding of research goals among some members of the design team. Finally, it is important to be clear whether the current school really is broken, and if so, emphasize that starting over means starting from scratch.

On the positive side, this experience was an important discovery of the research. It highlights the importance of a facilitator of really getting to know the culture of the school or district and how people are feeling about the changes they are being asked to 
make. Who will gain and who will lose in the change and how will that plays out during the process is also important to know.

\section{Summary}

"Designing Innovative Alternative High Schools" was researched and developed to provide a process for school leaders to follow as they form teams to create alternative forms of schooling that are different from traditional high schools. The process was developed using the R\&D process, which included an extensive literature review, an assessment of needs, and two preliminary field tests leading to validation and revisions. Then the process was utilized at and existing alternative high school for the main field test and operational product revision. The first seven steps of the process are outlined in this chapter. The product was reviewed by 22 “experts' in the field who provided formative evaluation of the process's content, format, and practicality. All suggestions, notes, and reviewers' comments were considered for improvement of the design process. The alternative high school design team provided a wealth of information on the usefulness of the design process. The researcher acted as a facilitator/participant and used five guiding questions as the format for sharing and understanding the alternative high school's experience using the design process. The educational R\&D process, based on a problem in the field of education, resulted in the development of an alternative school design process ready for future dissemination, implementation, and application in school settings. 


\section{CHAPTER 5}

\section{CONCLUSIONS, SPECULATIONS, AND RECOMMENDATIONS FOR LEADERSHIP}

“We don't need evolution in education, we need revolution in education."

-Sir Ken Robinson

This chapter summarizes the R\&D of a PBL product, Designing Innovative Alternative High Schools, which is a process through which school leaders learn what they need to know to create alternatives to traditional high schools. Specifically, this chapter discusses the overall assessment of the research experience; further discusses the results of the operational product revision (Step 7 of the R\&D process); speculates about further operational field testing, development, and dissemination for use of the school design process (Steps 8, 9, and 10 of the R\&D process). Lastly, this chapter provides recommendations for further study as well as recommendations for school leadership.

The intent of this study was to construct, field test, revise, and improve an educational product that addresses a real world problem in education. In this case the problem is leaders in education lacking the knowledge and a process to guide them in the creation of alternatives to traditional high schools. The national high school dropout crisis is a major indicator that an alternative high school design process is needed. An educational leaders' process was developed using the R\&D methodology recommended by Borg and Gall, (1996). The R\&D methodology used to develop the school design process consisted of the first seven steps of the R\&D cycle (see Table 1). The topic on which the school design process is based was established through extensive professional experience of the researcher and through a review of the literature. Discussions with 
professional educational administrators ranging from principals of schools from urban, suburban, and rural districts as well as state department of education and central office administrators, especially school district superintendents, further developed the researched concept.

A prototype of the product, an alternative high school design process, was developed prior to the 2011-2012 school year and used to develop a new and innovative alternative high school in the South Coast region of Oregon. Formal preliminary field testing first began in October 2012 at a statewide conference during which participants reviewed assumptions associated with the design process. Secondly, preliminary field testing also included evaluative feedback from five school leaders who had previously designed innovative alternative high schools. The product was then revised and improved based on the preliminary findings, and the main field testing occurred for further validation. The main field testing began in February 2013 at Whyland School. This field test utilized a local design team with two facilitator/participants who lead the team through closely related design and evaluation processes. A product of the design process was a comprehensive program description of an innovative alternative high school. The description is useful in that it serves as a "blueprint" for the implementation and evaluation of the alternative high school. It also serves as a mechanism to alert the internal and external school communities about the design of the alternative high school.

\section{Overall Conclusions and Assessment of the Experience}

The overall purpose of this study was to create process to assist school leaders to successfully design innovative alternatives to traditional high schools. At the same time, 
an underlying purpose was to reform or reshape the schooling experience of youth who are unsuccessful in traditional high schools. The following research objectives were achieved.

1. The literature review revealed there is a lack of information in the form of a systematic process for designing innovative alternatives to traditional high schools (Barr \& Parrett, 1997, Wilson \& Daviss, 1994). Having an objective design process will be a more efficient use of resources than using haphazard processes to create alternative high schools based on student needs and interests.

2. The literature review supported the contention that the United States continues to have a high school dropout crisis, with more than one million students annually unable to graduate in four consecutive years (Heckman \& LaFontaine, 2007; NCES, 2011b). "Square pegs in round holes" is an expression often used to describe the relationship of a quarter to one third of our nation's youth to high school education. A process to help school leaders create schools that meet the needs of all students is a significant research goal.

3. The process for designing innovative alternatives to traditional high schools was developed using an R\&D process to evaluate and improve the process. High school leaders who have been shown the process have expressed a high interest in using it to create new alternatives to their traditional high schools or to design new alternatives to replace alternative programs that have been 
discontinued. Having alternatives to traditional schools will enable more youth to complete high school in unconventional ways.

4. The design process for educational leaders to create innovative alternatives to traditional high schools was further refined and developed by the design team engaged during the main field test. Although the context of this research was less than ideal, significant learning was gained as to how to better facilitate and deliver the design process in the future.

When I began this dissertation, I asked others and myself what do leaders need to know to design innovative alternatives to traditional high schools? I began studying, learning, and relearning and felt it was a significant topic to address after completing many years of involvement in alternative education as a teacher, building administrator, district office administrator, and consultant. Those experiences shaped my ability to create a process for school leaders that gives them the tools to design alternatives to traditional high schools that may impact the dropout crisis. Through a variety of roles in education, and especially as a speaker at local, state and national educational conferences, I came to the belief that such $\mathrm{R} \& \mathrm{D}$ of a better design process would be beneficial to school leaders and lead to the development of more innovative high schools.

During the last few years, as a researcher I have utilized most of the concepts embedded in the design process through a variety of presentations to educators. One of these presentations, in partnership with Drew Hinds, was to jointly share our processes for "Designing and Evaluating Alternative High Schools" at the National Dropout Prevention Conference (NDPC) in Chicago in November 2011. Our session had 90 
participants; other conference sessions averaged 20 attendees. One month after that conference Mr. Hinds and I followed up as guests of an hour-long NDPC podcast that is available on the web. On a smaller scale, I have used my research to facilitate local professional development opportunities with small alternative schools. As an example, I led the staff of Rosemary Anderson High School, part of the Portland Industrialization Opportunities Center through an activity to determine the extent to which their school was addressing all 10 of the elements of effective alternative schools-the outcome of the activity was very favorable to their meeting requirements in all the elements. Also, recently I refined my research skills through work for the Clackamas County (Oregon) Juvenile Department and Clackamas Education Service District by conducting a needs assessment of youth involved in the juvenile justice system not attending high school. Under the leadership of the Clackamas County Juvenile Department director and the Clackamas Education Service District superintendent, a design team was formed and using my facilitation, the team created a shared vision of what the ideal high school would look like for the youth in question. I presented the needs assessment and vision statement to school district superintendents county-wide and as a result that work is currently being used to begin to establish a system utilizing existing and emerging alternative high schools to meet the educational needs of delinquent youth.

During this experience I have continually been surprised by the amount of information and positive feedback received. I have received information from educators through email, phone calls, letters, and personal meetings. Throughout this dissertation work, I have been invited to participate in statewide and national conferences as a 
speaker, facilitator, and educational consultant. This dissertation has opened up new opportunities for sharing my expertise and experience. Three school systems have already benefited from the process and related resources provided in the process to design innovative alternative high schools. Working through the R\&D process of the dissertation during the past few years, I have gained a deeper understanding of research coupled with the application of research to create a school design process that can assist school leaders in creating a positive and sustainable change to benefit students for years to come.

Assessing the experience, I believe I have experienced growth both as a researcher as well as a leader in group process, which is an essential role of an educational administrator. When challenging others assumptions, particularly those related to the basic building blocks of school design explored in this dissertation, I have learned to overcome resistance to change by using concrete data and examples from educational research. An aspect of this work that I thoroughly enjoyed was helping disparate individuals form a team with a common purpose, based on identified student needs, to create a shared vision of the kind of innovative school that will meet those students' needs. I have seen and been responsible for divergent opinions, from the hardcore traditional high school principal who believes teenagers should "shape up or ship out" to the art teacher who believes kids will do better if they are just hugged every day, coming together with creative ideas and a shared vision of how reluctant learners can indeed learn. Throughout the process of completing my doctoral work, I have learned to look at situations in new ways. Before, especially as a school district administrator, I believed it was necessary to seek quick solutions, decisions, and actions, as I had seen 
other leaders do, and to ignore or disregard the need for educational research. This process reminded me of the necessity to look at the whole scope of a problem, practice due diligence in seeking a range of answers, and make the best decision based on data which will enhance that decision's chances of success.

The next sections of this chapter discuss future research and goals, development, and use of the product. The discussion first requires a review of the current conceptual framework of the process for designing and evaluating innovative alternative high schools. This framework is represented in Figure 3.

Figure 3 presents four assumptions that are central to the knowledge leaders need to design innovative alternative schools are presented. The "stairs" on the left represent the accreditation standards that address the expectations, educational program, and supports for learning any school needs. The stairs on the right are the elements of successful alternative schools. The rectangle in the middle represents program evaluation. The fourth assumption, that it is more efficient to start over from the beginning when designing an innovative alternative school, is embedded in the entire design process. My colleague, Drew Hinds, conducted concurrent and collaborative dissertation research that is also represented by the central rectangle and its components. 


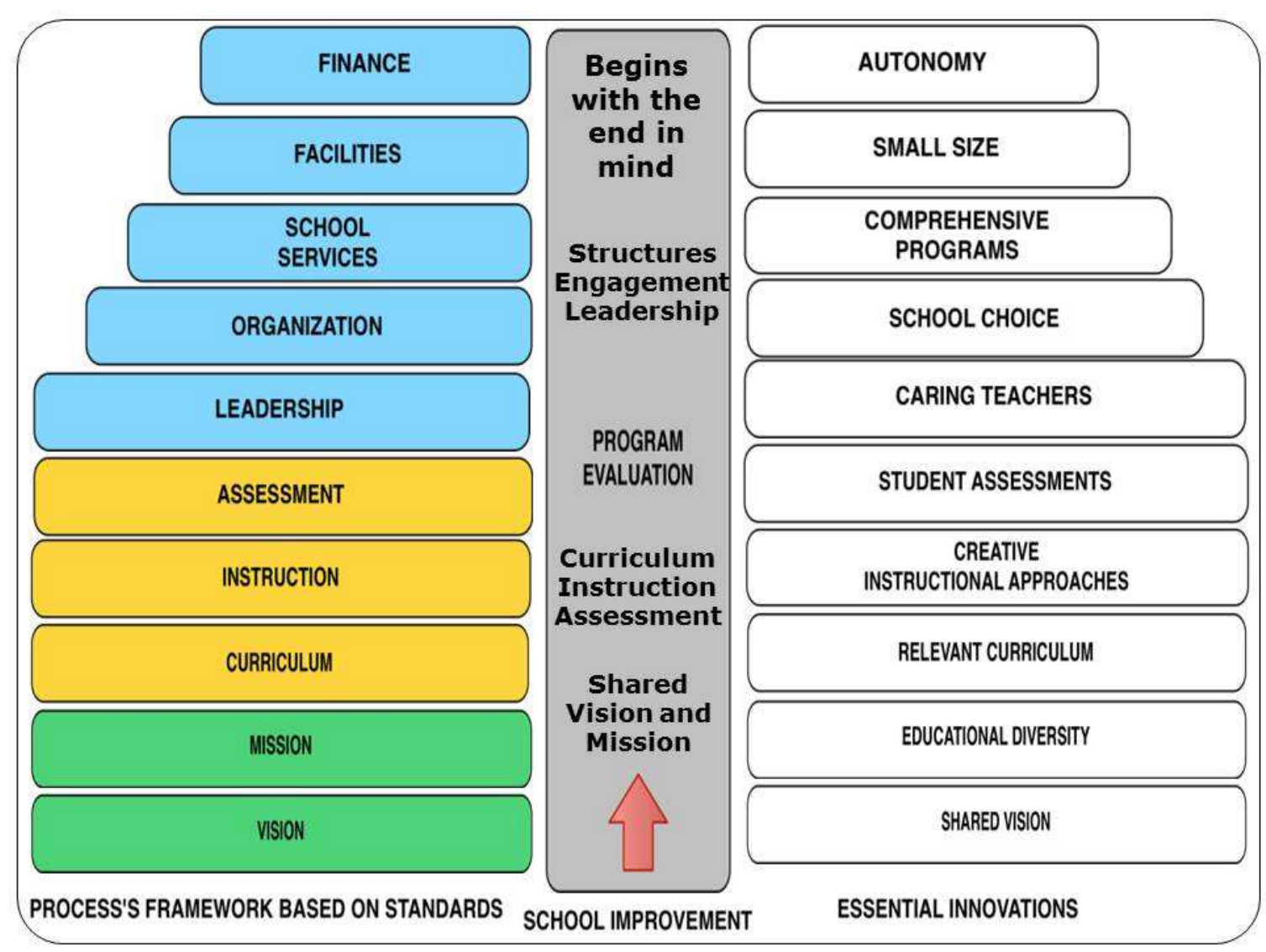

Figure 3. Designing and evaluating innovative alternative high schools.

\section{Future Research and Goals}

Future field research and goals that will make the educational product operational include: monitoring the need for alternative high schools; and, developing and implementing successful design teams where needed. Finding out where and why alternative high schools are needed will be important research that will determine where design processes are also needed. This research could be done in conjunction with assessing high dropout rates throughout a state, for example, studying causation, and offering solutions through the school design process. Implementing local design teams that are efficient and successful will also be a topic of future research. These topics 
emerged during the dissertation process. Topics related to high school dropouts in particular spurred interest during meetings and discussions with school leaders at association conferences and workshops. These are also topics with which school leaders must be familiar if academic rigor and success for all students is to be achieved each year, and as states are moving to a growth model to monitor the achievement of every student. Future research topics such as those just described may lead to publishing of educational articles and more national presentations.

Another research interest is focused on developing model high schools for the future. Some people recently asked me what I thought high schools would be like in the future. I told them I did not know, but I believe it is my job to create and facilitate a process by which individuals and groups of individuals working together can use research coupled with state and national standards-based conceptual framework to create their own future oriented high schools. Developing innovative models, and finding the human and fiscal resources to carry out that development, is part of my research interest. One model that seems to hold promise is a hybrid of online learning coupled with a place where students can regularly learn under the supervision of a trained teacher. This kind of school seems to be proliferating rapidly, but rather than simply replicate such a program locally, I will advocate for working with a design team to first achieve a shared vision for what will work for their students, then look at models that may fit their vision. This part of the process will benefit from further operational field testing and refinement of my own design process. 
Short-term goals include continuing to present at local, state, and national conferences. Another short term goal is to make more school district superintendents aware of the alternative high school design process. I also plan to continue as an active member of Portland State University's Educational Administration doctoral cohort, to support colleagues as they work to complete their dissertations.

Long-term goals include developing and evolving the design process into a graduate course for aspiring school administrators and leaders. The course would involve classmates working together to design a comprehensive model of an alternative high school. I would also like to develop the process into a publishable educational textbook. The National Dropout Prevention Center at Clemson University has previously expressed interest in this effort. Future career goals include working as a consultant to schools and school districts seeking new alternative high schools, and serving in a professorial role to teach aspiring administrators at the graduate level to think creatively about what schools of the future can be.

\section{Development}

The first seven steps of the R\&D process led to the development and improvement of a process to design innovative alternative high schools. Taking this process, an educational product, to scale requires completing the last three steps of the R\&D process: operational field testing, final product revision, and dissemination and implementation. The remainder of this section explores where those research steps may lead. 


\section{Step 8}

Operational Field Testing: This step could be accomplished in a variety of ways, but good opportunities exist for school districts in rural, suburban, and urban settings to apply the process. As an example, I was recently in South Dakota and a principal from a small, rural community told me his district's alternative program was not successful and his district could benefit from starting over to develop a new alternative school. Using the process in different settings and studying obstacles and successes in its use would support future revisions.

\section{Step 9}

Final Product Revision: This step includes improvements, editing of text, and further refinements made after analyzing the feedback from the operational field testing. During this step the product could be turned into a publication, perhaps a guidebook that would be professionally edited and reviewed by a graphic artist for visual design. The final revision would present the design process in both visual and textual form that has a more appealing layout than the researcher was able to create in the prototype guidebook.

\section{Step 10}

Dissemination and Implementation: This step involves ways to make the product more widely available to school and school district leaders. This may be achieved in a number of ways such as getting the "guidebook" published by a regional education services district, state school board association, state association of school administrators, state department of education, or a publishing firm. Self-publishing is another viable option available. As a researcher and facilitator I could offer professional development 
opportunities, perhaps under Title IIa, which are Federal resources that can be used by local school districts for ongoing professional development, to support designing innovative alternative high schools in local school districts.

Various applications of how the design process can be used are starting to emerge. The most obvious application is for a local school district to go through the needs assessment, design, implementation, and improvement phases of new school development. This application could be done by any school district wanting to start a new and innovative alternative high school, or by a school district wanting to discontinue an existing but unsuccessful alternative school and start a new one. Several schools or school districts could also collaborate regionally to develop a new alternative school. Other applications of the design process could be realized using parts of the school development process ad hoc. For an example could be a local community organization or agency using the needs assessment and shared vision parts of the process could create a political catalyst for a school district to address the needs of at-risk youth. Whether school leaders or school districts enter into the process is dependent on the capacities of the school leaders and school districts to use the process.

Educational research related to school reform could also benefit from the application and use of the design process. A researcher could determine if the process could be used to design any school, not just alternative high schools for at-risk youth and dropout prevention. School systems in various states could pilot the design process to determine how it can be applied in a different contexts and cultures. Researchers could also discover how adjustments to the process could assist school leaders in leading 
reform efforts. Large scale research could include using the process to transform schools on statewide and even national levels. Such a study could measure the effectiveness of the design process and monitor the sustainability of newly design schools over time.

\section{Recommendations for Leadership}

Research has shown that leadership actions can foster transformational change (Gardner, 1995; Heifetz \& Linsky, 2002). The following is a list of recommendations for leadership based on my experience as a researcher studying what leaders need to know to design alternatives to traditional high schools.

1. Be open to who can start an alternative high school. Though ideally a school board or school district superintendent will be the impetus, an alternative high school may be initiated by a single determined person or a small group of individuals who perceive a need. A group of committed and organized parents may be the most effective way to get an alternative high school started. A group of teachers who want to organize an alternative high school around a particular theme or curriculum content may also start a new school. As mentioned previously in this chapter, a cluster of school districts may decide to band together to create a regional approach. Whoever decides to start an alternative high school needs to think globally and to find like-minded partners. Also, they will need an efficient process to guide them through its design. Building a design team of internal and external stakeholders, some of whom have been invested in creating the alternative high school from the beginning, is essential to the future success of the school. 
2. Be aware of mandates for school reform and the resources associated with such mandates. Many states have passed legislation requiring school districts to provide alternative education or charter schools. Magnet schools have resulted from federal court mandates. School districts may have board policies that encourage the development of alternatives to traditional high schools. Federal legislation that promotes innovative schools may impact state regulations and local school district policy. Community colleges are growing nationwide and may have additional resources to start alternative high schools that bridge the gap between high school and college for establishing a middle college. Foundations may support new approaches to high school education and cite at-risk youth as a priority. Public and private non-profit organizations may be able to contract with local school districts to provide alternative high schooling to students in unique settings and situations, such as a zoo or a science museum. In addition to these potential resources, the most important resource for leaders trying to initiate an innovative alternative high school is a group of high school students who can articulate their educational needs and experiences and be a force for change. Engaging any of these resources will require a process to develop a comprehensive description of the new high school. It is also important to recognize that school funding, either by reallocating funds to alternative programs, or removing students from some schools, can be a difficult thing to do. Either way, it has an impact on resource allocation within a school district. 
3. Be clear about the purpose and motive for starting an alternative high school. Barr and Parrett (1997) point out a "dark side" (p. 89) of alternative education, in that some school leaders' primary interest in starting an alternative school may be increasing a school district's enrollment and its concomitant state school support. Private, religious, or home school leaders may also seek to use an "alternative" designation to receive public funds. School district leaders may primarily be interested removing difficult students from a mainstream setting. Or, as I like to call it, creating a bad school for the bad kids so the good kids can learn.

4. The motive for establishing an alternative high school ought to be creating an effective school for all students served. Following a design process that begins with creating a shared vision and direction among a diverse team of alternative high school designers should eliminate any deception by making transparent the purpose of the new school to the whole community.

5. Work through the high school design process in sequence, beginning with a shared vision and purpose. Although the "steps" illustrated in Figure 4 may not be accomplished in order, a facility may be identified early, for example, it is critical to begin with the creation of a shared vision before discussing curriculum, attendance policy, and other details. Also, leaders who want to create innovative alternatives to traditional high schools often assume they should begin by looking at model schools first, especially popular or successful models, rather than first establishing a locally defined shared vision 
for a school that would ideally meet local needs, before looking for models that simulate their vision. Leaders should have a process that includes a research-based set of standards as a framework for design, a set of elements of effective alternative schools (all of which must be paid attention), an understanding of program evaluation that begins with the end in mind, and an agreement to start over to conceptualize the new high school.

6. Be prepared for suspicion and skepticism. Researchers have determined that alternative schools are often considered to be illegitimate by education professionals and the public (Barr \& Parrett, 1997; Raywid, 1994; Wehlage, 1989). A vast majority of youth and adults have only had experience with traditional high school-for generations. The common mental model of high school may be viewed by most of the public as the only model of what a high school can be. An innovative high school that attracts media attention because of its success with its students may lead to criticism, and perhaps envy, among those in the traditional education community. An innovative alternative high school that is organized in non-traditional ways may also cause compliance concerns among regulatory agencies. Following a facilitated, team process to design an innovative alternative high school may reduce suspicion by creating and publicizing a complete description of the new school. Positive community relations should result from making a comprehensive "blueprint" of the new high school readily available to internal and external publics—-before the innovative alternative high school even opens. 
These recommendations were derived during the work done to create a process to design innovative alternatives to traditional high schools. Who may start an alternative school, how to find resources to fund it, a clear purpose, sequential planning, and overcoming skepticism were all part of design team discussions as member sought to identify leadership concerns associated with the outcome of the school design venture.

\section{Summary}

Increased educational accountability across America today necessitates school leaders who are not only good administrators, but increasing student achievement requires leaders who can foster ways to better serve each and every student in their care. In addition to maintaining the components that keep a school running, school leaders must have the knowledge and skills to develop new kinds of schools that will integrate their local community's beliefs and values with systems that will make schools relevant to students in today's world and prepare students for life in the future. This effort starts with the fundamental belief that all students deserve a quality education. If a newly designed and implemented alternative high school is the causation for a drop in student achievement or growth over time, that new school's leaders need to be prepared to formatively evaluate it. Leaders need to have a continuous willingness and have the autonomy to start over in conceptualizing the school and what it can be. School leaders also need a conceptual framework of standards to build upon. Finally, leaders need to pay attention to every element of effective alternative schools while building a new design.

This study informs school leaders about what they need to know and do if they feel their traditional high schools are not meeting the needs of all of their students. It 
assists school leaders by providing a comprehensive, step-by-step process meant to develop schools to educate more students while maintaining quality. This dissertation identified the problem as a lack of information or knowledge among traditional school leaders who lacked a process for designing innovative alternative high schools. The school design process developed in this dissertation is part of the solution to this problem. Through the R\&D process of recursive development and field testing, a valid tool has been established that can successfully guide school leaders as they shape a shared vision and purpose, enrich the educational program, and create support for a new kind of high school. Together with my colleague, Drew Hinds, we have developed a promising educational product, Designing and Evaluating Alternative Schools. However, we realize there is much more to learn and that there is an undiminished need for new processes to create new schools that are vastly different from schools of the past. Perhaps one of the participants in the main field test said it best, "The process is fully capable of creating innovative schools." This means the school design process can successfully guide a team through the steps necessary to create an alternative to traditional high schools if the time and care is taken to complete all of the steps. The real value of going through the design process may lie in further study of other benefits of the process, such as improved community relations, developing administrative and teacher support for the new school, and using resources more efficiently.

In this era of educational accountability with its emphasis on high stakes testing, leaders must remember that education is an art as well as a science. Education is also a service that creates human capital. All educators must be able to see the highest potential 
in each and every student, and be enabled to re-imagine the American educational enterprise at the school level so that all students benefit from more innovative schools. Educational leaders in the present must protect the students of the future by creating the most ideal schools that can be conceived for the future. School leaders now and in the future must have the will, the experience, and the products and processes that unleash the creativity and innovation that have been hallmarks of the American educational system in the past. The creators and the designers of new and innovative alternatives to traditional high schools must be given the tools, resources, and permission to excel beyond the strictures of the status quo, and to make a difference in education for years to come. We know what to do. We should not be afraid. We must move forward. 


\section{REFERENCES}

AdvancED. (n.d.a). Accreditation the AdvancED way. Alpharetta, GA: Author.

AdvancED. (n.d.b). We are AdvancED. Alpharetta, GA: Author. Retrieved from http://www.advanc-ed.org/press-room

AdvancED. (n.d.c). What is accreditation? Alpharetta, GA: Author. Retrieved from http://www.advanc-ed.org/what-accreditation

Anglin, T. M., Naylor, K. E., \& Kaplan, D. W. (1996). Comprehensive school-based health care: High school students' use of medical, mental health, and substance abuse services. Pediatrics, 97(3), 318-330.

Arnove, R., \& Strout, T. (1980, May). Alternative schools for disruptive youth. The Educational Forum, 29(1), 452-471.

Barr, R. D. (1981). Alternatives for the eighties: A second decade of development. Phi Delta Kappan, 62(8), 570-573.

Barr, R. D., Colston, B., \& Parrett, W. (1977). The effectiveness of alternative public schools. Viewpoints, 53(4), 1-30.

Barr. R. D., \& Parrett, W. H. (1995). Hope at last for at-risk youth. Boston, MA: Allyn \& Bacon.

Barr. R. D., \& Parrett, W. H. (1997). How to create alternative, magnet, and charter schools that work. Bloomington, IN: National Educational Service.

Barr. R. D., \& Parrett, W. H. (2001). Hope fulfilled for at-risk and violent youth: K-12 programs that work (2nd ed.). Boston, MA: Allyn \& Bacon.

Barr. R. D., \& Parrett, W. H. (2008). Saving our students, saving our schools. Thousand Oaks, CA: Corwin.

Barth, R. S. (1990). Improving schools from within. San Francisco, CA: Jossey-Bass.

Barth, R. S. (1991). Restructuring schools: Some questions for teachers and principals. Phi Delta Kappan, 73(2), 123-129.

Barth, R. S. (2001). Learning by heart. San Francisco, CA: Jossey-Bass.

Bass, B. M. (1985). Leadership and performance beyond expectations. New York, NY: Free Press. 
Black, P., Harrison, C., Lee, C., Marshall, B., \& William, D. (2003). Assessment for learning: Putting it into practice. New York, NY: McGraw-Hill.

Blase, J., \& Blase, J. (2000). Effective instructional leadership: Teachers' perspectives on how principals promote teaching and learning in schools. Journal of Educational Administration, 38(2), 130-141.

Bloom, B. S. (1994). Reflections on the development and use of the taxonomy. In L. W. Anderson, \& L. A. Sosniak (Eds.), Bloom's taxonomy: A forty-year retrospective (pp. 1-8). Chicago, IL: University of Chicago National Society for the Study of Education.

Bohman, L. G., \& Deal, T. E. (2003). Reframing organizations: Artistry, choice and leadership (3rd ed.). San Francisco, CA: Jossey-Bass.

Borg, W. R., \& Gall, M. D. (1989). Educational research: A guide for preparing a thesis or dissertation proposal in education $\left(5^{\text {th }}\right.$ ed.). White Plains, NY: Longman Inc.

Botstein, L. (1997). Jefferson's children: Education and the promise of American culture. New York, NY: Doubleday.

Boyer, E. L. (1995). The basic school: A community for learning. San Francisco, CA: Jossey-Bass.

Bradley, C. L., \& Renzulli, L. A. (2011). The complexity of non-completion: Being pushed or pulled to drop out of high school. Social Forces. doi:10.1093/sf/

Bridges, E. M., \& Hallinger, P. (1995). Implementing problem based learning in leadership development. Eugene, OR: ERIC Clearinghouse on Educational Management.

Brookover, W. B., \& Lezotte, L. W. (1977). Changes in school characteristics coincident in changes in student achievement. East Lansing, MI: Michigan State University.

Bryk, A., \& Thum, Y. (1989, Fall). The effects of high school organization on dropping out: An exploratory investigation. American Educational Research Journal, 26(3), 353-383.

Burns, J. M. (1978). Leadership. New York, NY: Harper \& Row.

Burns, J. M. (2003). Transforming leadership: A new pursuit of happiness. New York, NY: Grove/Atlantic. 
Callahan, R. E. (1962). Education and the cult of efficiency. Chicago, IL: University of Chicago Press.

Case, B. (1981). Lasting alternatives: A lesson in survival. Phi Delta Kappan, 62(8), 554-557.

Cash, T., \& Edwards, C. (2007). Seattle Public Schools: External evaluation report on alternative schools. Clemson, SC: Clemson University, National Dropout Prevention Center.

Chalker, C. S. (1996). Effective alternative education programs. Lancaster, PA: Technomic.

Chenoweth, T. G., \& Everhart, R. B. (2002). Navigating comprehensive school change: A guide for the perplexed. Larchmont, NY: Eye on Education.

Clinchy, E. (2000). Creating new schools: How small schools are changing American education. New York, NY: Teachers College Press.

Conley, D. T. (1996). Are you ready to restructure? A guidebook for educators, parents, and community members. Thousand Oaks, CA: Corwin Press.

Conley, B. E. (2002). Alternative schools: A reference handbook. Santa Barbara, CA: $\mathrm{ABC}$.

Coomes, M. D., \& DeBard, R. (Eds.). (2004). Serving the millennial generation (New Directions for Student Services No. 106). Hoboken, NJ: Wiley \& Sons.

Cotton, K. (2003). Principals and student achievement: What the research says. Alexandria, VA: Association for Supervision and Curriculum Development.

Covey, S. (1989). The 7 habits of highly effective people. New York, NY: Free Press.

Cremin, L. (1961). The transformation of the school: Progressivism in American education, 1876-1957. New York, NY: Knopf.

Cuban, L. (1984). How teachers taught: Constancy and change in American classrooms, 1890-1980. New York, NY: Longman.

Cubberley, E. P. (1916). Public school administration: A statement of the fundamental principles underlying the organization and administration of public education. Boston, MA: Houghton Mifflin. 
Danielson, C. (2002). Enhancing student achievement: A framework for school improvement. Alexandria, VA: Association for Supervision and Curriculum Development.

Darling-Hammond, L., Ancess, J., \& Falk, B. (1995). Authentic assessment in action: Studies of schools and students. New York, NY: Teachers College Press.

Darling-Hammond, L., Ancess, J., \& Ort, S. W. (2002). Reinventing high school: Outcomes of the coalition campus schools project. American Educational Research Journal, 39(3), 639-673.

Deal, T. E. (1975, April). An organizational explanation of the failure of alternative secondary schools. Educational Researcher, 4(4), 10-16.

Deal, T. E. (1978). Alternative schools: A conceptual map. The School Review 87(1), 29-49.

Deal, T. E., \& Peterson, K. D. (1999). Shaping school culture: The heart of leadership. San Francisco, CA: Jossey-Bass.

Dewey, J. (1916). Democracy and education. New York, NY: MacMillan.

Diakiw, J. Y. (2012, May 8). It's time for a new kind of high school. Education Week. Retrieved from http://www.edweek.org/ew/articles/2012/05/09/ 30diakiw.h31.html

DuFour, R. (2004, May). What is a "professional learning community"? Educational Leadership, 82(2), 123-128.

Duke, D. L., \& Perry, C. (1978). Can alternative schools succeed where Benjamin Spock, Spiro Agnew, and B. F. Skinner have failed? Adolescence, 13(51), 375-392.

Dupper, D. R. (2008). Guides for designing alternative programs for dropout prevention. In C. Franklin, M. B. Harris, \& P. Allen-Meares (Eds.), The school practitioners concise companion to preventing dropout and attendance problems (23-34). New York, NY: Oxford University Press.

Dynarski, M., \& Gleason, P. (1998). How can we help? What we have learned from evaluations offederal dropout-prevention programs. Princeton, NJ: Mathematica Policy Research, Inc.

Earthman, G. I. (2002). School facilities condition and student academic achievement. Los Angeles, CA: University of California, Los Angeles. Institute for Democracy, Education, and Access. 
Edmonds, R. R. (1982). Programs of school improvement: An overview. Educational Leadership, 12(4), 97-120.

Eisner, E. W. (1985). The art of educational evaluation: A personal view. Philadelphia, PA: The Falmer Press.

Elmore, R. F. (2000). Building a new structure for school leadership. Washington, DC: The Albert Shanker Institute.

Epstein, J. L. (1995). School/family/community partnerships: Caring for the children we share. Phi Delta Kappan, 76(9), 701-12.

Epstein, J. L., Jansorn, N. R., Sheldon, S. B., Sanders, M. G., Salinas, K. C., Simon, B. S. (2009). School, family, and community partnerships: Your handbook for action. Thousand Oaks, CA: Corwin Press.

Fantini, M. (1973a). Public schools of choice. New York, NY: Simon and Schuster.

Fantini, M. (1973b, April). The what, why, and where of the alternatives movement. National Elementary Principal, 52(6), 14-22.

Farkas, S., Johnson, J., Duffett, A., \& Foleno, T. (2001). Trying to stay ahead of the game: Superintendents and principals talk about school leadership. New York, NY: Public Agenda.

Fernandez, K. E. (2011). Evaluating school improvement plans and their affect on academic performance. Educational Policy, 25(2), 338-367.

Fetterman, D. M. (1994, February). Empowerment evaluation. Evaluation Practice, 15(1), 1-15.

Fields, G. (2008, October 21). The high school dropout's economic ripple effect. The Wall Street Journal, p. A13.

Fine, M. (1986, Spring). Why urban adolescents drop into and out of public high school. Teachers College Record, 87(3), 393-409.

Fine, M. (1991). Framing dropouts: Notes on the politics of an urban high school. Albany, NY: State University of New York Press.

Finn, C. E., Manno, B. V., \& Vanourek, G. (2001). Renewing public education: Charter schools in action. Princeton, NJ: Princeton University Press. 
Finnigan, K. S. (2007). Charter school autonomy: The mismatch between theory and practice. Educational Policy, 21(3), 503-526.

Fitzsimons-Lovett, A. (2001). Alternative education programs: Empowerment or entrapment? In M. B. Bullock \& R. A. Gable (Eds.), Addressing the social, academic, and behavioral needs of students with challenging behavior within inclusive and alternative settings (pp. 37-41). Las Vegas, NV: Council for Children with Behavioral Disorders.

Fizzell, R., \& Raywid, M. A. (1997). If alternative schools are the answer...What's the question? Reaching Today's Youth, 1(2), 7-9.

Florida Department of Education. (19991). Quality standards for dropout prevention programs. Tallahassee, FL: Author.

Foley, R. M., \& Pang, L. (2006). Alternative education programs: Program and student characteristics. The High School Journal, 89(3), 10-21.

Fritz, R. (1996). Corporate tides: The inescapable laws of organizational structure. San Francisco: Berrett-Koehler.

Fullan, M. (2001). Leading in a culture of change. San Francisco, CA: Jossey-Bass.

Fullan, M. (2006). Turnaround leadership. San Francisco, CA: Jossey-Bass.

Gabriel, J. G., \& Farmer, P. C. (2009). How to help your school thrive without breaking the bank. Alexandria, VA: Association for Supervision and Curriculum Development.

Gardner, H. (1995). Leading minds: An anatomy of leadership. New York, NY: Basic Books.

Gay, L. R., Mills, G. E., \& Airasian, P. W. (2009). Educational research: Competencies for analysis and applications. Columbus, $\mathrm{OH}$ : Merrill.

Gold, M., \& Mann, D. (1984). Expelled to a friendlier place: A study of effective alternative schools. Ann Arbor, MI: The University of Michigan Press.

Goodman, P. (1960). Growing up absurd: Problems of youth in the organized society. New York, NY: Vintage.

Graubard, A. (1972). The free school movement. Harvard Educational Review, 42(3), 351-373. 
Gregg, S. (1999). Creating effective alternatives for disruptive students. The Clearing House, 73(2), 107-113.

Gregory, T. (2001). Fear of success? Ten ways alternative schools pull their punches. Phi Delta Kappan, 82(8), 577-581.

Guernsey, J. (1970, May). Portland's unconventional Adams High. American Education, 6(4), 3-7.

Hallinger, P., \& Heck, R. H. (1996). Reassessing the principal's role in school effectiveness: A review of empirical research, 1980-1995. Educational Administration Quarterly, 32(1), 5-44.

Hallinger, P., \& Heck, R. H. (2002). What do you call people with visions? The role of vision, mission and goals in school leadership and improvement. In. K. A. Leithwood \& P. Hallinger (Eds.), Second international handbook of educational leadership and administration (vol. 8; pp. 9-40). New York, NY: Springer.

Hamre, B. K., \& Pianta, R. C. (2006). Student-teacher relationships. In G. G. Bear \& K. M. (Eds.), Children's needs III: Development, prevention, and intervention (pp. 59-71). Washington, DC: National Association of School Psychologists.

Hanushek, E. A. (1989). The impact of differential expenditures on school performance. Educational Researcher, 18(4), 45-62.

Hanushek, E. A., Rivkin, S. G., Taylor, L. L. (1996). Aggregation and the estimated effects of school resources (NBER Working Paper No. 5548). Retrieved from http://www.nber.org/papers/w5548

Heckman, J., \& LaFontaine, P. (2007). The American high school graduation rate: Trends and levels. Bonn, Germany: Institute for the Study of Labor.

Hefner-Packer, R. (1991). Alternative education programs: A prescription for success. Athens, GA: The University of Georgia.

Heifetz, R. A., \& Linsky, M. (2002). Leadership on the line. Boston, MA: Harvard Business School Press.

Henderson, H., \& Raywid, M. A. (1994). Small revolution in New York City. Journal of Negro Education, 63(1), 28-45.

Herman, R., Dawson, P., Dee, T., Greene, J., Maynard, R., Redding, S., \& Darwin, M. (2008). Turning around chronically low-performing schools: IES practice guide. Jessup, MD: National Center for Education Evaluation and Regional Assistance. 
Hinds, D. (2012). Evaluating the impact of alternative high schools: An alternative high school program evaluation toolkit (Unpublished doctoral proposal). Portland State University, Portland, OR.

Judge, T. A., \& Bono, J. E. (2001). Relationship of core self-evaluations traits-selfesteem, generalized self-efficacy, locus of control, and emotional stability-with job satisfaction and job performance: A meta-analysis. Journal of Applied Psychology, 86(1), 80-92. doi:10.1037/0021-9010.86.1.80

Kellmayer J. (1995). How to establish an alternative school. Thousand Oaks, CA: Corwin.

Kleiner, B., Porch, R., \& Farris, E. (2002). Public alternative schools and programs for students at-risk of educational failure: 2000-01 (NCES 2002-04). Washington, DC: U. S. Department of Education, National Center for Education Statistics.

Koetke, C. (1999). One size doesn't fit all. TECHNOS, 8(2), 20-26.

Kotter, J. P. (1995, March-April). Leading change: Why transformation efforts fail. Harvard Business Review. Retrieved from http://depts.washington.edu/ccph/ pdf_files/Kotter.pdf

Lancaster, L. C., \& Stillman, D. (2002). When generations collide. New York, NY: Harper Business.

Lance, K. C., Rodney, M. J., \& Hamilton-Pennell, C. (2000). How school librarians help kids achieve standards: The second Colorado study. Denver, CO: Colorado State Library.

Lange, C. M., \& Sletten, S. J. (2002). Alternative education: A brief history and research synthesis. Alexandria, VA: National Association of State Directors of Special Education.

Legters, N. E., Balfanz, R., Jordan, W. J., \& McPartland, J. M. (2002). Comprehensive reform for urban high schools: A talent development approach. New York, NY: Teachers College Press.

Leithwood, K. A. (2003). What we know about successful school leadership. New Brunswick, NJ: Rutgers University.

Leithwood, K. A., \& Jantzi, D. (2000). The effects of transformational leadership on organizational conditions and student engagement with school. Journal of Educational Administration, 38(2), 112-129. 
Leone, P. E., \& Drakeford, W. (1999). Alternative education: From a "last chance" to a proactive model. The Clearing House, 73(2), 86-88.

Levin, B. (2010, December). In Canada: International comparisons. Phi Delta Kappan, 92(4), 95-96.

Levin, B., \& Riffel, J. A. (1997). School system responses to external change: Implications for parental choice of schools. In R. Glatter, P. A. Woods, \& C. Bagley (Eds.), Choice and diversity in schooling: Perspectives and prospects (pp. 44-58). London, England: Routledge.

Levin, H. M. (1987). New schools for the disadvantaged. Teacher Education Quarterly, 96(14), 60-83.

Levin, H. M. (1989). Accelerated schools: A new strategy for at-risk students (Policy Bulletin No. 6). Bloomington, IN: Consortium on Educational Policy Studies.

Levin, H. M. (1998). Accelerated schools: A decade of evolution. In A. Hargreaves, A. Lieberman, M. Fullan, \& D. Hopkins (Eds.), International handbook of educational change: Part two (pp. 807-830). Boston, MA: Kluwer.

Levin, H. M. (2004). Learning from school reform. In J. C. Lee, L. N. Lo, \& A. Walker (Eds.), Partnership and change (pp. 31-55). Hong Kong: Chinese University Press.

Levin, H.M., \& Belfield, C.R. (2007). Educational Interventions to Raise High School Graduation Rates. In C.R. Belfield and H.M. Levin (Eds.), The price we pay: Economic and social consequences of inadequate education (pp. 177-199). Washington, DC: Brookings Institution Press.

Lezotte, L. W. (1989). School improvement based on effective schools research. International Journal of Educational Research, 13(7), 815-825.

Lopez, C. (1999). General education: Regional accreditation standards and expectations. Liberal Education, 85(3), 46-51.

Lorenz, R., \& Pichert, J. W. (1989). Evaluation of education program developments: Illustration of the research and development cycle. The Diabetes Educator 15(3), 253-256. Retrieved from http://www.sagepub.com/journalsReprints.nav

Lubienski, C. (2003). Innovation in education markets: Theory and evidence on the impact of competition and choice in charter schools. American Educational Research Journal, 40(2), 395-443. 
MacDonald, J. P., Mohr, N., Dichter, A., \& McDonald, E. C. (2007). The power of protocols: An educator's guide to better practice. New York, NY: Columbia University, Teachers College.

Mager, R. F. (1984). Preparing instructional objectives ( $2^{\text {nd }}$ ed.). Belmont, CA: FearonPitman.

Marzano, R. (2003). What works in schools: Translating research into action. Alexandria, VA: Association for Supervision and Curriculum Development.

Marzano, R., Waters, T., \& McNulty, B. (2005). School leadership that works. Alexandria, VA: Association for Supervision and Curriculum Development.

Meier, D. (2002). The power of their ideas: Lessons for America from a small school in Harlem. Boston, MA: Beacon Press.

Meier, D., \& Scherer, M. (1994). On schools where students want to be: A conversation with Deborah Meier. Educational Leadership, 52(1), 4-8.

Meyer, J. W. (1992). Innovation and knowledge use in American public education. In J. W. Meyer \& W. R. Scott (Eds.), Organizational environments: Ritual and rationality (updated ed., pp. 233-260). Beverly Hills, CA: Sage.

Middle States Association of Colleges and Schools, Commissions on Secondary Schools (2007). Standards for accreditation of schools. Philadelphia, PA: Author.

Molnar, A. (1996). Charter schools: The smiling face of disinvestment. Educational Leadership, 54(2), 9-15.

Montecel, M. R. (1999). Disciplinary alternative education programs in Texas-What is known; what is needed. San Antonio, TX: Intercultural Development Research Association.

Moretti, E. (2007). Crime and the costs of criminal justice. In C. Belfield \& H. Levin (Eds.), The price we pay: Economic and social consequences of inadequate education (pp. 142-159). Washington, DC: The Brookings Institution.

Morgan, G. (2006). Images of organization. Thousand Oaks, CA: Sage.

Morley, R. E. (1991). Alternative education: Dropout prevention research reports. Clemson, SC: National Dropout Prevention Center/Network.

Morley, R. E. (2002). A framework for learning alternatives in Iowa. Iowa Association of Alternative Education Journal, 3(1), 16-19. 
Morley, R. E. (2003). Foreword. In M. S. Reimer \& T. Cash, Alternative schools: Best practices for development and evaluation (p. 2). Clemson, SC: National Dropout Prevention Center/Network.

Morrison, G. R., Ross, S. M., Kemp, H. E., \& Kalman, H. (2009). Designing effective instruction (6th ed.). New York, NY: John Wiley.

Muennig, P. (2007). Consequences in health status and costs. In C. Belfield \& H. Levin (Eds.), The price we pay: Economic and social consequences of inadequate education (pp. 125-141). Washington, DC: The Brookings Institution.

Narvaez, A., Jr. (1994). A gem of choice. Educational Leadership, 52(1), 9-11.

Nathan, J. (1999). Charter schools: Creating hope and opportunity for American education. New York, NY: Jossey-Bass.

National Center for Education Statistics. (2011a). Digest of education statistics. Washington, DC: Author. Retrieved from http://nces.ed.gov/programs/digest/ d10/tables/dt10_100.asp

National Center for Education Statistics. (2011n). High school dropout and completion rates in the United States: 2007. Washington, DC: U. S Department of Education. Retrieved from http://nces.ed.gov/pubsearch/index.asp?HasSearched= $1 \&$ searchcat $2=$ subjectindex $\& \mathrm{~L} 1=251 \& \mathrm{~L} 2=1$

Natriello, G. M., McDill, E. L., \& Pallas. A. (1990). Schooling disadvantaged children: Racing against catastrophe. New York, NY: Teachers College Press.

New England Association of Schools and Colleges, Commission on Public Secondary Schools. (2011). Standards for accreditation. Bedford, MA: Author.

Noddings, N. (1992). The challenge to care in schools: An alternative approach to education. New York, NY: Teachers College Press.

Nolan, R. R., \& Deal, T. F. (1978). Alternative schools: Ideologies, realities, guidelines. Chicago, IL: Nelson-Hall.

Northwest Accreditation Commission. (2010). This is an accredited school. Boise, ID: Author.

Northwest Accreditation Commission. (2011). Special purpose schools: Consensus selfstudy manual. Boise, ID: Author. 
O’Day, J. A. (2002). Complexity, accountability, and school improvement. Harvard Educational Review, 72(3) 293-329.

Oregon Department of Education. (2010). Expanded options annual report 2009-2010. Retrieved from http://www.ode.state.or.us/search/results/?id=350

Oregon Revised Statute 339.251. Retrieved from http://www.leg.state.or.us/ors/339.html

Patton, M. Q. (2011). Developmental evaluation: Applying complexity concepts to enhance innovation and use. New York, NY: Guilford Press.

Pearce, C. L., \& Conger, J. A. (2003). Shared leadership: Reframing the how's and why's of leadership. Thousand Oaks, CA: Sage.

Phillips, V. (2011). It's time for public schools and public charters to work together. Education Week. Retrieved from http://www.edweek.org/ew/articles/ 2011/01/12/15phillips.h30.html

Purkey, S. C., \& Smith, M. S. (1983). Effective schools: A review. The Elementary School Journal, 83(4), 426-452

Ravitch, D. (1974). The great school wars: New York City, 1805-197. New York, NY: Basic Books.

Ravitch, D. (2010). The death and life of the great American school system. New York, NY: Perseus.

Raywid, M. A. (1981). The first decade of public school alternatives. Phi Delta Kappan, 62(8), 551-553.

Raywid, M. A. (1982). The current status of schools of choice in public secondary education. New York, NY: Hofstra University.

Raywid, M. A. (1983). Alternative schools as a model for public education. Theory into Practice, 22(3), 190-197.

Raywid, M. A. (1989). The mounting case for schools of choice. In J. Nathan (Ed.), Public schools by choice: Expanding opportunities for parents, students, and teachers. Bloomington, IN: Meyer Stone Books.

Raywid, M. A. (1993). Alternatives and marginal students. Unpublished manuscript, .

Raywid, M. A. (1994). Alternative schools: The state of the art. Educational Leadership, 52(1), 26-31. 
Raywid, M. A. (1999). Current literature on small schools. Charleston, WV: ERIC Clearinghouse on Rural Education and Small Schools.

Raywid, M. A. (2001). What to do with students who are not succeeding. Phi Delta Kappan, 82(8), 582-584.

Raywid, M. A., Schmerler, G., Phillips, S. E., \& Smith, G. A. (2003). Not so easy going: The policy environments of small urban schools and schools-within schools. Charleston, WV: ERIC Clearinghouse on Rural Education and Small Schools.

Reeves, T. C., \& Okey, J. R. (1996). Alternative assessments for constructivist learning environments. In B. G. Wilson (Ed.), Constructivist learning environments: Case studies in instructional design (pp. 191-202). Englewood Cliffs, NJ: Educational Technology Publications.

Reimer, M. S., \& Cash, T. (2003). Alternative schools: Best practices for development and evaluation. Clemson, SC: National Dropout Prevention Center/Network.

Rossi, P., Lipsey, M. W., \& Freeman, H. E. (2004). Evaluation: A systematic approach (7th ed.). Thousand Oaks, CA: Sage.

Rourke, J., \& Mero, D. (2008). Changing course. Principal Leadership, 8(10), 40-43.

Rumberger, R. W. (1987). High school dropouts: A review of issues and evidence. Review of Educational Research, 57(2), 101-121.

Rumberger, R. W. (2002). Student mobility and academic achievement. Charleston, WV: ERIC Clearinghouse on Rural Education and Small Schools.

Rumberger, R. W. (2004). Why students drop out of school. In G. Orfield (Ed.), Dropouts in America: Confronting the graduation rate crisis (pp. 131-155). Cambridge, MA: Harvard Education Press.

Rumberger, R. W., \& Lamb, S. P. (2003). The early employment and further education experiences of high school dropouts: A comparative study of the United States and Australia. Economics of Education Review, 2(4), 353-366.

Rutter, M., Maughan, B., Mortimore, P., \& Ouston, J. (1979). Fifteen thousand hours. Cambridge, MA: Harvard University Press.

Sagor, R. (1999). Equity and excellence in public schools: The role of the alternative school. The Clearing House, 73(2), 72-75. 
Saphier, J., \& King, M. (1985, March). Good seeds grow in strong cultures. Educational Leadership, 42(6), 67-74.

Sarason, S. B. (1972). The culture of school and the problem of change. Teachers College Record, 73(3), 465-468.

Sarason, S. B. (1996). Revisiting "the culture of school and the problem of change." New York, NY: Teachers College Press.

Schargel, F. P. (2003). Dropout prevention tools. Larchmont, NY: Eye on Education.

Schargel, F. P., \& Smink, J. (2001). Strategies to help solve our school dropout problem. Larchmont, NY: Eye on Education.

Schmidt, J. J. (2003). Counseling in schools: Essential services and comprehensive programs (4th ed.). Needham Heights, MA: Allyn \& Bacon.

Schwarz, P. (1993). Dear students, parents, and staff. Central Park East Secondary School Newsletter, 31, 1-2.

Scriven, M. (1991). Beyond formative and summative evaluation. In M. W. McLaughlin \& D. C. Phillips (Eds.), Evaluation and education: At quarter century (pp. 19-64). Chicago, IL: National Society for the Study of Education.

Scriven, M. (2002). Evaluation models. Evaluation in education and human services, 49(3), 249-278.

Scriven, M. (2005). The logic and methodology of checklists. Retrieved from www.wmich.edu/evalctr/checklists/

Scriven, M., Tyler, R. W., \& Gagne, R. M. (1967). Perspectives of curriculum evaluation. Chicago, IL: Rand McNally.

Senge, P., Cambron-McCabe, N., Lucas, T., Smith, B., Dutton, J., \& Kleiner, A. (2000). Schools that learn. New York, NY: Doubleday.

Sergiovanni, T. J. (1992). Moral leadership: Getting to the heart of school improvement. San Francisco, CA: Jossey-Bass.

Sergiovanni, T. J. (1994). Building community in schools. San Francisco, CA: JosseyBass. 
Sergiovanni, T. J. (1998). Leadership as pedagogy, capital development and school effectiveness. International Journal of Leadership in Education: Theory and Practice, 1(1), 37-46.

Sergiovanni, T. J. (2001). The principalship: A reflective practice perspective (4th ed.). Needham Heights, MA: Allyn \& Bacon/Longman.

Shadish, W. R. (1994). Need-based evaluation: What do you need to know to do a good evaluation? Evaluation Practice, 15(3), 347-358.

Sizer, T. R. (1997). Horace's school: Redesigning the American high school. New York, NY: McGuffy.

Smink, J. (1997). All students can learn: Best practices for alternative schooling. Reaching Today's Youth, 1(2), 65-68.

Smink, J., \& Schargel, F. P. (2004). Helping students graduate: A strategic approach to dropout prevention. Larchmont, NY: Eye on Education.

Smith, P. L., \& Ragan, T. J. (1999). Instructional design (2nd ed.). New York, NY: John Wiley.

Southworth, G. (2002). Lessons from successful leadership in small schools. In K. Leithwood \& P. Hallinger (Eds.), Second international handbook of educational leadership and administration (pp. 451-483). London, England: Kluwer Academic Publishers.

Stiggins, R. (2002). Assessment crisis: The absence of assessment for learning. Phi Delta Kappan, 83(10), 758-765.

Stiggins, R. (2004). New assessment beliefs for a new mission. Phi Delta Kappan, 86(1), 22-27.

Swarts, L. (2002). Alternative education accountability. Louisville, KY: Sapphire.

Stuit, D. A. (2012). Are bad schools immortal? New York, NY: Fordham University.

Taylor, F. W. (1911). The principles of scientific management. Retrieved from http://www.enebooks.com/data/JK82mxJBHsrAsdHqQvsK/2010-0119/1263902254.pdf

Tice, P., Carver, P. R., \& Lewis, L. (2010). Alternative schools and programs for public school students at risk of educational failure 2007-08: First look. Institute of Education Sciences: Washington, DC: Houghton, Mifflin, Harcourt. 
Tobin, T., \& Sprague, J. (1999, Summer). Alternative education programs for at-risk youth: Issues, best practices, and recommendations. Oregon School Study Council Bulletin, 42(4), 1-19.

Troutt, W. E. (1981). Relationships between regional accrediting standards and educational quality. New Directions for Institutional Research, 29, 45-59.

Tyack, D. (1974). The one best system: A history of American urban education. Cambridge, MA: Harvard University Press.

Tyack, D., \& Cuban, L. (1995). Tinkering toward Utopia: A century of public school reform. Cambridge, MA: Harvard University Press.

Tyack, D., \& Hansot, E. (1982). Managers of virtue: Public school leadership in America, 1820-1980. New York, NY: Basic.

Vaughan, M. (2006). Summerhill and A. S. Neill. Columbus, OH: Open University Press.

Wang, C., \& Edwards, C. R. (2009, August 3-5). A concept paper on effective evaluation of alternative education programs in Oregon. Paper presented at State Superintendent's Institute, Eugene, Oregon.

Warren, J. R., \& Halpern-Manners, A. (2007). Is the glass emptying or filling up? Reconciling divergent trends in high school completion and dropout. Educational Researcher, 36(3), 335-343.

Wasley, P. A., Fine, M., Gladden, M., Holland, N. E., King, S. P., Mosak, E., \& Powell, L.C. (2000). Small schools: Great strides. New York, NY: Bank Street College of Education.

Wehlage, G., \& Rutter, R. (1987). Dropping out: How much do schools contribute to the problem? In G. Natriello (Ed.), School dropouts: Patterns and policies (pp. 7088). New York, NY: Teachers College Press.

Wehlage, G., Rutter, R., Smith, G., Lesko, N., \& Fernandez, R. (1989). Reducing the risk: Schools as communities of support. New York, NY: The Falmer Press.

Western Association of Schools and Colleges. (2012). WASC focus on school-wide criteria. Burlingame, CA: Author.

Whitaker, K. S., \& Moses, M. C. (1994). The restructuring handbook: A guide to school revitalization. Boston, MA: Allyn and Bacon. 
Wiggins, G. (1998). Educative assessment: Designing assessments to inform and improve student performance. San Francisco, CA: Jossey-Bass.

Wilson, K. G., \& Daviss, B. (1994). Redesigning education. New York, NY: Holt.

Worthen, B. R., Sanders, J. R., \& Fitzpatrick, J. L. (1997). Program evaluation: Alternative approaches and practical guidelines (2nd ed.). White Plains, NY: Longman.

Yazzie-Mintz, E. (2010). Leading for engagement. Principal Leadership. Retrieved from http://www.indiana.edu/ ceep/hssse/images/Yazzie-Mintz\%20Principal\% 20Leadership\%20March\%202010.pdf

Young, T. (1990). Public alternative education. New York, NY: Teachers College Press. 
APPENDIX A

ALTERNATIVE HIGH SCHOOL LEADERSHIP DESIGN SURVEY 


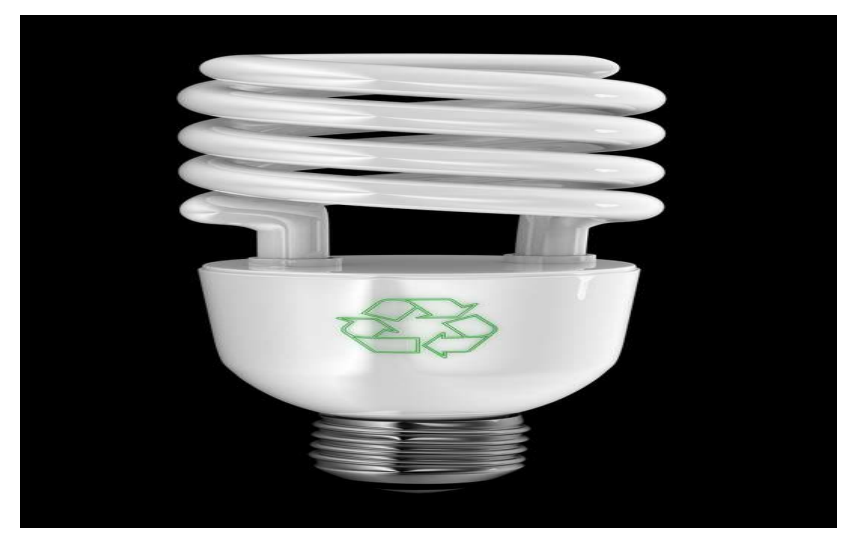

\section{Alternative High School Design Leadership Survey}

\section{Northwest Innovative Schools Network Annual Conference 2012}

\section{Completing this survey assumes your voluntary informal}

\section{consent to use this data in a Portland State University}

\section{$\underline{\text { research project. }}$}

Thank you for attending today's presentation. Please take the time to complete this survey. I am interested in what you believe is an effective process for designing innovative alternatives to traditional high schools. Your answers are completely confidential and will be combined with the responses of other alternative school leaders and released only as summaries in which no individual's answers can be identified.

This survey will take about 10 minutes to complete. 


\section{PLEASE RETURN YOUR COMPLETED SURVEY AT THE CLOSE OF THIS CONFERENCE SESSION.}

DIRECTIONS: In section I, if you lead more than one high school or program, please think about the high school in which you devote the most time when answering the questions.

\section{Section I: Participant and School Information}

This section asks about your background experience and about the high school in which you are currently working. Please place an $\mathrm{X}$ next to $\mathrm{ONE}$ response to each question unless otherwise directed.

\section{School Information}

1. In what part of Oregon is your school located?

Portland Metro-Area

North Coast

South Coast

Willamette Valley

Central Oregon

Southern Oregon

Eastern Oregon

Other (Please identify):

2. What is your administrative title?

Superintendent

Principal

Director

Coordinator

Lead Teacher

Other (Please identify):

3. Is your school a high school or include high school grade levels?

Yes

No (If you checked No, please stop here and return the survey.) 
4. Is your high school a traditional public, alternative public, public charter, or private high school?

Traditional Public

Alternative Public

Public Charter

Private

5. What grade levels are taught at your high school? (Please check all that apply.) ${ }^{9}{ }^{-10} 10 \_11 \_12$

6. How many students are enrolled in your high school?

Less than 25 students

26 to 50 students

51 to 100 students

101 to 150 students

151 to 250 students

Over 250 students

7. Is your high school located in its own building?

Yes

No (Where is it located?)

8. How many teachers work in your school (FTE/ full time equivalent)?

1 to 5 teachers

6 to 10 teachers

11 to 15 teachers

16 to 20 teachers

Over 21 teachers

\section{Administrative Experience}

9. How many years have you been a school leader in any setting?

I have had no prior administrative experience in any setting. Less than one year

1 to 3 years

4 to 6 years

7 to 9 years

Over 10 years 
10. How many years have you been a school leader in an alternative high school setting?

I have had no prior administrative experience in a public alternative setting. Less than one year

1 to 3 years

4 to 6 years

7 to 9 years Over 10 years

11. Do you currently hold an administrative license?

Yes
No

12. Have you participated in the design of a new and innovative alternative high school?

- Yes

\section{Section II: Effective Alternative High School Design Process}

This section asks your perceptions, as a school leader, about the effectiveness of the alternative high school design process about which you were just informed.

Directions: Please rate each item using the scale "Not Essential" to "Absolutely Essential." Please use the "Comments" section immediately following each group of items if you wish to discuss the ratings you gave.

\section{Scale:}

$\mathbf{1}=$ Not Essential $\mathbf{2}=$ Somewhat Essential 3 = Moderately Essential 4 = Absolutely Essential

\section{How essential are each of the following to designing an innovative alternative high} school?

\section{Elements of Effective Alternative Schools}

Circle One Response

13. Considering all of the elements of effective alternative schools. $\quad \begin{array}{llll}2 & 2 & 3\end{array}$

14. Taking a considerable amount of time to develop a shared vision and mission (purpose) for the new school.

$\begin{array}{llll}1 & 2 & 3 & 4\end{array}$

15. Diversifying the educational program based on the needs and interests of students. 
16. Developing relevant and focused curriculum that meaningfully connects students to school.

17. Forming a community of learners centered around creative and flexible Instructional approaches.

$\begin{array}{llll}1 & 2 & 3 & 4\end{array}$

18. Using assessments for learning rather than of learning.

$\begin{array}{llll}1 & 2 & 3 & 4\end{array}$

19. Hiring caring and demanding teachers who choose to work in the school.

20. Engaging all participants through voluntary participation in the school.

21. Having comprehensive educational programs that are equitable for all students.

22. Organizing around small school size for a personalized learning environment.

23. Sharing governance and having local autonomy that increases "ownership" of the school by all involved.

Comments about elements of effective alternative schools:

\section{Scale:}

$\mathbf{1}=$ Not Essential $\mathbf{2}=$ Somewhat Essential 3 = Moderately Essential $4=$ Absolutely Essential

How essential are each of the following to designing an innovative alternative high school?

\section{Organizational Leadership and Starting Over}

Circle One Response

24. Leading a design team to agree to start over from the beginning of a design process.

25. Having a design team agree it is more efficient to start over and design a new school than to remodel and existing school. 
26. Using organizational leadership strategies to achieve team consensus regarding starting over to design a new school.

27. Considering cultural and symbolic leadership as a strategy to achieve team consensus when starting over to design

a new school.

$\begin{array}{llll}1 & 2 & 3 & 4\end{array}$

28. Considering visionary leadership as a strategy to achieve team consensus when starting over to design a new school.

29. Considering historical perspective leadership to achieve team consensus when starting over to design a new school.

Comments about leadership and starting over:

\section{Scale:}

$1=$ Not Essential 2 = Somewhat Essential 3 = Moderately Essential 4 = Absolutely Essential

How essential are each of the following to designing an innovative alternative high school?

\section{Accreditation Standards as a Framework for Design $\quad$ Circle One Response}

30. Using accreditation standards as a framework for school design.

$\begin{array}{llll}1 & 2 & 3 & 4\end{array}$

31. Developing a mission (purpose), beliefs, and expectations for student learning.

$\begin{array}{llll}1 & 2 & 3 & 4\end{array}$

32. Designing curriculum for mission fulfillment.

$\begin{array}{llll}1 & 2 & 3 & 4\end{array}$

33. Planning quality instruction for student learning.

$\begin{array}{llll}1 & 2 & 3 & 4\end{array}$ 
34. Formulating assessments for student learning.

35. Leading and organizing for student learning.

36. Delineating school services and supports for learning.

37. Identifying facilities and finance for support of student learning. $\begin{array}{lllll}1 & 2 & 3 & 4\end{array}$ Comments about accreditation standards:

\section{Scale:}

$\mathbf{1}=$ Not Essential $\mathbf{2}=$ Somewhat Essential $\mathbf{3}=$ Moderately Essential $4=$ Absolutely Essential

How essential are each of the following to designing an innovative alternative high school?

\section{Program Evaluation that Begins With the End in Mind Circle One Response}

38. Planning for a program evaluation from the beginning of the design process with the full development of the new school in mind.

39. Advocating for a formative evaluation of educational program quality that goes beyond standardized test scores. 
40. Compiling an inventory of school practice and policy.

$\begin{array}{llll}1 & 2 & 3 & 4\end{array}$

41. Complying with federal and state laws.

$\begin{array}{llll}1 & 2 & 3 & 4\end{array}$

42. Maintaining a checklist of quality indicators for alternative schools.

$\begin{array}{llll}1 & 2 & 3 & 4\end{array}$

43. Encouraging creative thinking about what an alternative school can be within the constraints of program evaluation.

$\begin{array}{llll}1 & 2 & 3 & 4\end{array}$

44. Considering the context and circumstance under which the alternative school was designed to be established for program evaluation.

45. Establishing the outcomes for which the alternative school will be held accountable in the future when fully implemented. $\quad \begin{array}{llll}1 & 2 & 3 & 4\end{array}$ Comments about program evaluation:

Thank you for completing this survey. I appreciate the time you took to respond to each question. The information you have provided will be used to further the understanding of effectively designing alternative high schools. Please return the completed survey at the end of the conference session. 
APPENDIX B

RESEARCH LETTER TO ALTERNATIVE HIGH SCHOOL DESIGNERS 
December 2012

Portland, OR 97212

chetedwards5@gmail.com

, Principal

Alternative High School

, OR 97XXX

Dear Principal,

I am conducting graduate research in the EdD program of educational leadership at Portland State University. As a leader of an innovative Oregon high school, my understanding is that you were involved in its original design-before the school first opened. By "design," I mean the area of new school development lying between an assessment of potential students' needs and the implementation (or start up) of the new school, as illustrated by this figure.

New School Development: Needs Assessment $\rightarrow \underline{\text { DESIGN }} \rightarrow$ Implementation

My dissertation research focuses on "design." To that end, I am requesting that you describe, in your own words, the process used to design your school. Questions you can use to guide the description of your design process are as follows.

Guiding Questions:

2. What was the position of the person who initiated or led the design process for your innovative high school?

2 . What obstacles did you experience when designing your innovative high school?

3. What conceptual framework(s) did you use when designing your innovative high school?

6. Was a team approach used to design your innovative high school? If so, what was the general composition of the team? How effective was the team approach? 
7. What impact, if any, did the results of your design process have on students at-risk of high school failure?

I am requesting that you respond soon so that I may obtain current research data that will improve the effectiveness of a process I am developing, with other researchers, to design and evaluate new and innovative high schools. The information obtained will be used to develop critical components of the design process and will pertain to meeting the educational needs of all high school youth.

The information you provide will remain confidential and anonymous. A brief description of your school will be included in appendices of my dissertation, but all data will be aggregated for research purposes and no connections to individual responses to this request will be made regarding specific schools.

\section{Please:}

- Do not include any identifying information by using in your description a pseudonym for the name of your school and for any other identifiers.

- Type your response and send a hard copy to me in the enclosed, addressed, and stamped return envelope.

- Contact me by the email: chetedewards5@gmail.com or by phone: 503-866-6289 if you have any questions.

I estimate it will take about 20-30 minutes to complete the design process description.

Thank you.

Yours,

Chet Edwards 


\section{APPENDIX C}

PROGRAM DESCRIPTION FOR WHYLAND SCHOOL 


\section{Whyland School}

\section{Description}

Whyland School is part of the ZeeLand School District. Whyland is an alternative to traditional public schools. The mission of Whyland is dedicated to helping students discover their passion and develop the strong academic and life skills required for healthy, vibrant lives of lifelong learning and positive participation in the community. Whyland provides a learning environment preparing students for success in college and a future career.

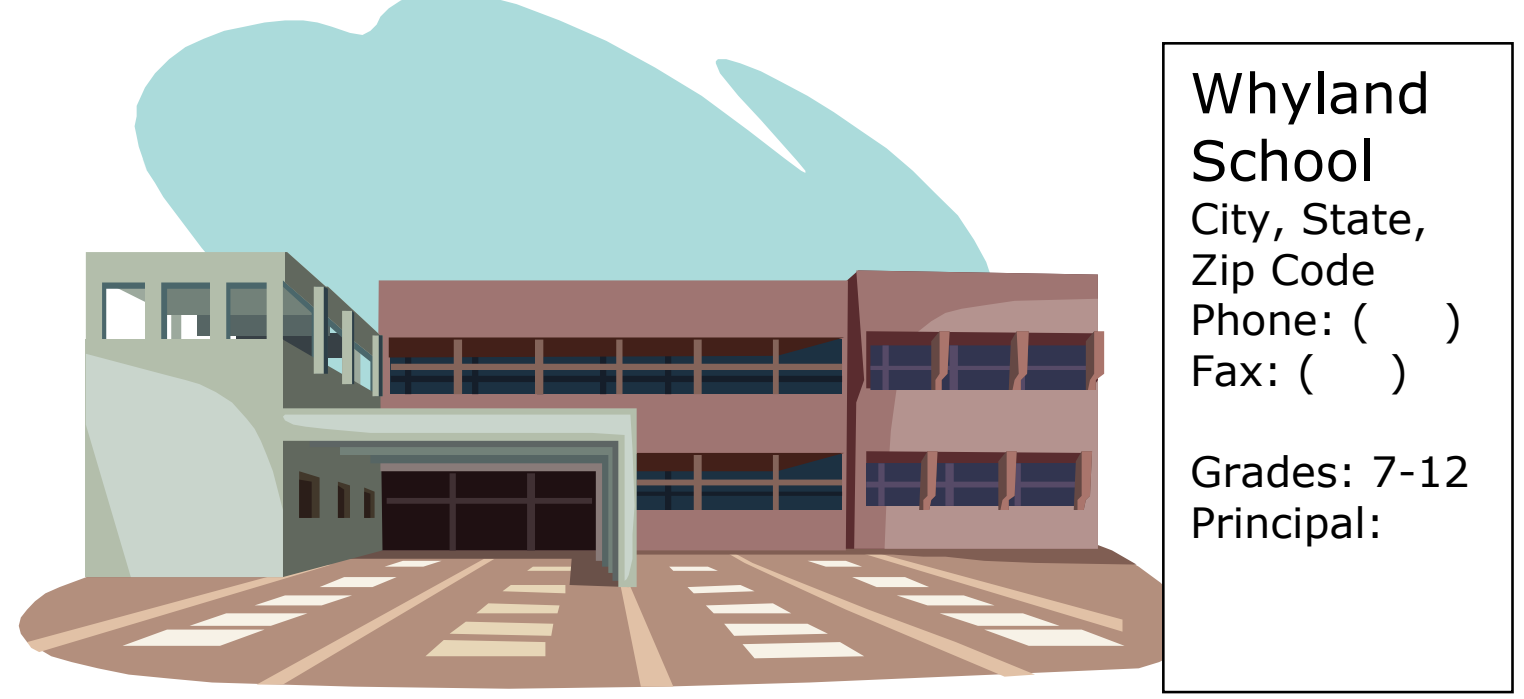

Whyland School is located in a one-story building in a suburban area. Whyland is open to all students in the Zeeland School District and is a tuition free, public school. Students are referred to Whyland by their home school or they may refer themselves. Whyland actively prepares students for college or a career. Service Learning is integral to how Whyland makes learning relevant. Common to all Whyland programs is a strong sense of community. Whyland actively builds a strong school culture where students feel safe, included, and connected. Advisor teachers help students set personal and educational goals, reflect on learning, choose classes, and track graduation credits. Advisor teachers also serve as parents' point of contact for the school. Whyland offers several distinct programs designed to match the learning needs of students. All Whyland programs offer the opportunity to earn a high school diploma. Whyland is designed for students who 
wish to attend a small high school. Whyland serves a maximum enrollment of approximately 160 students.

\section{Vision}

The Zeeland School District's vision of Whyland School is:

\section{BELIEFS}

$>$ Strive to provide everything to every student.

$>$ See the potential in everyone involved.

> Teachers act as guides, advisors, and coaches.

$>$ We are proud of our school.

\section{Core Value}

Our learning community commits to continuously improving the quality of our work while creating a rich, equitable learning environment.

\section{ACCESS}

$>$ Students choose to attend.

$>$ The school will have a safe learning environment

$>$ The materials and staff to reach desired academic outcomes.

$>$ Staff members are creative, caring, smart, and skilled.

\section{OUTCOMES and EXPECTATIONS}

$>$ The student to staff ratio is at a high enough level to provide support that is reflected in positive student outcomes.

$>$ The school will emphasize meeting student needs on a nontraditional timeline.

$>$ Students and the school community will fully recognize the real outcomes of the learning experience.

$>$ Academics will prepare students for the next steps of their lives.

CULTURE

> Staff and students are committed to long-term success.

$>$ The school has a strong link to community and parents.

$>$ Students will have access to mental health supports to develop the social emotional skills necessary. 
$>$ The school emphasizes quality over quantity and supports the academic social emotional needs of students.

$>$ The school has a culture built on relationships.

$>$ The school has high expectations, both academic and behavioral, for staff and students.

TEACHING AND LEARNING

$>$ The school has an environment and curriculum that are flexible and individualized.

$>$ The school staff have a knowledge of student needs and interests which guides the structure of learning.

> Students will have multiple opportunities to learn and demonstrate learning.

\section{Educational Program}

Whyland offers day and evening programs. Most classes run Monday through Friday 8:45a.m.-3:20p.m. Middle school students start at 9:25. The evening program runs from 4:00 p.m. to 8:00 p.m, Monday through Thursday. Teachers meet Wednesday mornings and classes begin at 9:45. Students typically attend six classes per day which include language arts, math, science, social studies, world language, and electives. Class sizes average 12-16 students and are mixedgrade. Some students receive small group instruction. Elective classes are varied and designed to expand student learning. Grades are awarded quarterly. Support for Special Education is part of the school program. All students work toward a high school diploma that meets all state and local graduation requirements. Classes offered during 2012-2013 include: 
WHYLAND SCHOOL CONTENT AREAS AND COURSES

\section{REQUIRED}

\section{LANGUAGE ARTS}

English 1-2

English 3-4

English 5-6

English 7-8

SOCIAL STUDIES

$\underline{\text { Economics }}$

U.S. History

World/Global Studies

\section{MATHEMATICS}

Principles of Algebra \& Statistics

Algebra 1

Algebra 2

Geometry

\section{SCIENCE}

Environmental Science

Earth Science

Physical Science

\section{HEALTH}

Health Education

PHYSICAL EDUCATION

Physical Education

\section{ELECTIVE}

Community Service

Math Support

Credit Recovery

Music

Planet Earth

Pre-Algebra

Work Experience

Senior Transitions 
Instruction at Whyland School is based on state common core standards. Students participate in whole and small group projects that are individualized based on students' interests. The environment created for each student is positive, caring, and flexibly adaptable to individual needs. Teachers at Whyland School meet frequently in Professional Learning Communities to map curriculum and compare assessment data. The school principal provides curriculum, observes classes to support teachers in meeting high academic standards, and arranges in-service on effective educational techniques.

The core of Whyland School's evaluation assessment system is based on formative assessment. Student conferences are conducted and parents receive written student progress reports every three weeks. In addition, teachers use various methods forms of communicating with students about daily work. The goal is to create direct personal communication about academic work between the teacher and student, and to foster student academic success. Marks earned in grades 9-12 form their official transcript. All students at Whyland School take the statewide assessments and complete work samples which lead to a high school diploma.

\section{School Leadership and Organization}

The Whyland School teaching staff and administration is dedicated to implementing the school's vision and mission.

The school principal is a veteran in public education. The principal served as a classroom teacher for seven years before going into school administration 23 years ago.

Each Whyland teaching staff member is highly qualified with many years of experience utilizing effective teaching strategies. Staff continuously monitor their instructional practices. Each student receives a daily teacher led advisor. Teachers use Wednesday mornings for professional development activities.

The climate of the school is safe, positive, and respectful. Student successes are regularly acknowledged and celebrated as students are nominate by staff for demonstrating pride in their school. 


\section{School Services}

All student services available to any students in Zeeland School District are also available to all Whyland School students. These services include school-to-college, health, library, Special Education, and family and community services. Services include personal, career, and college counseling. Collaborative outreach to community and area mental health agencies and social services for students are maintained. Appropriate support of Special Education services for students is provided.

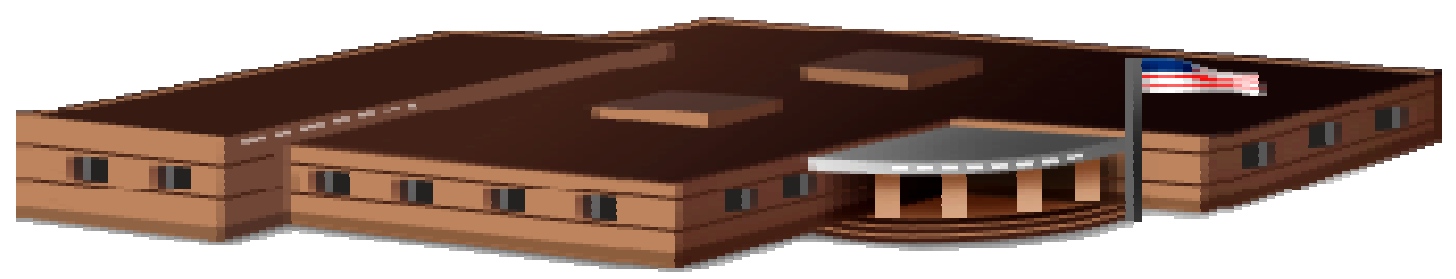

\section{Facilities}

Whyland School has a mix of large and small group spaces for learning. Secretarial, counseling, and administrative staff have office spaces. The campus has up-to-date computer access. The facility has a large library and an commercial kitchen. Whyland is housed in a former church building. The purpose of the location and physical plant is designed to give students the sense they are part of a unique school culture and climate.

\section{School Finance}

Students attend Whyland School free-of-charge. Financial resources meet the purposes of the educational program and are subjected to accepted accounting principles and audited annually. Sound and ethical business practices are followed by the administration. Free and reduced price lunch guidelines to students at Whyland, as they do at any other school.

\section{Program Evaluation}

On at least an annual basis, Whyland School will complete a process of program evaluation that includes regular reporting, compliance, and quality. Students, parents, school staff and the community will be involved in the process and will assist in determining the extent to 
which Whyland is meeting the needs of students, carrying out the school mission and adhering to the district vision for the school. Alternative accountability metrics for program evaluation will be determined during the 2013-14 school year and implemented as a part of the school's continuous improvement planning and included in the district's achievement compact. Additionally, timelines for evaluation will be established and specific feedback tools and processes will be developed in accordance with evaluation planning. Formative and summative data will be built into the process. Generally, the program will be evaluated on its ability to meet school standards while delivering innovative elements of school design. Goals areas in the evaluation will generally include academic achievement, school connection and climate.

\section{Admissions}

Students who wish to attend the Whyland School can follow the steps below to apply:

1. Pick up an application at Zeeland High School or at the Whyland School.

2. Make sure you are enrolled in the district.

3. Turn the application to your current school counselor and talk to him or her about why you believe a change of school would benefit you and your educational plan.

4. Take a tour of the Whyland School. Tours are offered every Monday school is in session at 3:30. Please call (phone number) to add your name to the tour. (Tours are optional)

5. Wait-after the application is turned in CLC and CHS meet to approve enrollment. This process can take up to two weeks.

6. Once your application is approved and you have withdrawn from CHS you will be called by CLC to come in with your parent/guardian to enroll, meet with your advisor teacher to review your schedule and begin classes. Our goal is to get you started as quickly as possible. 


\section{Frequently Asked Questions (FAQs)}

Q: Why do students come to Whyland?

A: Most students come to Whyland due to attendance, disciplinary, or credit concerns.

Q: What "type" of students attend Whyland?

A: Whyland serves students who are passionate about something, ready to make a change in their learning environment, want a smaller learning community, and want to develop positive relationships.

Q: What is the length of the school day?

A: See page 3 of this program description.

Q: What is the academic calendar?

A: Whyland operates on a year-round school calendar.

Q: How do students enroll and start going to Whyland?

A: See "Admissions" on page 7.

Q: Can students attend Whyland if they live outside the Zeeland School District?

A: Students need to live within Zeeland School District to attend Whyland School.

Q: Does Whyland serve Talented and Gifted (TAG) students? A: Yes. Whyland offers a wide array of classes. Many classes are in high interest areas for students and there are several classes that provide advanced levels in the high school curriculum.

Q: Does Whyland offer GED?

A: No, all students at Whyland are seeking a high school diploma.

Q: Do students earn a high school diploma?

A: Yes. WHYLAND students who complete the required amount of credits will initially be awarded diplomas through their local high school.

\section{Q: Is there a cost for tuition?}

A: No. Whyland is a public school within the Zeeland School District. There is no tuition or fees. 
Q: Do Whyland students prepare to attend college?

A: Yes. Whyland offers a number of programs aimed at preparing students for success in college.

Q: Does Whyland provide transportation to school?

A: Yes, all Whyland students are eligible for transportation.

Q: Can a student participate in sports and extra-curricular activities with their local high school while enrolled in Whyland?

A: Yes, but all eligibility requirements of local district schools must met.

Whyland School is regional accredited and during Spring 2013 Whyland was studied by a local design and evaluation team as part of research conducted by Portland State University. 


\section{APPENDIX D}

FIRST SESSION OF THE SCHOOL DESIGN PROCESS ANNOTATED AGENDA 


\title{
ZEELAND SCHOOL DISTRICT
}

\section{School Design/Evaluation Leadership Team Meeting \#1 January 23, 2012 - 3:30-5:30 P.M. @ Whyland School}

\author{
Annotated Agenda \\ \{DREW \& CHET INTRODUCE: "PSU RESEARCH"\}
}

- Introduce and Welcome the Team: Go-Round: Briefly describe why you want to be a team member-TAP THEIR EXPERIENCE $\mathbf{1 0}$ minutes

NEED: TO DEVELOP A VISION AND PURPOSE FOR THE KIND OF SCHOOLING WE WOULD LIKE TO SEE FOR STUDENTS IN WHYLAND SCHOOL). USE THE VISION STATEMENT TO ACCESS EXISTING ALTERNATIVE SCHOOLS OR THE RESOURCES TO DEVELOP NEW ALTERNATIVE SCHOOLING.

(Ground Rule - Norms) "Each member of the design/evaluation team is an equal partner; and WE are all experts in education."

(Next Steps) "Give the team a common LEXICON using an alternative school design process to develop a shared vision of an alternative school that will meet the educational needs of students involved with Whyland School."

- Review School Design Process

10 minutes

[1] PowerPoint_InnovativeSchools_Presentation.pptx - HANDOUT

[2] EvaluationWorksheet_1-21-13-HANDOUT

- Discuss "School Standards" and Guiding Principles

45 minutes

[3] PowerPoint Standards\&Principles.pptx - HANDOUT

(jigsaw activity - Bold as members present to team)

- "10 Essentials of Effective Alternative Schools"

[4] PowerPoint Ten Essentials.pptx - HANDOUT

45 minutes

(Ask team members to share, for example, what school choice means to them.)

- Preview: Creating an Alternative School Vision Statement

5 minutes

[5] Creating a School Vision.pptx - HANDOUT

(End with Dewey quote)

- Suggested Reading

5 minutes

- Meeting dates - all meetings are at WS 3:30-5:30 P.M. - Pizza at 4:30

○ $1 / 23,2 / 6$ (Design)

- 2/20, 2/27 (Evaluation)

- 3/13 (Reflection and Conclusion) 


\section{APPENDIX E}

SECOND SESSION OF THE SCHOOL DESIGN PROCESS ANNOTATED AGENDA 


\section{ZEELAND SCHOOL DISTRICT}

School Design Leadership Team Meeting

February 6, 2013

4:30 p.m. @ Whyland School

$\underline{\text { Annotated Agenda }}$

- Introduction - Drew \& Chet: HAND OUT SIGN IN SHEET 5-10 minutes

- Student Voices - WS Principal 20-30 minutes Invite students to join team

- Charge - Zeeland SD Superintendent [Purpose of team: Create a shared vision among team of the ideal alternative school for CSD] 5-10 minutes

- Brief Review of Standards, Elements, and Assumptions about Alternative School Design - Chet SHOW PROTOTYPE PROGRAM DESCRIPTION 5-10 minutes

- Development of Shared School Vision - Chet [PowerPoint "Creating a School Vision2_6_13"]: HANDOUT $1 \& 1 / 2$ hours

- Closure and Next Steps - Drew \& Chet 5-10 minutes 